\title{
CORRELATING DOUGH ELASTIC RECOVERY DURING SHEETING TO FLOUR ANALYSES AND RHEOLOGICAL PROPERTIES
}

by

\section{DANQIU REN}

B.S., South China University of Technology, 2005

\begin{abstract}
A THESIS
submitted in partial fulfillment of the requirements for the degree

MASTER OF SCIENCE

Department of Grain Science and Industry

College of Agriculture
\end{abstract}

\section{KANSAS STATE UNIVERSITY \\ Manhattan, Kansas}

2007

Approved by:

Approved by:

Co-Major Professor

Co-Major Professor

Dr. J.M.Faubion

Dr. C.E.Walker 


\section{Copyright}

\section{DANQIU REN}

2007 


\begin{abstract}
In commercial bakeries, the baker expects to get the same bread loaf, including weight and size, after sheeting the same size dough piece. Doughs made from different flours have different elastic recoveries to a great extent, which has an effect on the dough's size and density. Products made from differently elastic doughs can't have the same shape and height. Weight may also be affected.
\end{abstract}

The dough rheological behaviors of five flours and their blends having different chemical and physical properties were measured as were changes in thickness and snapback (thickness of the machined dough sheet relative to the roll gap) immediately following sheeting. Dough snapback was determined to be a function of both processing parameters, reduction ratio, and dough rest time, as well as different flour properties. The predication equation for dough snapback is based on multiple flour properties and sheeting conditions.

Among the variables, Mixograph work, reduction ratio, and dough rest time were the main factors affecting the elastic characteristics of the doughs. Minimum snapback occurred with the weakest flour experiencing the longest rest time and the smallest reduction ratio. A 7factor equation was found to be robust to predict the snapback of several flours, by combining Mixograph work, reduction ratio, dough rest time, Mixograph peak height and mixing time, Alveograph $\mathrm{P} / \mathrm{L}$, and protein content. 


\section{Table of Contents}

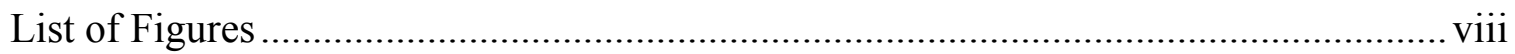

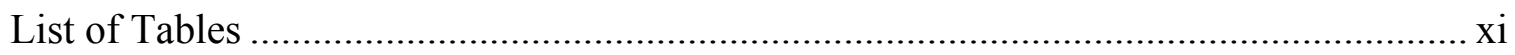

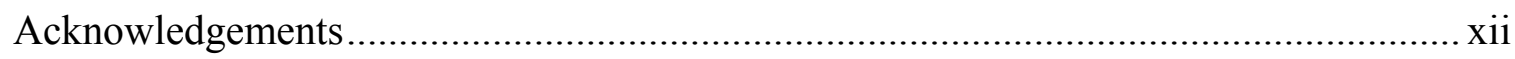

Preface

CHAPTER 1 - LITERATURE REVIEW ................................................................ 1

GENERAL INTRODUCTION TO BREAD DOUGH ............................................... 1

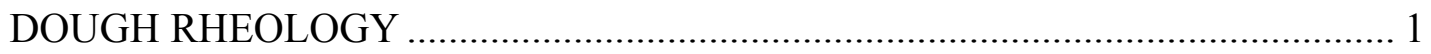

VISCOELASTIC PROPERTIES OF DOUGH ....................................................... 1

FACTORS AFFECTING DOUGH RHEOLOGY …………………………........ 2

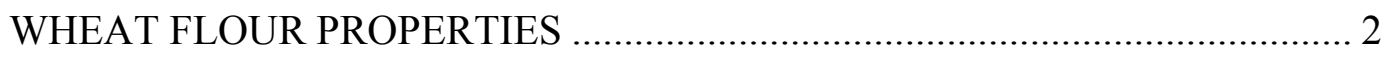

PROTEIN CONTENT ………………………………............................... 2

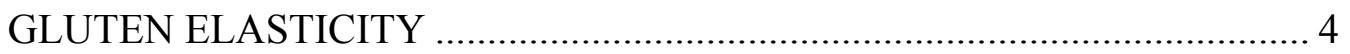

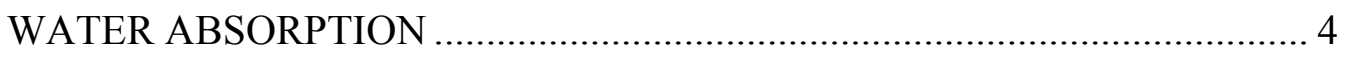

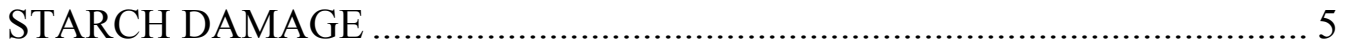

FLOUR ASH CONTENT ......................................................................... 5

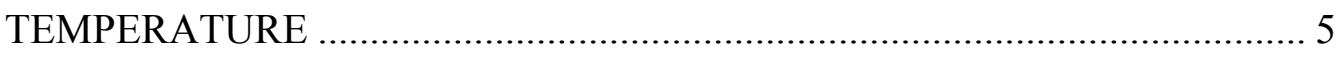

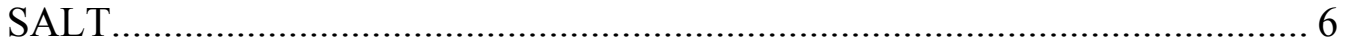

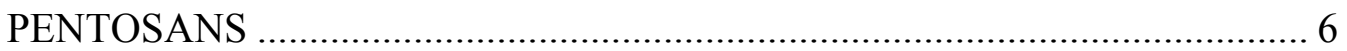

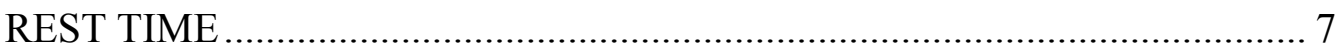

THE ROLE OF RHEOLOGY IN QUALITY CONTROL ……………….............. 7

RHEOLOGICAL TESTS FOR FLOUR MIXING PROPERTIES ……………........ 7

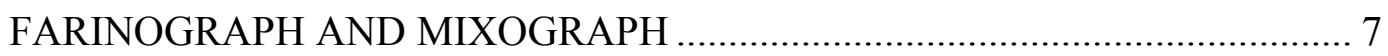

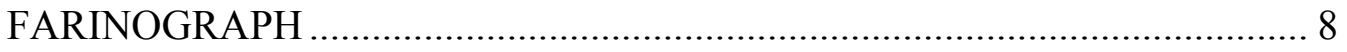

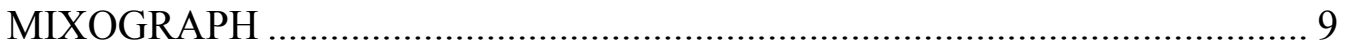

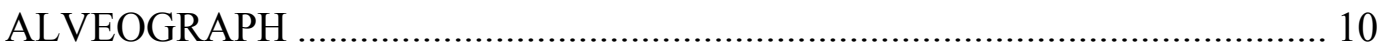

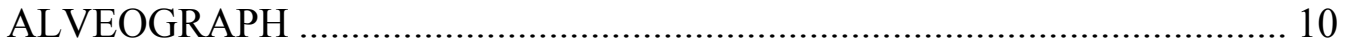

DESCRIPTIVE AND FUNDAMENTAL RHEOLOGICAL MEASUREMENTS . 10

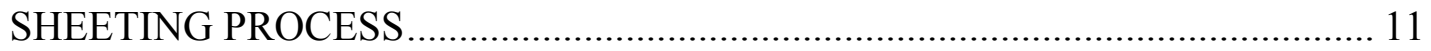


CORRELATION BETWEEN DOUGH'S VISCOELASTIC PROPERTIES AND BREAD

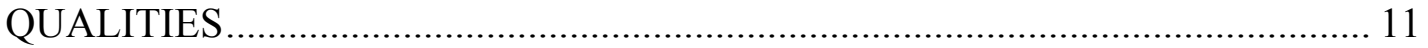

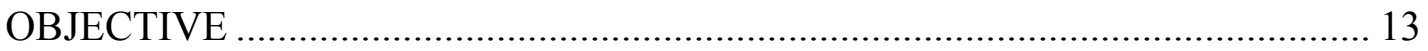

CHAPTER 2 - MATERIALS AND METHODS ………………………………......... 14

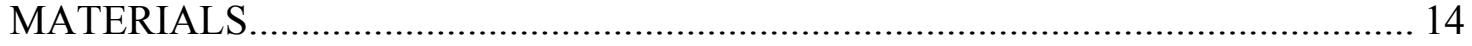

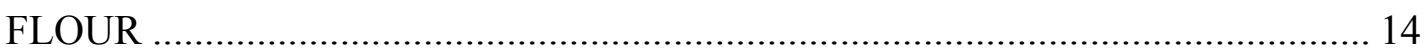

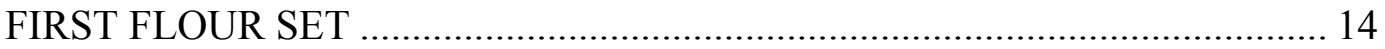

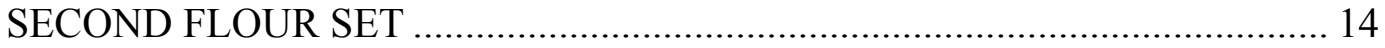

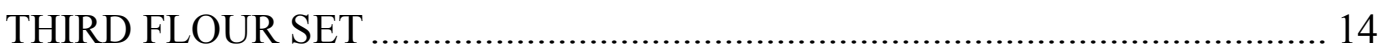

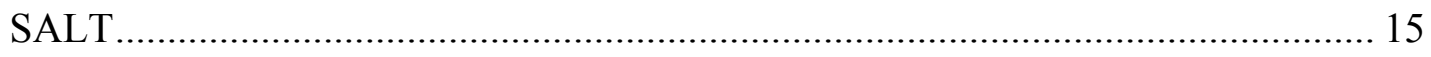

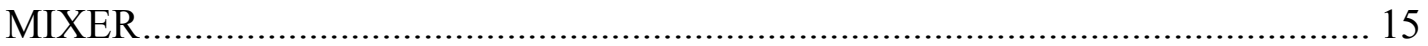

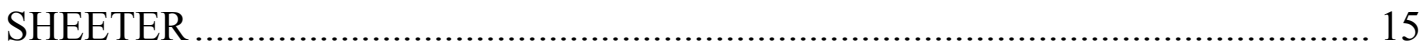

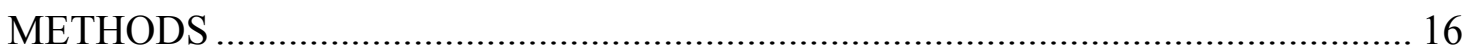

FLOUR CHARACTERIZATION BY EMPIRICAL RHEOLOGICAL EQUIPMENT

.

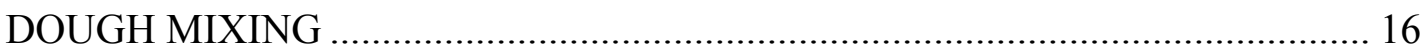

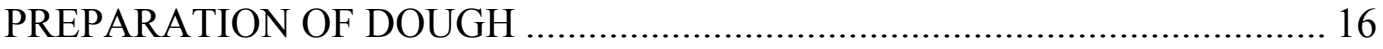

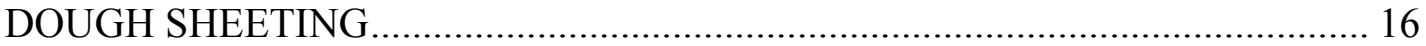

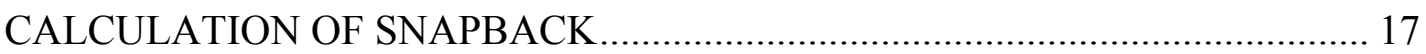

EXPERIMENTAL DESIGN, DEPENDENT \& INDEPENDENT VARIABLES .. 19

STATISTICAL TREATMENT OF DATA …………………………………...... 19

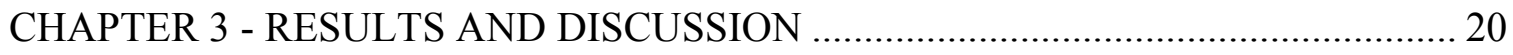

Chemical and rheological properties for three flour sets studied ................................ 20

Farinograph Measurements for three flour sets ...................................................... 22

Mixograph Measurements for three flour sets ...................................................... 25

Alveograph Measurements for three flour sets ....................................................... 29

The snapback for three flour sets studied ................................................................ 32

The snapback for bread, 50/50 blended, pastry flours of Set I, correlated with their reduction ratio and rest time changes. 32

The snapback for hard wheat, 50/50 blended, soft wheat flours of Set II, correlated with their reduction ratio and rest time changes 
The snapback for the first and second flour sets receiving 5 min rest time, correlated with their reduction ratio and protein content changes 38

The snapback for the first and second flour sets receiving 15 min rest time, correlated with their reduction ratio and protein content changes 40 The snapback for the first and second flour sets receiving 25 min rest time, correlated with their reduction ratio and protein content changes

The snapback for the first and second flour sets, correlated with their protein content and rest time changes for a reduction ratio of 1.5 . 44

The snapback for the first and second flour sets, correlated with their protein content and rest time changes for a reduction ratio of 2 . 46

The snapback for the first and second flour sets, correlated with their protein content and rest time changes for a reduction ratio of 2.5.

The snapback for the first and second flour sets, correlated with their protein content and rest time changes for a reduction ratio of 3 50

LINEAR STEPWISE REGRESSION ANALYSIS 52

LINEAR STEPWISE REGRESSION ANALYSIS FOR THE FIRST FLOUR SET52 LINEAR STEPWISE REGRESSION ANALYSIS FOR THE SECOND FLOUR SET

LINEAR STEPWISE REGRESSION ANALYSIS FOR THREE FLOUR SETS

COMBINED 54

SECOND ORDER RESPONSE SURFACE REGRESSION ANALYSIS FOR THREE FLOUR SETS COMBINED 56

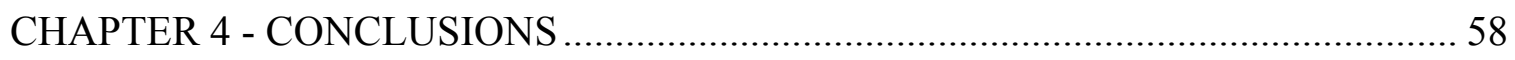

References......................................................................................................... 59

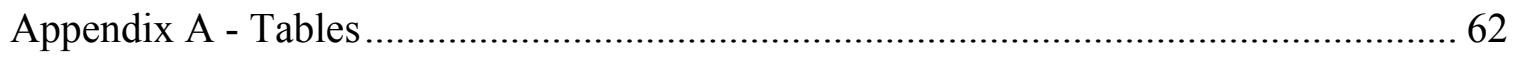

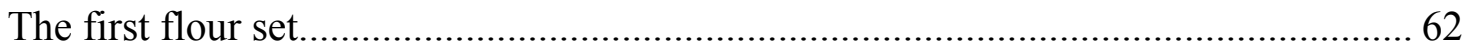

The snapback for the first flour set, correlated with their protein content using different reduction ratios.

The snapback for the first flour set, correlated with protein content using different rest times 
The snapback for the first flour set, correlated with Mixograph peak height using different reduction ratios. 69

The snapback for the first flour set, correlated with Mixograph peak height using different rest times

The snapback for the first flour set, correlated with Mixograph mixing time using different reduction ratios. 76

The snapback for the first flour set, correlated with Mixograph mixing time using different rest times 79

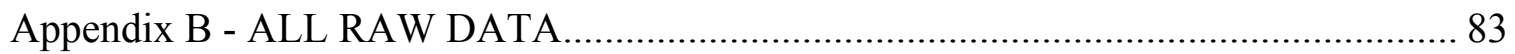

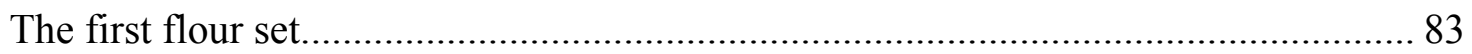

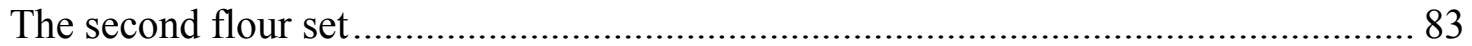

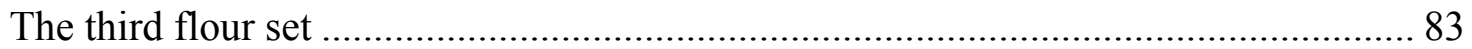

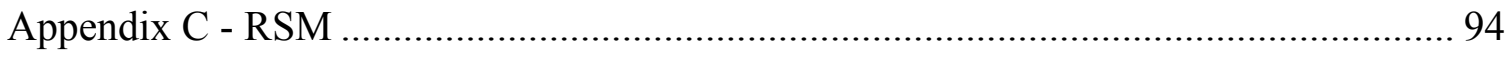




\section{List of Figures}

Figure 1.1 A sample curve and its measurement for the Farinograph ..................................... 9

Figure 1.2 A sample curve and its measurement for the Mixograph..................................... 9

Figure 1.3 A sample curve and its measurement for the Alveograph.................................... 10

Figure 2.1 A dough change during sheeting process .............................................................. 18

Figure 2.2 Set up initial setting $15 \mathrm{~mm} \quad$ Figure 2.3 Dough exits the rollers................ 18

Figure 2.4 Draw a rectangle on a dough Figure 2.5 Measure the initial thickness......... 18

Figure 2.6 Sep up desired reduction ratio $\quad$ Figure 2.7 Measure the area after sheeting..... 19

Figure 3.1 Farinograph measurement for bread flour ........................................................... 22

Figure 3.2 Farinograph measurement for 50/50 blended bread/pastry flour .......................... 22

Figure 3.3 Farinograph measurement for pastry flour .................................................... 23

Figure 3.4 Farinograph measurement for hard wheat flour ................................................ 23

Figure 3.5 Farinograph measurement for 50/50 blended hard/soft wheat flour ....................... 24

Figure 3.6 Farinograph measurement for soft wheat flour .................................................... 24

Figure 3.7 Farinograph measurement for commercial flour............................................... 25

Figure 3.8 Mixograph measurement for bread flour............................................................ 25

Figure 3.9 Mixograph measurement for 50/50 blended bread/pastry flour ............................. 26

Figure 3.10 Mixograph measurement for pastry flour..................................................... 26

Figure 3.11 Mixograph measurement for hard wheat flour ............................................. 27

Figure 3.12 Mixograph measurement for 50/50 blended hard/soft wheat flour ....................... 27

Figure 3.13 Mixograph measurement for soft wheat flour................................................. 28

Figure 3.14 Mixograph measurement for commercial flour............................................. 28

Figure 3.15 Alveograph measurement for bread flour...................................................... 29

Figure 3.16 Alveograph measurement for 50/50 blended bread/pastry flour ......................... 29

Figure 3.17 Alveograph measurement for pastry flour................................................... 29

Figure 3.18 Alveograph measurement for hard wheat flour ................................................ 30

Figure 3.19 Alveograph measurement for 50/50 blended hard/soft wheat flour..................... 30

Figure 3.20 Alveograph measurement for soft wheat flour ................................................. 30 
Figure 3.21 Alveograph measurement for commercial flour.

Figure 3.22 The snapback (\%) for bread flour, correlated with different reduction ratios and rest times

Figure 3.23 The snapback (\%) for 50/50 blended bread/pastry flours, correlated with different reduction ratios and rest times

Figure 3.24 The snapback (\%) for pastry flour, correlated with different reduction ratios and rest times.

Figure 3.25 The snapback (\%) for hard wheat flour, correlated with different reduction ratios and rest times

Figure 3.26 The snapback (\%) for 50/50 blended hard/soft wheat flour, correlated with different reduction ratios and rest times 35

Figure 3.27 The snapback (\%) for soft wheat flour, correlated with different reduction ratios and rest times 36

Figure 3.28 The snapback (\%) for the first flour set, correlated with protein content using different reduction ratios at $5 \mathrm{~min}$ rest time. 38

Figure 3.29 The snapback (\%) for the second flour set, correlated with protein content using different reduction ratios at $5 \mathrm{~min}$ rest time. 38

Figure 3.30 The snapback (\%) for the first flour set, correlated with protein content using different reduction ratios at $15 \mathrm{~min}$ rest time.

Figure 3.31 The snapback (\%) for the second flour set, correlated with protein content using different reduction ratio at $15 \mathrm{~min}$ rest time

Figure 3.32 The snapback (\%) for the first flour set, correlated with protein content using different reduction ratios at 25 min rest time.

Figure 3.33 The snapback (\%) for the second flour set, correlated with protein content using different reduction ratios at $25 \mathrm{~min}$ rest time.

Figure 3.34 The snapback (\%) for the first flour set, correlated with protein content using different rest times for a reduction ratio of 1.5

Figure 3.35 The snapback (\%) for the second flour set, correlated with protein content using different rest times for a reduction ratio of 1.5

Figure 3.36 The snapback (\%) for the first flour set, correlated with protein content using different rest times for a reduction ratio of 2 
Figure 3.37 The snapback (\%) for the second flour set, correlated with protein content using

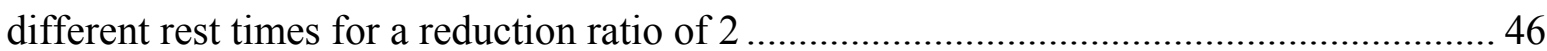

Figure 3.38 The snapback (\%) for the first flour set, correlated with protein content using

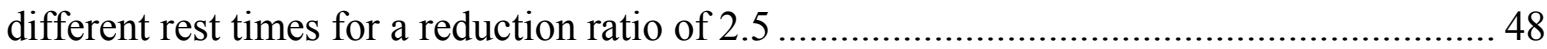

Figure 3.39 The snapback (\%) for the second flour set, correlated with protein content using

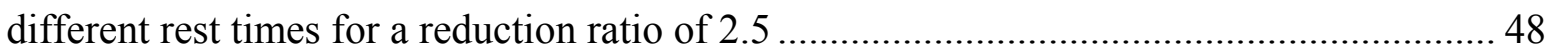

Figure 3.40 The snapback (\%) for the first flour set, correlated with protein content using different rest times for a reduction ratio of 3

Figure 3.41 The snapback (\%) for the second flour set, correlated with protein content using

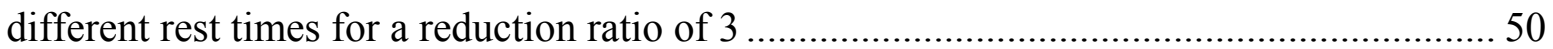




\section{List of Tables}

Table 1.1 Summary of Common Rheological Tests ............................................................. 12

Table 2.1 Summary of protein content and moisture for three flour sets studied..................... 14

Table 3.1 Chemical and rheological properties for three flour sets studied ............................ 21

Table 3.2 Linear stepwise regression analysis for snapback in the first flour set......................52

Table 3.3 Linear stepwise regression analysis for snapback in the second flour set.................. 53

Table 3.4 Linear first order stepwise regression analysis for snapback-including all 7 flours.... 54 


\section{Acknowledgements}

I would like to thank the following people:

Dr. Chuck Walker, my co-advisor, mentor, and friend, helped and led me in every aspect. He brought me and took care of me from the beginning until now. Without his help, I did not think I could get through all my difficulty in academic and life changes. He was a good example ahead of me to help any person who needed help. He was dedicated to all his students without any charge of return, with great patience and joy. He polished every word in my thesis and me as a grown up. I really appreciated his encouragement and investment on me.

Dr. Jon Faubion, my co-advisor, guided me as a great successful example both in academic and industrial fields. He was full of knowledge in dough rheology and always had this office door open for me.

Miss Camila Yoo, my lab mate and best friend, was a very nice lady with great sense of humor. She always worked hard and helped me analyze and solve problems.

Miss Shifeng Ruan, Jian Li and Hsing-I Lin, my lab mates and friends, were always around me when I needed help. When I was in trouble, they were the first people to ask for help. I really appreciate their support and love in me.

Mr. Ron Stevenson was a great company through all the years here. He was the most patient person to help me and talk to.

Mr. Tinh Hoang, and Dr. Miller, helped me test and analyze my samples.

My mom, Yun Yang, was my home, harbor, and hope in my life. She gave me faith and positive attitude to make wise decision. I thank her for never-ending love and support in my life. 


\section{Preface}

Predicting and controlling the thickness of a wheat flour dough as it emerges from a sheeting roll or set of rolls and the amount of snapback immediately after it exits the sheeting stage has long been a concern of bakeries and their equipment manufacturers. It is important when setting roll gaps as well as line speeds, and is critical to maintaining dough piece weight and finished piece size.

A number of papers have been written on the theory of the sheeting operation. Kempf et al (2006) recently performed sheeting experiments, the results of which they analyzed by several mathematical models, measuring the differences between the predicted and actual degree of snapback. Their analysis was drawn from an engineering approach and did not consider the effect of factors such as temperature, flour characteristics, and absorption that the commercial baker or dough processor must face every day.

The purpose of this work was to measure elasticity in doughs from several flours with different chemical \& physical properties, to determine the main factors affecting dough elastic properties, and to attempt to correlate the results with not only controllable mechanical variables such as roll diameter, speed, and spacing, but also with flour properties determined using common physical dough analysis/ applied-rheology equipment as well as common process variables such as absorption and temperature. Finally, the objective was to develop predication equations for dough elastic properties during sheeting, based on the most relevant appropriate flour properties and processing conditions. 


\section{CHAPTER 1 - LITERATURE REVIEW}

\section{GENERAL INTRODUCTION TO BREAD DOUGH}

\section{DOUGH RHEOLOGY}

Rheology is the science concerned with the study of viscosity and deformation of a plastic substance. Elasticity and viscosity are the most familiar rheological concepts in this area and "how to measure" these properties mentioned above becomes a significantly concerned topic. Currently, rheological measurements are extensively used in the baking industry for testing flour quality and adherence to specifications. Empirical dough rheological instruments such as the Farinograph, Mixograph, Alveograph, and Extensograph, are used to measure the physical response of doughs to external forces. The types of forces provided by the four machines are mixing arms, mixing pins, air pressure, or a curved hook, respectively. The basic parameters from the devices measure the doughs' stress and strain properties and quantify the elastic and viscous properties. These empirical results supply adequate information for operational bakers and millers. The general information on rheology and application to doughs may be found in several locations.

\section{VISCOELASTIC PROPERTIES OF DOUGH}

Dough is viscoelastic, which means that it has both viscous and elastic characteristics and combines the properties of both solid and liquids. For ideal elastic solids, the strain is always proportional to the stress. For ideal viscous liquids, the strain is always proportional to the rate of stress. 'When both types of simple ideal behavior coexist, the ratio stress:strain is a function of the stress or strain as well as time, and material shows nonlinear viscoelasticity' (Hibberd and Parker, 1975). The mechanical properties of a dough show both kinds of behavior, so that it is classified as a nonlinear viscoelastic material. If it is too viscous and flows too much during sheeting, the dough does not maintain the desired final shape. If the dough lacks in its elastic properties, it is difficult to form into the desired shape with the result that the final products are not desired by the customers. If it is too sticky, pieces stick together and a dough being divided and processed has an excessive amount of 'doubles'. If it is not sticky enough, the dough will 
not be sufficiently cohesive to be formed by sheeting, and the final product does not have the desired crumb structure.

Therefore, a correct balance of viscoelastic properties is very important to a successful sheeting process. On the one hand, it is necessary to control the extensibility of the dough. Otherwise, the dough piece is too long after sheeting. On the other hand, it is important to control the elasticity. Sometimes, the dough springs back too far after sheeting and produces a dough too short to fill the pan completely. It is necessary to have an appropriate extent of stickness to hold the folded layers of dough together and to prevent large holes in the final baked food.

In addition, the rheological properties of a dough help determine bread loaf shape during proofing before baking. The dough should expand to fill the pan but flow to keep a good product shape. If the viscous dough is too weak, it flows to fill the corners of the pan. It will cause a problem with sharp edges and a flat top. Conversely, if the dough is too strong, it does not expand sufficiently during the proofing or baking, resulting in a low volume.

\section{FACTORS AFFECTING DOUGH RHEOLOGY}

\section{WHEAT FLOUR PROPERTIES}

The rheological properties of a flour-water dough are affected by ingredient interactions during dough mixing. Most of the properties result from the interactions with flour, water, and air. Other factors such as salt, yeast, oxidizers, and emulsifiers are widely known to have effects also.

\section{PROTEIN CONTENT}

Flour proteins are classified into four categories, albumin, globulin, prolamin, and glutelin, according to a solubility scheme by Osborne. Albumins are soluble in water, whereas globulins are insoluble in water but are in dilute salt solutions. Prolamins are soluble in $70 \%$ ethyl alcohol, whereas glutelins are soluble in dilute acids or bases. Gliadin is the specific name given the prolamins from wheat, and glutenin is the name given the wheat glutelins. Glutenins and gliadins, when wetted and mixed, form gluten, which is unique to wheat.

The gluten proteins - gliadins, are rather small and single chained, ranging from 30,000 to about $100,000 \mathrm{Da}$ in molecule weight. 'Gliadins contain intra-molecular disulfide bonds, 
breaking of which causes unfolding of the protein molecule' (Bloksma, 1990). They are apparently responsible for the cohesive property of gluten.

The gluten proteins - glutenins, are much larger than the gliadins, with an average molecule weight of about $3 \times 10^{6} \mathrm{Da}$. The glutenin proteins are multi-chained and appear to be mainly polymerized by disulfide bonds and not cross-linked (Ewart, 1977, 1979, 1987). These proteins appear to give the gluten its elastic properties.

The molecular unit of glutenin is supposed to link together as a chain. 'This consists of a variable number of polypeptide chains, not necessarily of the same type, which are joined together by disulfide bonds to form a super-molecule possessing a linear configuration' (Greenwood and Ewart, 1975). This configuration is often entangled with one another and regions of strong interaction of entanglement points form the cross-links that are essential for rubber-like elasticity. 'The native state of polypeptide chains is a coiled and folded conformation, stabilized by secondary forces, and the tendency when unfolded, to return to the native state of lower free energy, is responsible for the elastic restoring force of the dough' (Greenwood and Ewart, 1975).

The cross-linked web of protein fibrils would provide a very efficient system for incorporating elasticity into the dough system. This restoration of bonds along the fibrils provides a mechanism for elastic recovery of the system (Bernardin and Kasarda, 1973).

Glutenin consists of many large molecules whose random coils would be expected to offer numerous opportunities for molecular associations. 'This complex pattern of associations in glutenin promotes cohesion and elasticity' (Wall and Beckwith, 1969). It is reasonable to assume that glutenin is the major determinant of the viscoelasticity of dough.

Simple correlation between bread strength parameters and the proportion of each protein faction or combination of fractions shows that the proportions of both glutenin and residue protein have a direct effect on baking performance. 'The ratios of gliadin to glutenin and albumin to globulin are also significantly positively corrected with loaf volume per unit protein' (Orth and Bushuk, 1972).

'The relative quantity of glutenin is highly positively correlated with loaf volume, extensigraph dough resistance and extensibility, and mixograph peak development time of these flours' (Singh, Donovan, and MacRitchie, 1990). 


\section{GLUTEN ELASTICITY}

The elastic properties of a dough are affected strongly by gluten elasticity. How does gluten elasticity form? There are two reasonable hypotheses. Tatham et al. (1985) hypothesized that the major elastic components of gluten were the HMW subunits of glutenin. 'The repetitive $\beta$-turns in the central domain formed an elastic $\beta$-spiral, and these elastic monomers were assembled into gluten polymers by intermolecular disulfide bonds between the cysteine residues in the $\alpha$-helical domains near the $\mathrm{N}$ - and C-termini'.

The 'Linear glutenin hypotheses' of Ewart $(1968,1972,1978)$, proposed that glutenin contained molecules joined by disulfide bonds into linear polymers, with only a limited amount of branching. These molecules were responsible for elasticity.

\section{WATER ABSORPTION}

Dough water absorption has a strong influence on its rheological properties. Many ingredients in a dough compete with the flour for the available water. 'If there is insufficient water to meet the hydration needs of all the dough ingredients, the gluten does not become fully hydrated and the elastic nature of dough does not become fully developed' (Faridi \& Faubion, 1990). Conversely, an excessive level of free water in the dough causes a sticky dough because the dough decreases in resistance elasticity and increases in extensibility, in a visco-elastic system.

The high percentage of amide side chains also contributes to extensive hydrogen bonding between chains. The importance of this interaction to gluten elasticity was clearly demonstrated by Beckwith et al. (1963). 'They treated gluten with methanolic hydrochloric acid, converting amide groups to esters. Conversion increased solubility, decreased intrinsic viscosity of protein solutions, and decreased cohesion of the hydrated gluten. Individual hydrogen bonds are relatively weak but the presence of large numbers of them lends overall strength to the interaction' (Cauvain and Young, 1998). 'The fact that the resistance of dough to elastic deformation decreases with increasing temperature emphasizes the importance of hydrogen bonds in the proteins' (Bloksma and Nieman, 1975). Besides inter-chain bonding, hydrogen bonds also stabilize the $\beta$-turn spirals in the central portions of glutenin molecules. These play a role in the development of elasticity. 


\section{STARCH DAMAGE}

During the milling process, some of the starch granules are damaged when the endosperm is broken into small particles and then made into flour. The granules have elastic properties after they are subjected to high pressure during the reduction. Hard wheat flours normally have a higher damaged starch content than soft wheat flours because more pressure is exerted at the reduction rolls. It is reported that in a hard wheat flour, about $15 \%$ of the starch granules are damaged. Also, the damaged starch is related to how fine the people grind their flour and the initial physical hardness of the wheat kernel as well as the tempering process prior to milling.

'Damaged starch has a profound effect on the water absorption capacity of flour when a dough is made, because the capacity of damaged starch to absorb water is many times higher than that of the intact granular starch' (Farrand, 1964). Because the starch granules develop cracks and fissures during the reduction processing, water can move easily to penetrate into the interior of the granules and interact with the amorphous regions.

In addition, those flours with damaged starch granules are susceptible to $\alpha$-amylase action. Under ordinary conditions, however, intact starch granules are resistant to amylolytic attack. Flours with damaged starch have a decreased water-holding capability during the proofing process. More water in a dough matrix results in an increase in pan flow.

\section{FLOUR ASH CONTENT}

Ash content is directly related to the amount of bran in the flour, because bran contains a higher mineral content than the endosperm and germ. Flours with higher ash contents have darker colors and show difficulty in dough processing and handling. Bran may damage the gluten network. In addition, 'the presence of non-starchy network-forming polysaccharides such as pentosans affects the rheological properties of wheat flour doughs' (Faridi \& Faubion, 1990).

\section{TEMPERATURE}

Dough is a viscoelastic material. The resistance of elastin increases with increasing temperature in the same way as that of rubber (Dorrington and McCrum, 1977). When the temperature is relatively high, the dough becomes soft and viscous but shows less elastic properties. Conversely, when the temperature is relatively low, the dough is hard to push and difficult to extend. It results in a larger extent of snapback. 


\section{SALT}

Some of the minor ingredients such as salt affect the rheological properties of a dough. The salt interacts with the major constituents of the dough and changes water interactions between the components. It alters the configuration of proteins due to its competition for water. Salt enhances the strength of the electrostatic bonds, because ion pairs are common on concentrated salt solutions. So 'the addition of salt increases the resistance of dough to mechanical mixing and decreases water absorption, due to enhanced gluten aggregation' (Cauvain and Young, 1998). The salt combination is attributed to increasing the dough mixing times, so the addition of salt is usually delayed until late in the mixing process.

\section{PENTOSANS}

Non-starch polysaccharides represent only about 2-2.5\% of flour (Michniewicz et al., 1990), but have a disproportionate influence on dough properties due to their high waterabsorbing capacity. 'The water-soluble pentosans absorb 4.4 times their weight of water and the water-insoluble pentosans 9.9 times their weight' (Kim and D’Appolonia, 1997).

The water-absorbing properties of pentosans aid in wheat flour dough formation, and the increased viscosity influences the viscoelastic behavior of dough, a result of water-soluble pentosans. 'The effect of wheat pentosans illustrates the influence of $2-4 \%$ additions on Farinograph, Alveograph and Extensograph values, and on bread volume quality and shelf-life' (Casier, 1975).

What is the mechanism? Pentosans may be treated with certain oxidants, and ferulic acid may be esterified to arabinoxylans. Oxidants promote crosslinking between ferulic acid residues and cause suspensions containing both WI and WS pentosans. Cysteine binds to WS pentosans (Sidhu et al., 1980), presumably through addition of the -SH bond across the activated double bond. 'Carboxylic acids with an activated double bond (e.g. fumaric acid and cinnamic acids) drastically reduce the mixing stability of doughs' (Hoseney and Faubion, 1981). 'These facts have been interpreted to mean that, during normal dough mixing, ferulic acid units attached to pentosans are attached to gluten proteins via the addition of sulfhydryl groups across the activated double bond, generating crosslinks and enhancing dough elasticity' (Cauvain and Young, 1998).

The quantity of retained gas is apparently a function of the high level of water-soluble pentosans that it contains (Hoseney and Rogers, 1990). These pentosans increase the viscosity of 
the aqueous phase. Casier et al. (1973) have shown that 'the addition of pentosan material to a number of flours results in the dough retaining gas to a much larger extent than flours without the additional pentosans'.

The pentosans, minor constituents of wheat flour, may significantly affect the rheological properties of dough and thereby the quality of bread (Jelaca and Hlynka, 1971; Holas and Tipples, 1978; Hoseney, 1984).

\section{REST TIME}

Introduction of the rest period reduced the time required to mix to peak consistency. 'These effects were more pronounced with longer rest periods and at higher absorption' (Tipples and Kilborn, 1977).

Baking studies confirmed that a rest period exaggerates the unmixing effect, which may take place even when a developed dough is subsequently remixed for a very short time at high speed.

\section{THE ROLE OF RHEOLOGY IN QUALITY CONTROL}

Through rheological measurements, a dough's mechanical properties could be described quantitively and the information about molecular structure and dough composition could be obtained. The more important function is to simulate the dough's performance for process control, design and quality control. Many rheological tests attempt to predict the final product related to their mixing behavior, baking performance, and texture.

The rheological tests replace the human being's touch to assess their elasticity and extensibility related to end-use quality. The machines use quantitative descriptions to assess the dough's properties. They are good indicators of gluten polymer molecular structure and predictors of functional behavior in bread making.

\section{RHEOLOGICAL TESTS FOR FLOUR MIXING PROPERTIES}

Some important factors affecting the rheological behavior of a dough are wheat variety and quality, the amount of water added, and work done on the developing dough.

\section{FARINOGRAPH AND MIXOGRAPH}

The Farinograph and Mixograph are torque-measuring devices, but have totally different mixing actions. 'The Farinograph provides a gentler kneading type of mixing, while the 
Mixograph uses a harsher pin mixing method' (Faridi \& Faubion, 1990). Mixing properties of flours are measured by recording the resistance of the dough to the mixing blades during prolonged mixing. The information from the instruments provides the development time, the tolerance to overmixing, and optimum water absorption

\section{FARINOGRAPH}

For the Farinograph, the most important factor is the peak time, which is the time required for a dough to reach the point of minimum mobility. Peak time is related to how strong the flour is and how fast the flour reacts with the water. The other factor usually recorded for the Farinograph is the water absorption. Farinograph absorption is the water to flour ratio that results in a recording trace centered on the 500 Brabender units line. When using a Farinograph, it is assumed that water level is the only factor changing the consistency of a dough when reaching its optimum development point. The absorption number represents the relative water uptake by the various components. The water absorption is sufficient to give a dough a uniform consistency. If the protein level or starch damage is greatly different among the flours tested, the Farinograph is not always a good choice. 
A sample curve and its measurement for the Farinograph is shown in Figure 1.1.

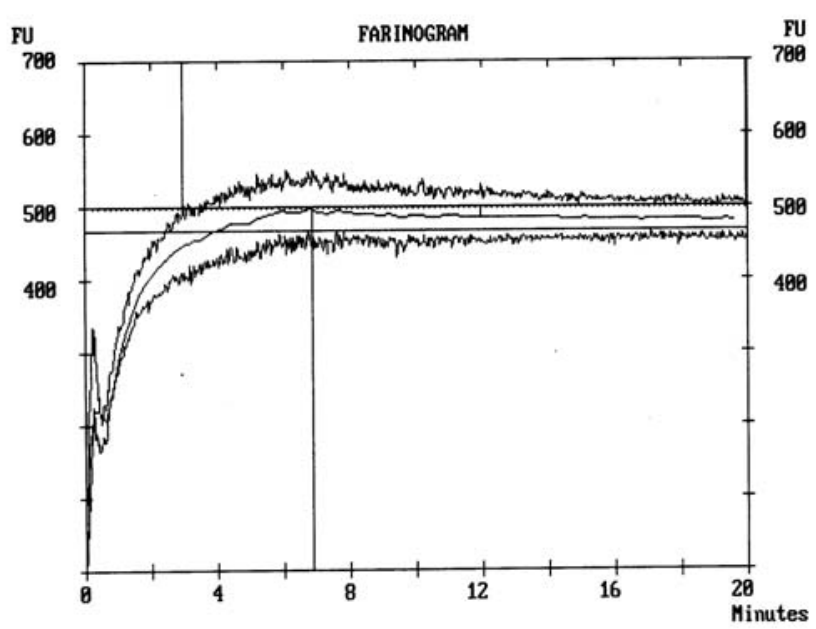

Figure 1.1 A sample curve and its measurement for the Farinograph

\section{MIXOGRAPH}

In a Mixograph, a dough in the mixing bowl gives enhanced resistance as the mixing head rotates. The process from a simple mixture of water and flour to a dough correlates with an increased resistance to mixing. Different flours have different resistance properties and they are shown to have different peak heights in the resulting curves. The peak time is also related to how strong the flour is, how it develops its gluten, and how fast the flour reacts with the hydration water.

A sample curve and its measurement for the Mixograph is shown in Figure 1.2.

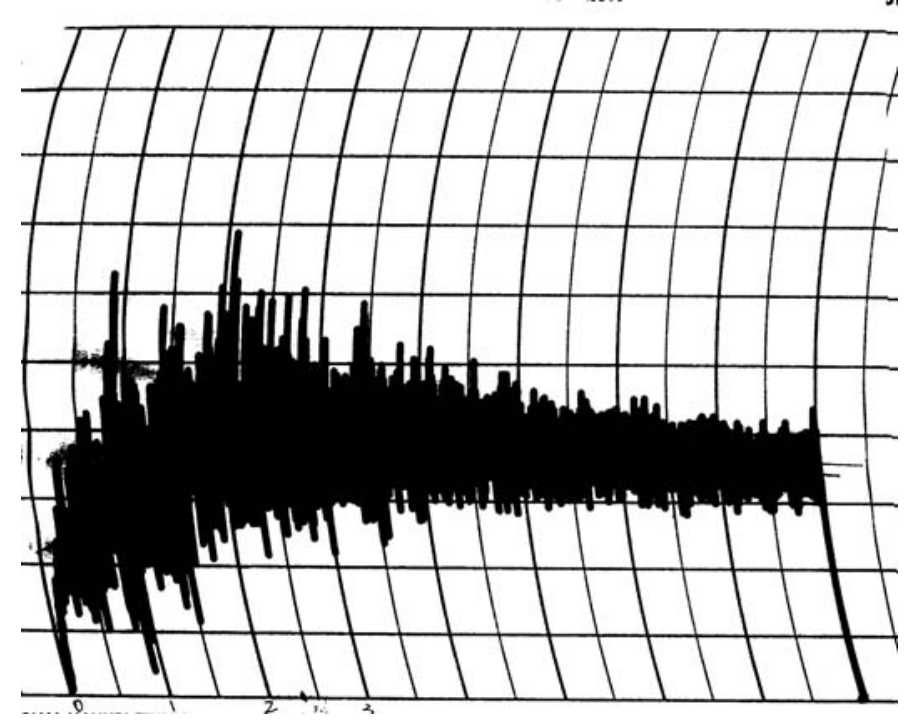

Figure 1.2 A sample curve and its measurement for the Mixograph 


\section{ALVEOGRAPH}

The measurement of the visco-elastic properties of a dough after mixing is a stress-strain relationships which provides information on elasticity. One of the common instruments used for this purpose is the Chopin Alveograph.

\section{ALVEOGRAPH}

The Alveograph measures the pressure required to blow a bubble in a uniformly thick sheeted piece of dough. The Alveograph expands the dough in two directions and the rate of expansion changes with the bubble growth. The $\mathrm{P}$ (or pressure) value is an indicator of resistance to deformation. The maximum height of the curve shows the elasticity or resistance to extension of a dough. The L (or length) of the curve is related to the viscous portion of a dough, or its extensibility. So the $\mathrm{P} / \mathrm{L}$ ratio is another indication of the balance of elastic to viscous components in a dough.

A sample curve and its measurement for the Alveograph is shown in Figure 1.3.

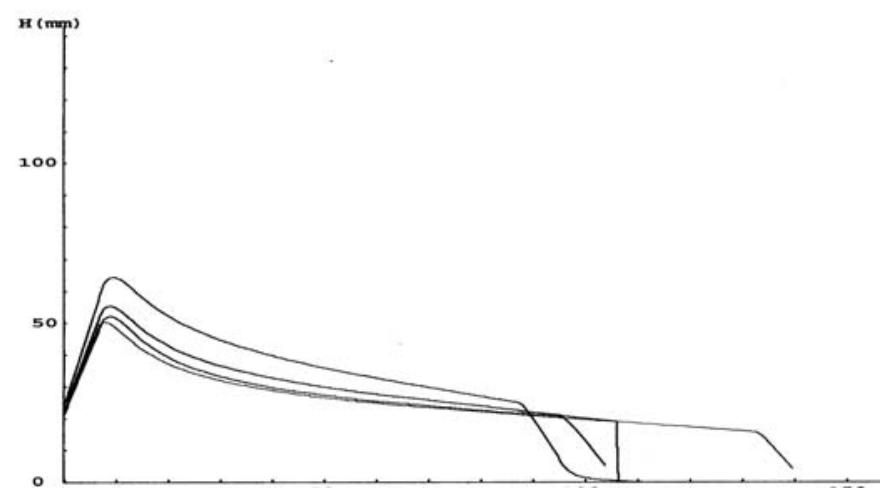

Figure 1.3 A sample curve and its measurement for the Alveograph

\section{DESCRIPTIVE AND FUNDAMENTAL RHEOLOGICAL MEASUREMENTS}

Empirical tests (Table 1.1) are often used in the practical industry. They are very helpful in evaluating performance for process and quality control. The instruments have specific condition constraints such as environments and require skilled technicians. 'They have provided a great deal of information on the quality and performance of cereal products such as consistency, hardness, texture, viscosity, etc' (Cauvain, 2003). But they are descriptive and dependent on the instrument's type and size and specific conditions. 'Many of these are used as 'single point' tests, where a single parameter is often arbitrarily selected from a whole range of data acquired 
during the test in selecting the peak torque from a mixing trace and then using this to correlate with performance' (Cauvain, 2003).

Fundamental rheological tests (Table 1.1) measure well-defined physical properties independent of size, shape and how they are measured, and can be used for process design calculations and to model complex processing situations not amenable to direct measurement. There are four main types of those tests, dynamic oscillation, creep and stress relaxation, extensional measurements, and flow viscometry.

\section{SHEETING PROCESS}

Many factors in the sheeting process affect a dough's elastic properties. The speed, diameter, and work of the sheeter are important parameters in predicting the snapback. The work of the sheeter gives different pressure on the dough over the same area. The diameter of the sheeter rolls determines the area being touched and hence worked as the dough is being sheeted. The speed of the sheeter indicates the time being touched, which gives a different energy transfer rate. Other factors also have an influence on the dough's rheological properties. The belt material and the amount of dusting flour provide different friction levels, which affect dough elastic properties.

\section{CORRELATION BETWEEN DOUGH'S VISCOELASTIC PROPERTIES AND BREAD QUALITIES}

'Recent work has shown that bread doughs exhibit strain hardening under large extensional deformations, and that these extensional rheological properties are important in baking performance' (Kokelaar et al., 1996; Dobraszczyk, 1997). Strain hardening toughens the expanding gas cell walls and increases their resistance to extension as the bubble walls become thinner. It provides the bubbles with greater stability, decreases the possibility of coalescence, and gives better gas retention. It is expected therefore that doughs with good strain hardening characteristics should result in a finer crumb texture and larger bread loaf volume than doughs with poor strain hardening properties. 'It has been shown that good breadmaking doughs have good strain hardening properties and inflate to a larger single bubble volume before rupture, while poor breadmaking doughs inflate to lower volumes and have much lower strain hardening' (Cauvain, 2003). 
Table 1.1 Summary of Common Rheological Tests

\begin{tabular}{|c|c|c|}
\hline Method & Products & Property measured \\
\hline Empirical Methods & & \\
\hline $\begin{array}{c}\text { Mixers: } \\
\text { Farinograph } \\
\text { Mixograph }\end{array}$ & Dough & $\begin{array}{l}\text { Mixing time/torque } \\
\text { Apparent viscosity }\end{array}$ \\
\hline Extensigraph & Dough & Uniaxial Extensibility \\
\hline TA-XT2/Kieffer rig & Dough, gluten & Extensibility \\
\hline Alveograph & Dough, gluten & Biaxial extensibility \\
\hline Amylograph, RVA & Pastes, suspensions & $\begin{array}{l}\text { Apparent viscosity } \\
\text { Gelatinisation temp. }\end{array}$ \\
\hline Falling number & Fluids & Apparent viscosity \\
\hline Fundamental Methods & & \\
\hline $\begin{array}{c}\text { Dynamic oscillation: } \\
\text { Concentric cylinders } \\
\text { Parallel plates }\end{array}$ & $\begin{array}{c}\text { Fluids, pastes, batters } \\
\text { doughs }\end{array}$ & $\begin{array}{c}\text { Dynamic shear } \\
\text { moduli } \\
\text { Dynamic viscosity }\end{array}$ \\
\hline $\begin{array}{l}\text { Tube viscometers: } \\
\text { Capillary } \\
\text { Pressure, extrusion } \\
\text { Pipe flow }\end{array}$ & $\begin{array}{c}\text { Fluids } \\
\text { Sauces, Pastes, dough }\end{array}$ & $\begin{array}{c}\text { Viscosity } \\
\text { Viscosity } \\
\text { In-line viscosity }\end{array}$ \\
\hline $\begin{array}{c}\text { Transient flow: } \\
\text { Concentric cylinders } \\
\text { Parallel plates }\end{array}$ & $\begin{array}{c}\text { Semi-solid } \\
\text { viscoelastic material }\end{array}$ & $\begin{array}{l}\text { Creep relaxation } \\
\text { Moduli and time }\end{array}$ \\
\hline $\begin{array}{c}\text { Extension: } \\
\text { Uniaxial, biaxial } \\
\text { TAXT2 dough inflation } \\
\text { system } \\
\text { Lubricated compression }\end{array}$ & $\begin{array}{l}\text { Solid foods, } \\
\text { doughs }\end{array}$ & $\begin{array}{c}\text { Extensional viscosity } \\
\text { Strain hardening }\end{array}$ \\
\hline
\end{tabular}

Cited from the book (Cauvain, 2003) 


\section{OBJECTIVE}

The purpose of this work was to measure elasticity in doughs from several flours with different chemical \& physical properties, to determine the main factors affecting dough elastic properties, and to attempt to correlate the results with not only controllable mechanical variables such as roll diameter, speed, and spacing, but also with flour properties determined using common physical dough analysis/ applied-rheology equipment as well as common process variables such as absorption and temperature. Finally, the objective was to develop predication equations for dough elastic properties during sheeting, based on the most relevant appropriate flour properties and processing conditions. 


\section{CHAPTER 2 - MATERIALS AND METHODS}

\section{MATERIALS}

\section{FLOUR}

\section{FIRST FLOUR SET}

Hard wheat bread flour and soft wheat pastry flours were commercial mill mixes donated by ConAgra Foods (Omaha, NE). A composite flour was a 50/50 blend of the bread and pastry flours, prepared in a Wenger double ribbon blender (Sabetha, KS).

\section{SECOND FLOUR SET}

Pure variety Karl hard wheat purchased from the KSU Foundation Seed Association was milled in the KSU milling lab to a flour of $71.6 \%$ extraction. Pure variety Bess soft wheat bought from the Missouri Seed Improvement Association was milled in the KSU milling lab to a $70.7 \%$ extraction flour. A composite flour was also created as a 50/50 blend of the two flours.

\section{THIRD FLOUR SET}

Commercial hard wheat bread flour was donated by ConAgra Foods (Omaha, NE).

Table 2.1 Summary of protein content and moisture for three flour sets studied

\begin{tabular}{|c|c|c|c|}
\hline & Flour Type & Protein Content (\%) & Moisture (\%) \\
\hline \multirow{3}{*}{ Set I } & Bread flour & 13.69 & 13.1 \\
\cline { 2 - 4 } & $50 / 50$ blended flour & 10.49 & 13.3 \\
\cline { 2 - 4 } & Pastry flour & 7.28 & 13.5 \\
\hline \multirow{3}{*}{ Set II } & Hard wheat flour & 13.63 & 13.0 \\
\cline { 2 - 4 } & $50 / 50$ blended flour & 11.29 & 12.7 \\
\cline { 2 - 4 } & Soft wheat flour & 9.00 & 12.9 \\
\hline Set III & Commercial flour & 12.86 & 12.1 \\
\hline
\end{tabular}

Protein is based on $14 \%$ M.B. 
SALT

Sodium chloride (Morton Salt, Chicago, IL)

MIXER

200 g flour capacity pin mixer (National Manufacturing/TMCO, Lincoln, NE)

\section{SHEETER}

A Sewer-Rondo reversible sheeter (Rondo Inc., NJ, USA) with roll speed $147.6 \mathrm{rpm}$ and diameter $84.4 \mathrm{~mm}$ was used (peripheral velocity $=652.3 \mathrm{~mm} / \mathrm{sec}$ ). No load low belt speed is $603.3 \mathrm{~mm} / \mathrm{sec}$.

The real height of the roller gap " $\mathrm{H}$ " is based on an equation: $\mathrm{H}=-0.022 \mathrm{~h}^{2}+1.371 \mathrm{~h}-0.437$ (h-gap setting). 


\section{METHODS}

\section{FLOUR CHARACTERIZATION BY EMPIRICAL RHEOLOGICAL EQUIPMENT}

Protein and moisture methods are based on AACC Approved Methods (AACC 2000) 46$30,44-15 \mathrm{~A}$, respectively.

Traditional empirical rheological methods, used in bread dough testing, such as the Farinograph, Mixograph, and Alveograph, have been widely used in American bakeries.

Farinograph curves (and \% absorption) were obtained by AACC Approved Methods (AACC 2000) 54-21.

Farinograph, $50 \mathrm{~g}$ flour bowl. (Farinograph E, C.W.Brabender, Duisburg, Germany) Mixograph curve (and \% absorption) were obtained by AACC Approved Methods (AACC 2000) 54-40A.

Mixograph, $10 \mathrm{~g}$ flour bowl. (National Manufacturing Division of TMCO, Lincoln, NE)

Alveograph curves were obtained according to AACC Approved Method 54-30A (AACC 2000). (Model Alveographe NG, Chopin, France)

\section{DOUGH MIXING}

\section{PREPARATION OF DOUGH}

Dough was prepared by mixing $200 \mathrm{~g}$ of flour (14\% M.B.), $4 \mathrm{~g}$ salt and water, based on its Farinograph absorption, in a laboratory Pin Mixer (National Manufacturing/TMCO, Lincoln, NE). Mixing time for each flour was based on its Mixograph peak time at room temp. After mixing, the dough was rested at $23^{\circ} \mathrm{C}$, covered by plastic film, on the laboratory bench for 5minute, 15-minute, or 25-minute intervals before being sheeted.

\section{DOUGH SHEETING}

The dough, placed on a floured sheet, was transferred to the sheeter. Dough, adjusted by an initial roll setting of $30 \mathrm{~mm}$ prior to subsequent sheeting, was then sheeted at $25 \mathrm{~mm}$ roll gap, then down to $20 \mathrm{~mm}$, turning it 90 degrees, and sheeted at $17 \mathrm{~mm}$. The dough was finally sheeted at a $15 \mathrm{~mm}$ roll gap, and placed on the same floured sheet. A $6 \mathrm{~cm}$ by $6 \mathrm{~cm}$ rectangle was drawn with a black felt-tip marker near the center of the sheeted dough. Dough initial 
thickness was immediately measured by a vernier caliper at three different locations after drawing. The average of the three results was recorded as initial thickness "L". After the sheeter was set to the desired reduction ratio, the dough was sheeted and immediately transferred to the floured sheet. One minute after resting on the sheet, the lengths of the four sides of the rectangle and the angles between the two sides were measured. These values were used to calculate snapback.

Note: There is no big difference for dough snapback measured between $0.5 \mathrm{~min}$ and $2.5 \mathrm{~min}$ after sheeting.

\section{CALCULATION OF SNAPBACK}

The area of the shape after sheeting, S', was calculated as the sum of the areas of two triangles (Figure 2.1, Stage 2)

Equation 1: $\mathrm{S}^{\prime}=1 / 2 \times\left(\mathrm{a} \times \mathrm{b} \times \sin \theta+\mathrm{a}^{\prime} \times \mathrm{b}^{\prime} \times \sin \theta^{\prime}\right)$

Where $\mathrm{a}$ and $\mathrm{b}$ are adjacent sides and $\theta$ is the included angle of the triangle.

$a^{\prime}$ and b' are the opposite sides of a and b, $\theta^{\prime}$ is the opposite angle of $\theta$.

The final thickness, L', was calculated (Figure 2.1, Stage 1\&2)

Equation 2: $\mathrm{L}^{\prime}=\mathrm{L} \times \mathrm{S} / \mathrm{S}^{\prime}$

Where $\mathrm{L}$ is the initial thickness, $\mathrm{S}$ is the area of the initial drawn rectangle.

Snapback, defined by the percentage of the deformation between the final thickness and the roller gap, was calculated

Equation 3: Snapback $(\%)=\left[\left(L^{\prime}-H\right) / H\right] \times 100$

Where $\mathrm{H}$ is the height of the roller gap, and $\mathrm{L}^{\prime}$ is the final dough thickness. 


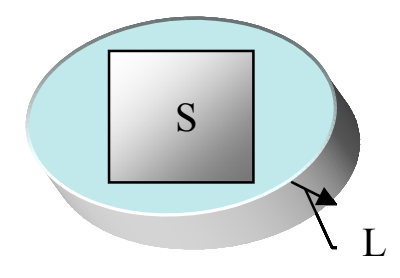

Stage 1

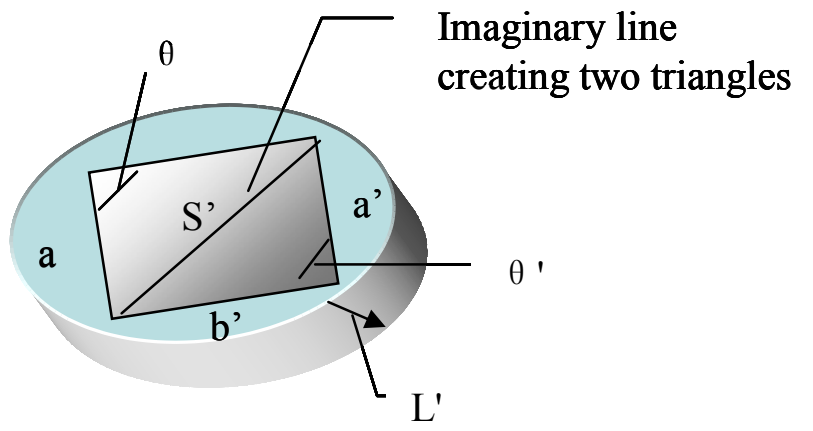

Stage 2

Figure 2.1 A dough change during sheeting process

The following four pictures show the sheeting process.

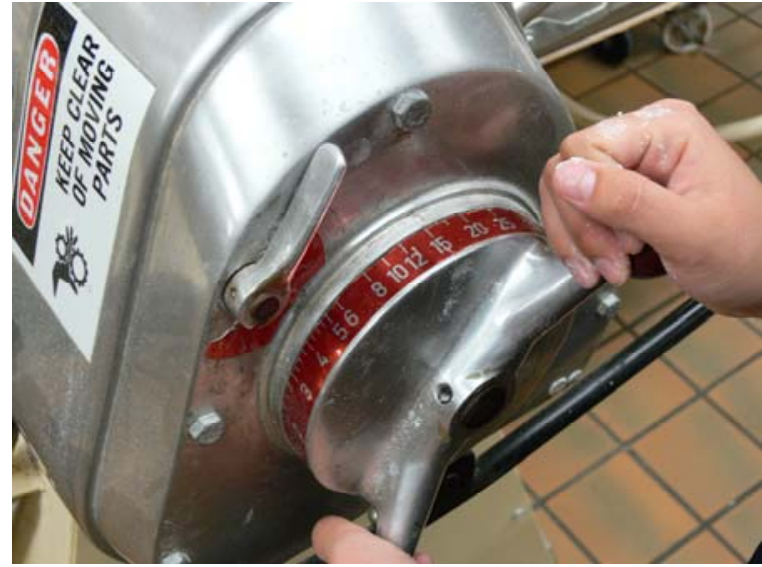

Figure 2.2 Set up initial setting $15 \mathrm{~mm}$

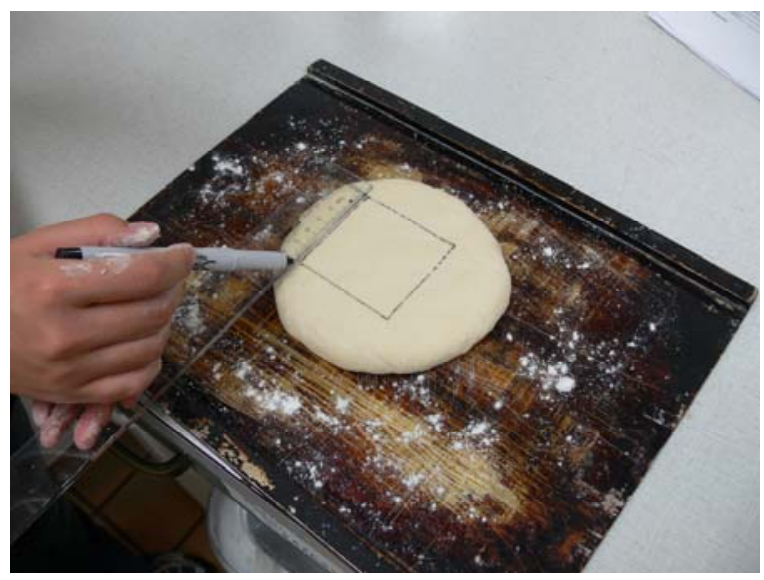

Figure 2.4 Draw a rectangle on a dough

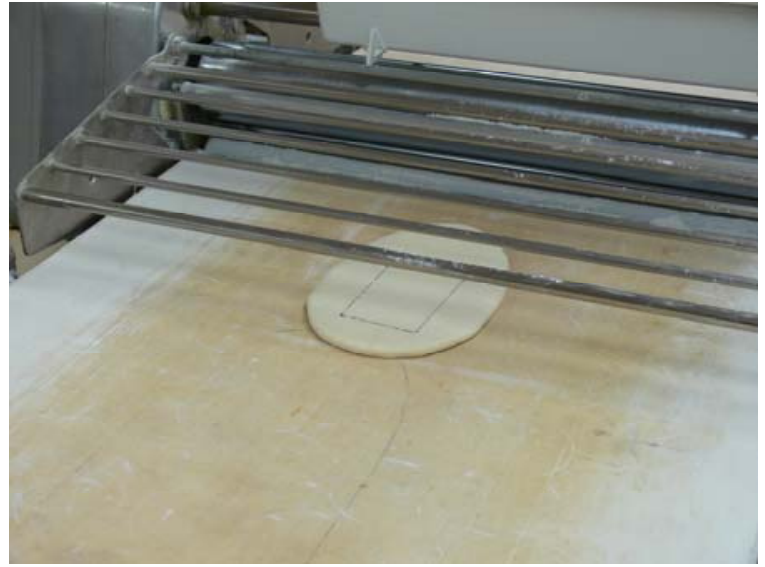

Figure 2.3 Dough exits the rollers

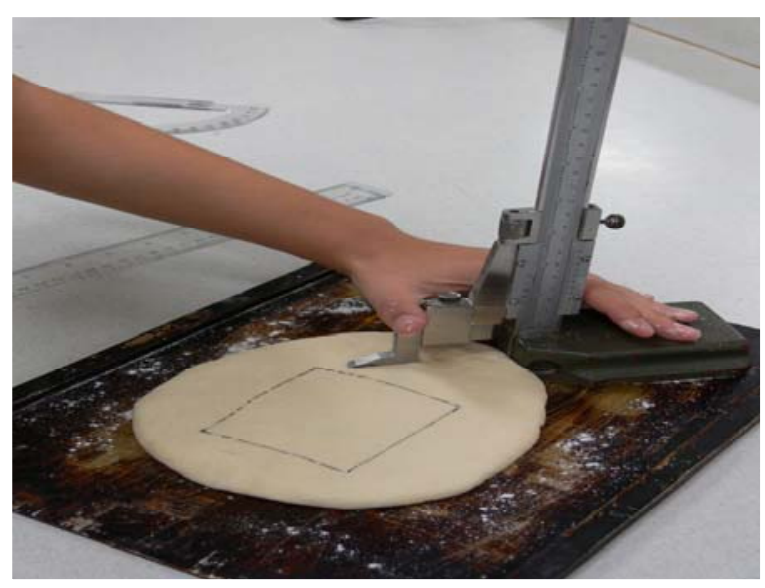

Figure 2.5 Measure the initial thickness 


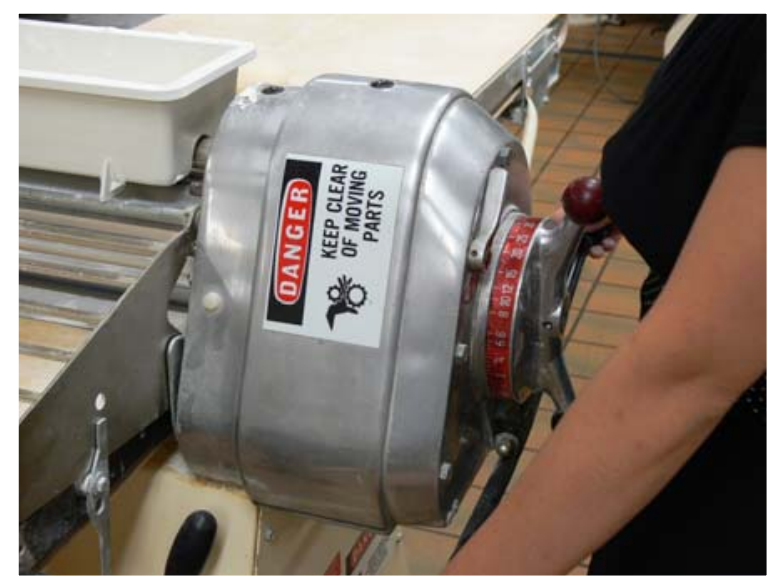

Figure 2.6 Sep up desired reduction ratio

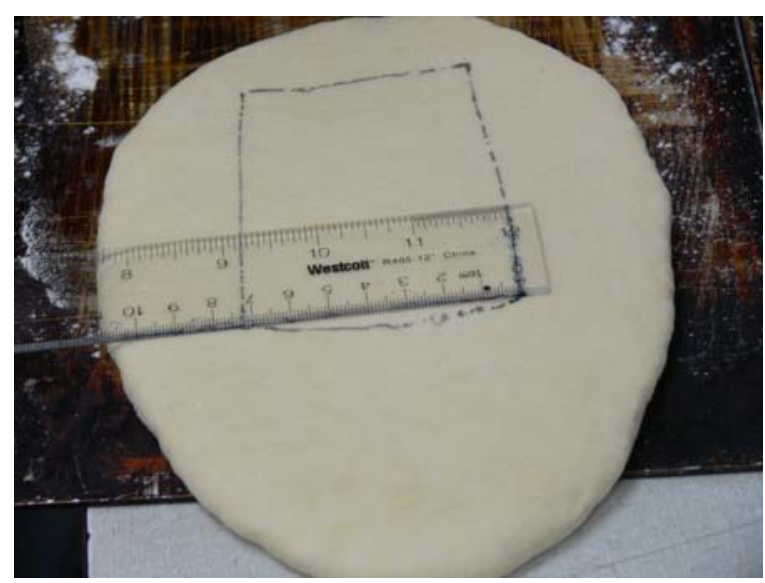

Figure 2.7 Measure the area after sheeting

\section{EXPERIMENTAL DESIGN, DEPENDENT \& INDEPENDENT VARIABLES}

The purpose of this experiment was to find out which factors affect the dough's elastic properties and how these factors have an influence on a dough's rheological properties. Then if possible, an equation describing their relationship will be developed to predict the dough's elasticity with changes in these factors. Every experiment had three replicates.

The dependent variable is usually the dough's snapback, which quantifies the dough's elastic properties.

Independent variables chosen are protein content, Mixograph work, mixing time and peak height, Farinograph water absorption, and mixing time, and Alveograph P/L and work.

\section{STATISTICAL TREATMENT OF DATA}

Minitab $^{\odot} 15$ statistical software $<$ Minitab Inc.> was used to analyze the data for more than one independent variable. It prepared a simple "response surface" contour plot representative of the apparent relationship between independent and dependent variables. It also analyzed the data by stepwise multiple linear regression to find the most important factors. The software's linear regression function provides an equation relating the independent and dependent variables and estimates how well the equation fits the data (Table 3.4), thus suggesting the most important independent variable factors affecting the dependent variable. 


\section{CHAPTER 3 - RESULTS AND DISCUSSION}

\section{Chemical and rheological properties for three flour sets studied}

There are many factors related to a dough's elastic properties. It is important that we find the most appropriate parameters to assist in predicting a dough's change in sheeting properties with different rest times and reduction ratios. The following section examines the various parameters tested to see which ones to use. Table 3.1 summarizes the flour characteristics for chemical and rheological properties. 
Table 3.1 Chemical and rheological properties for three flour sets studied

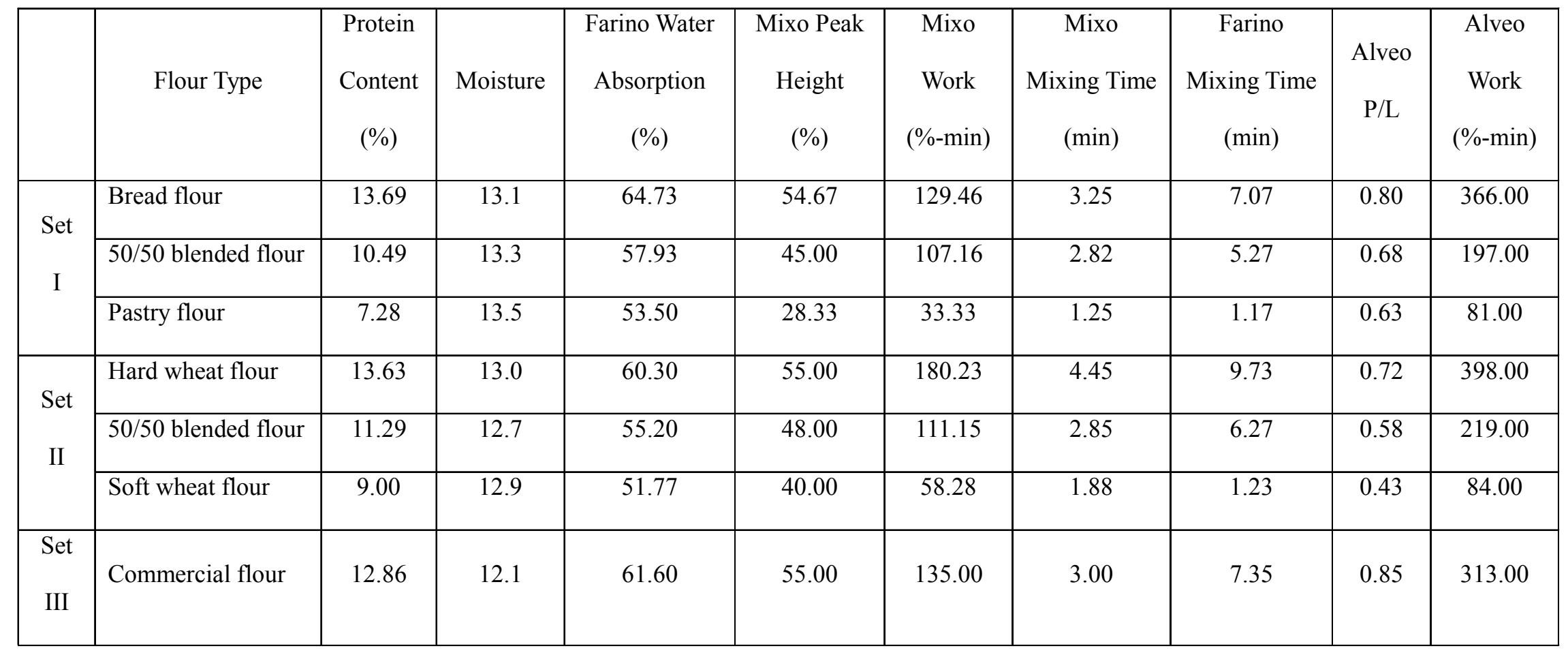

Protein is based on 14\% M.B. 
Farinograph Measurements for three flour sets

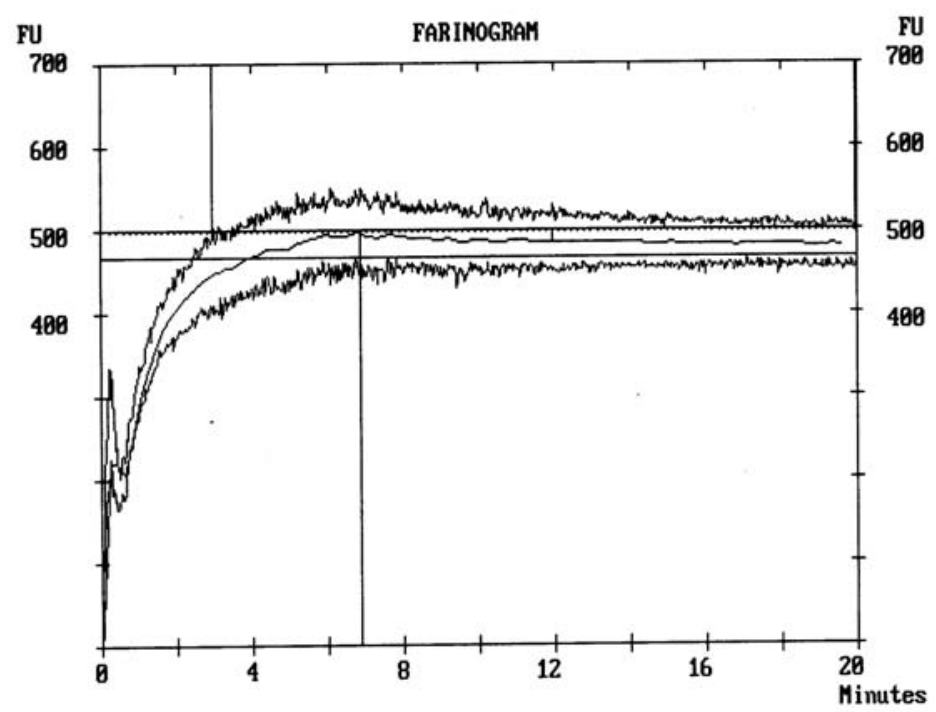

Figure 3.1 Farinograph measurement for bread flour

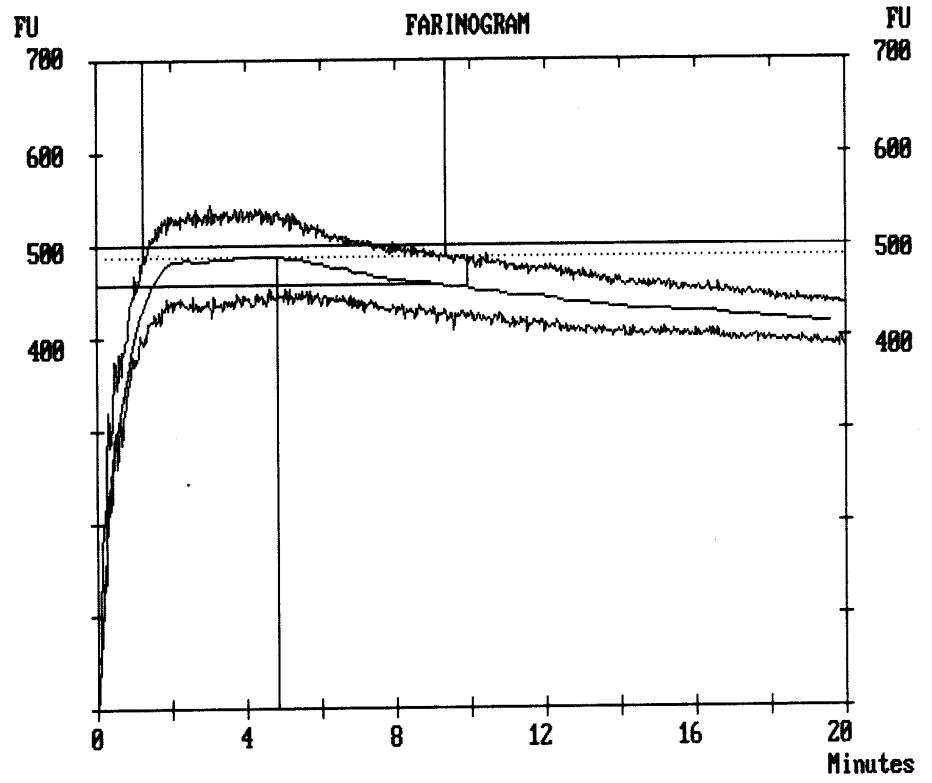

Figure 3.2 Farinograph measurement for $50 / 50$ blended bread/pastry flour 


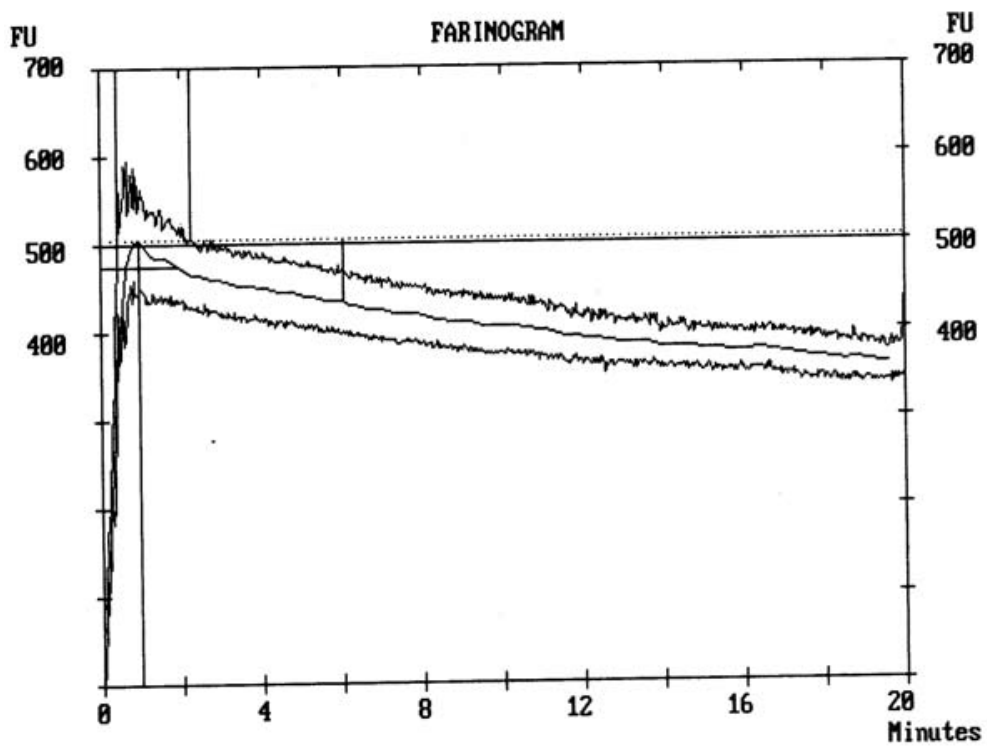

Figure 3.3 Farinograph measurement for pastry flour

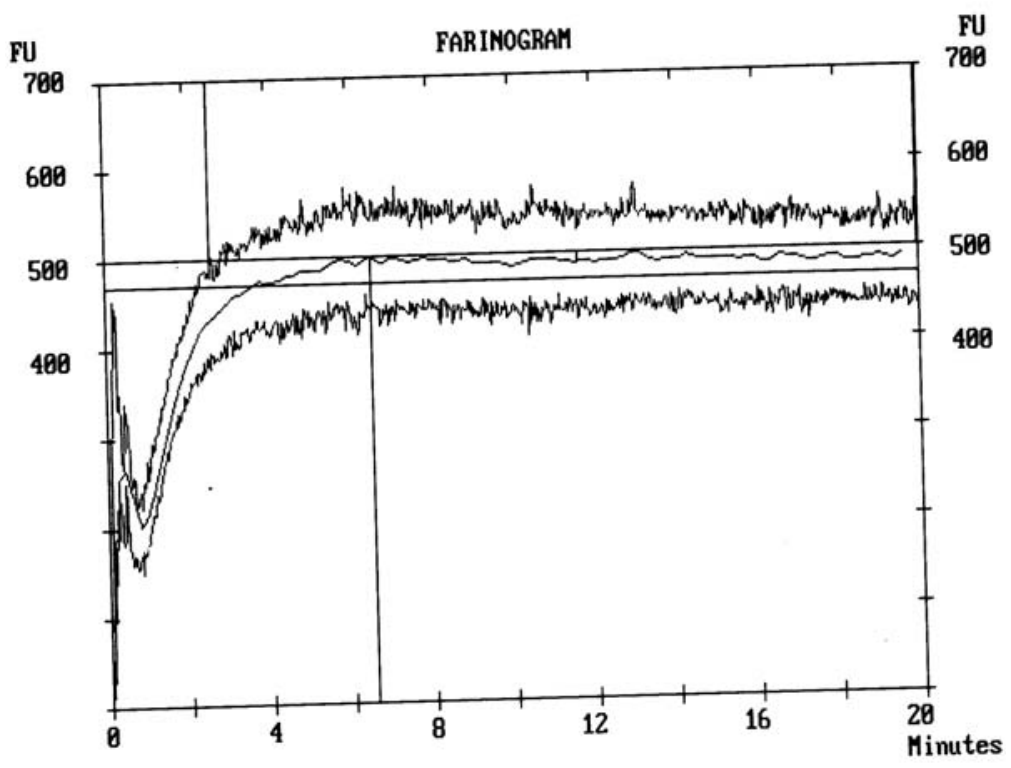

Figure 3.4 Farinograph measurement for hard wheat flour 


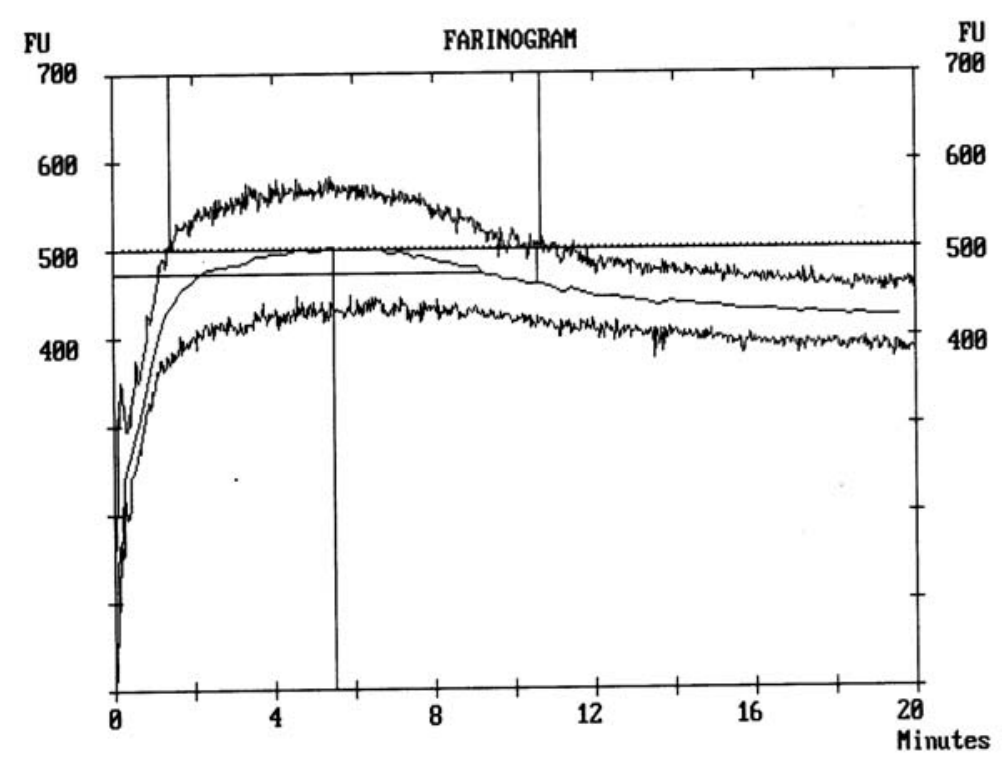

Figure 3.5 Farinograph measurement for 50/50 blended hard/soft wheat flour

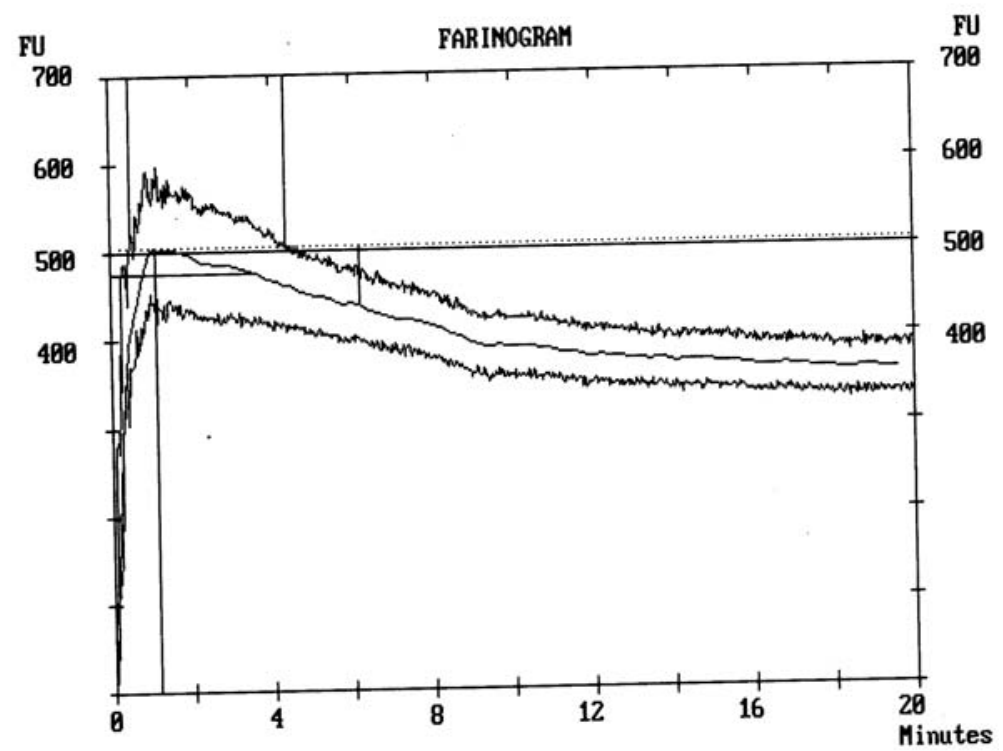

Figure 3.6 Farinograph measurement for soft wheat flour 


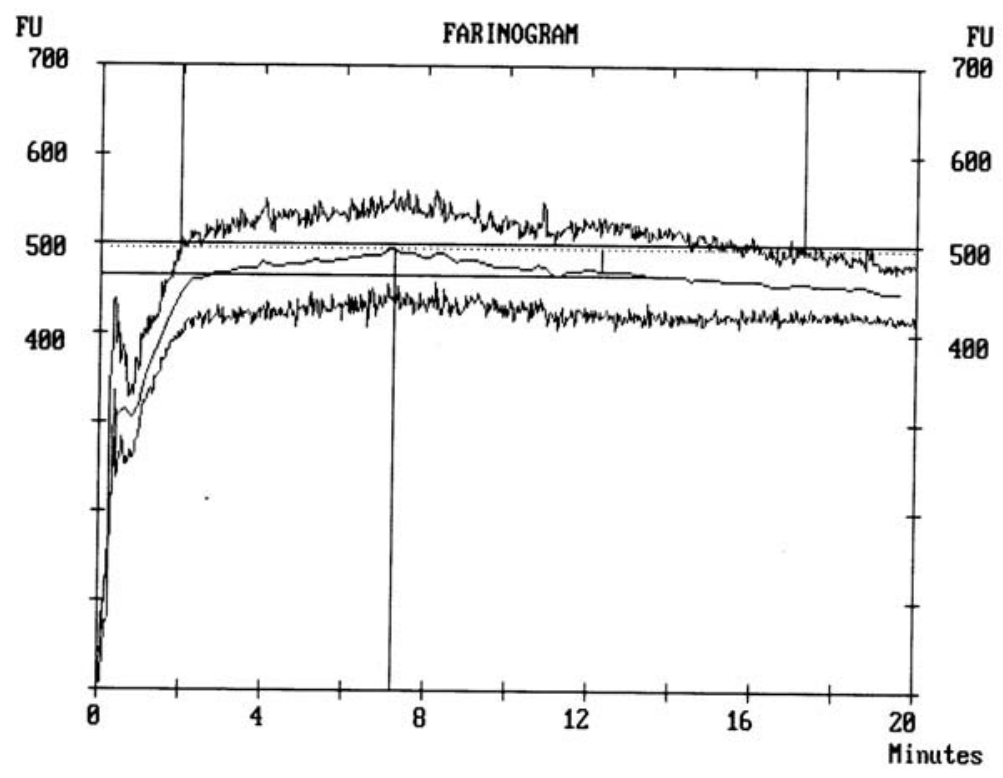

Figure 3.7 Farinograph measurement for commercial flour

Mixograph Measurements for three flour sets

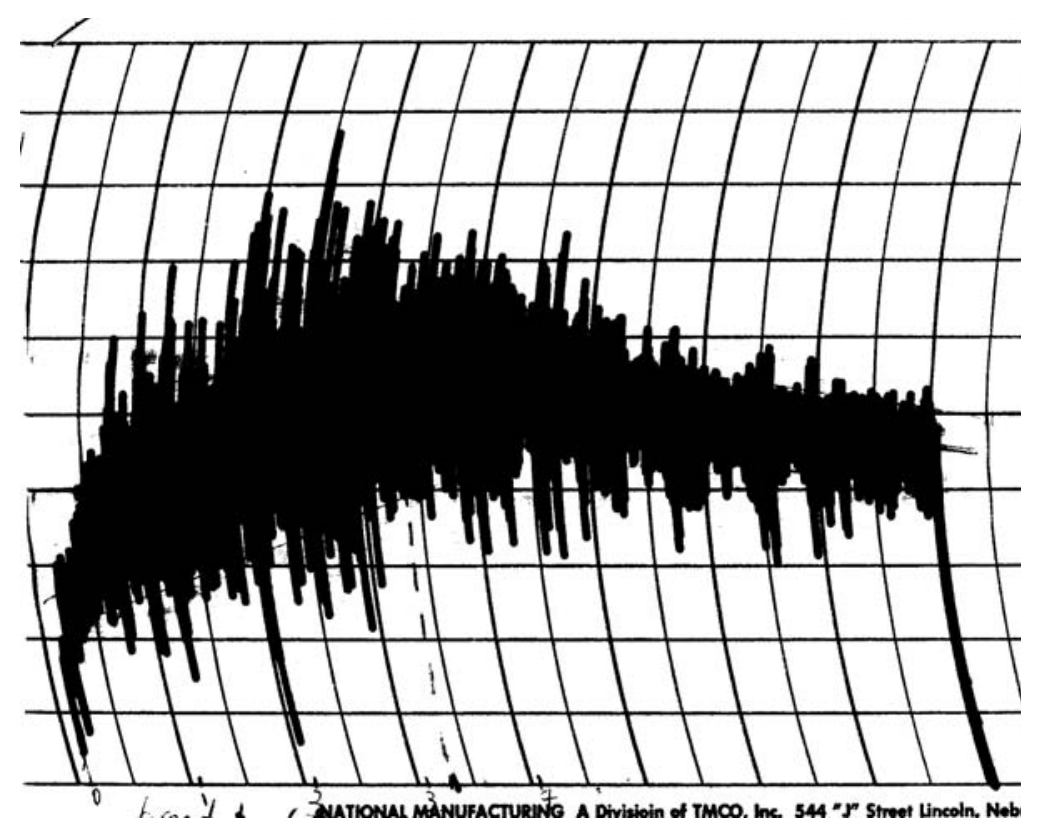

Figure 3.8 Mixograph measurement for bread flour 


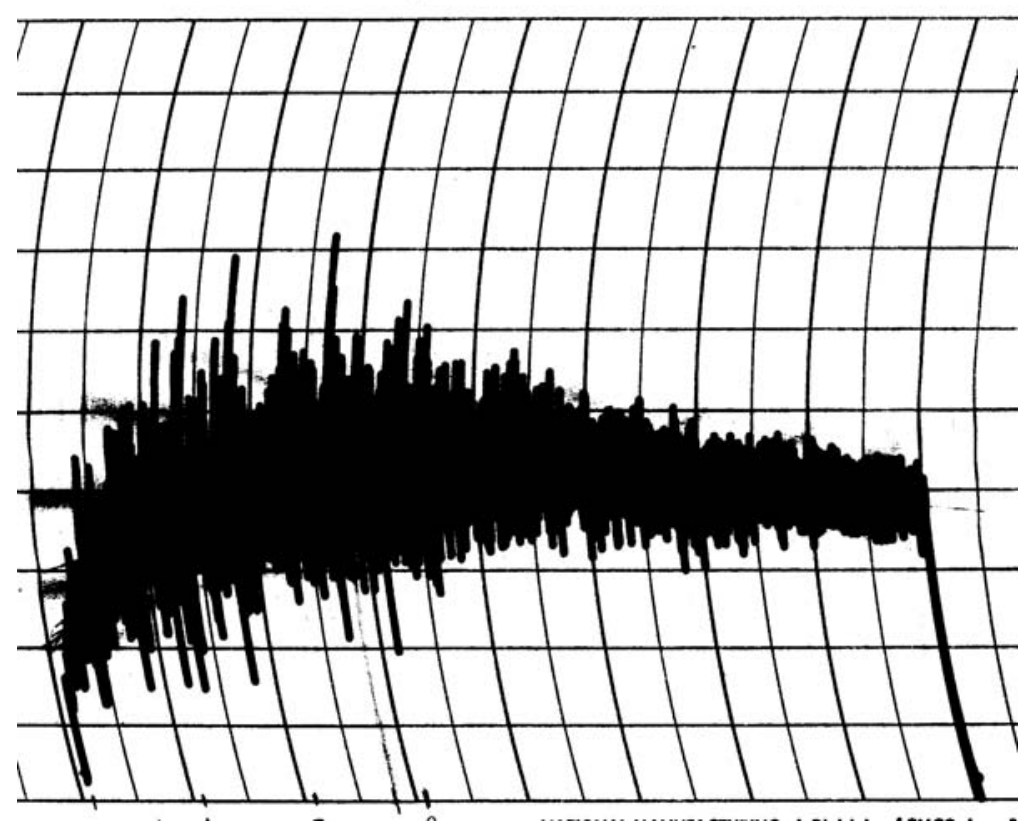

Figure 3.9 Mixograph measurement for 50/50 blended bread/pastry flour

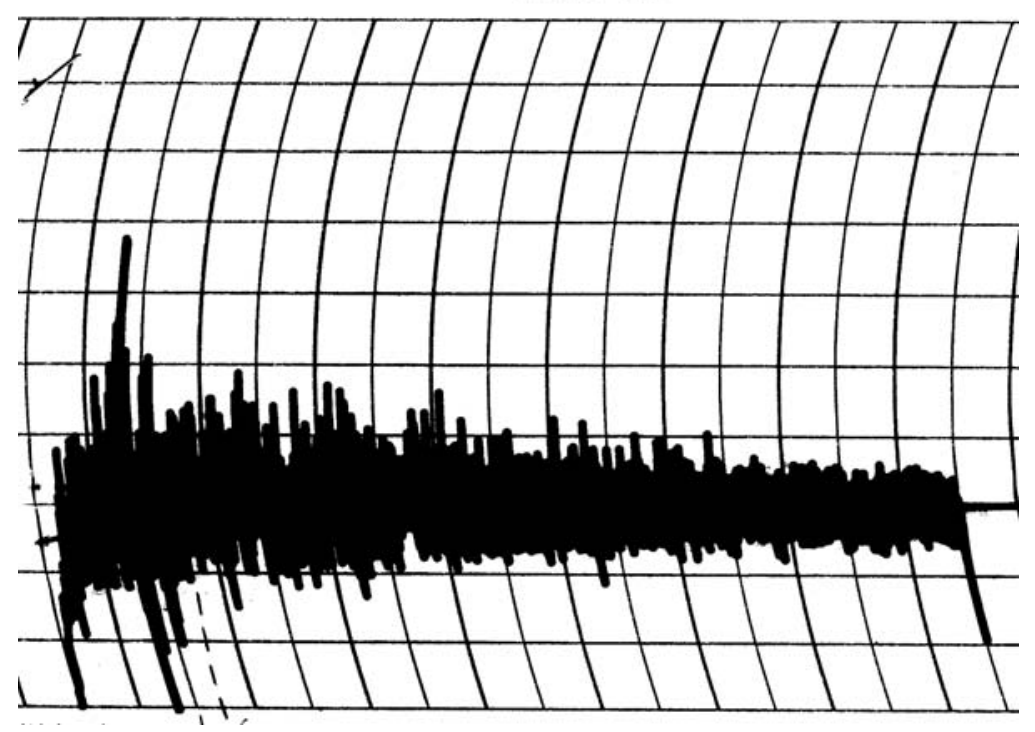

Figure 3.10 Mixograph measurement for pastry flour

26 


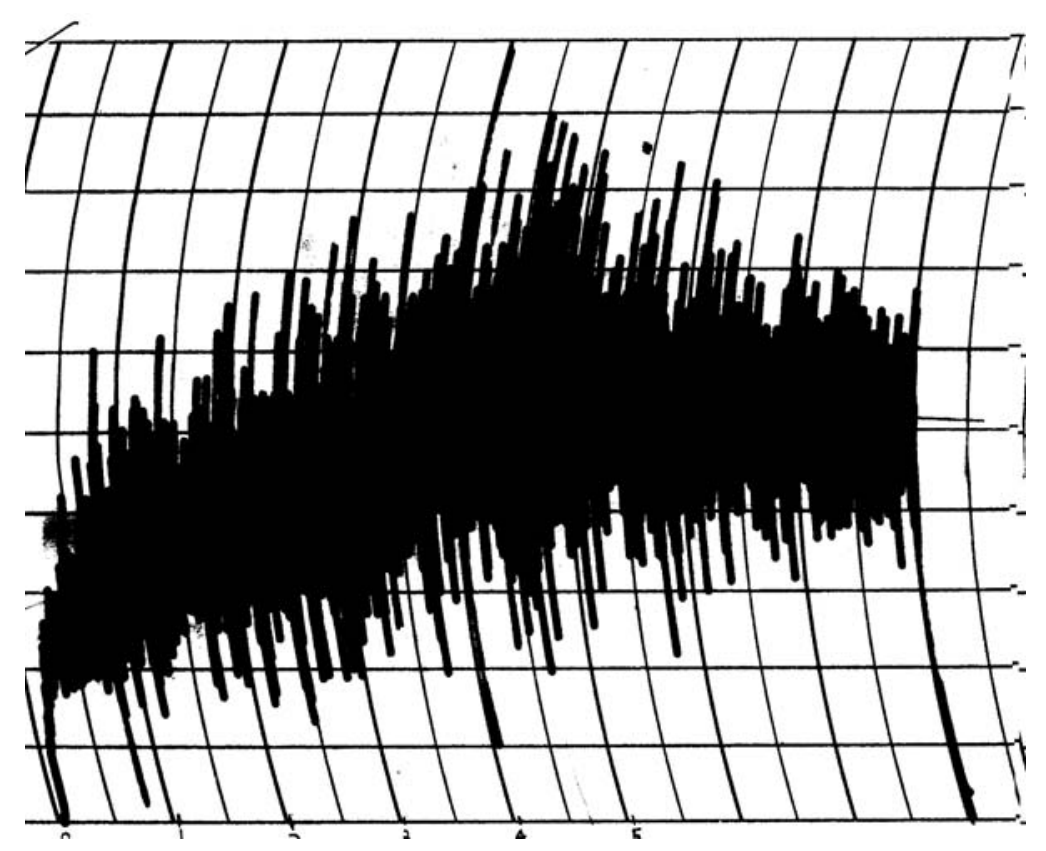

Figure 3.11 Mixograph measurement for hard wheat flour

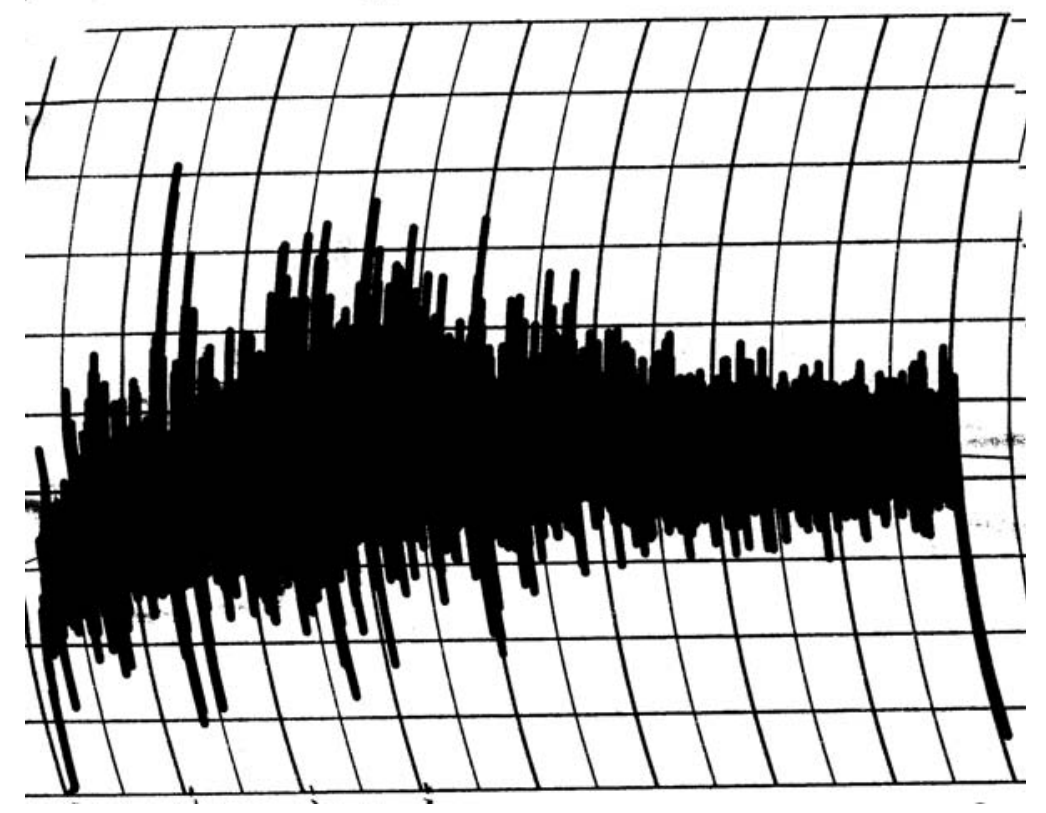

Figure 3.12 Mixograph measurement for 50/50 blended hard/soft wheat flour 


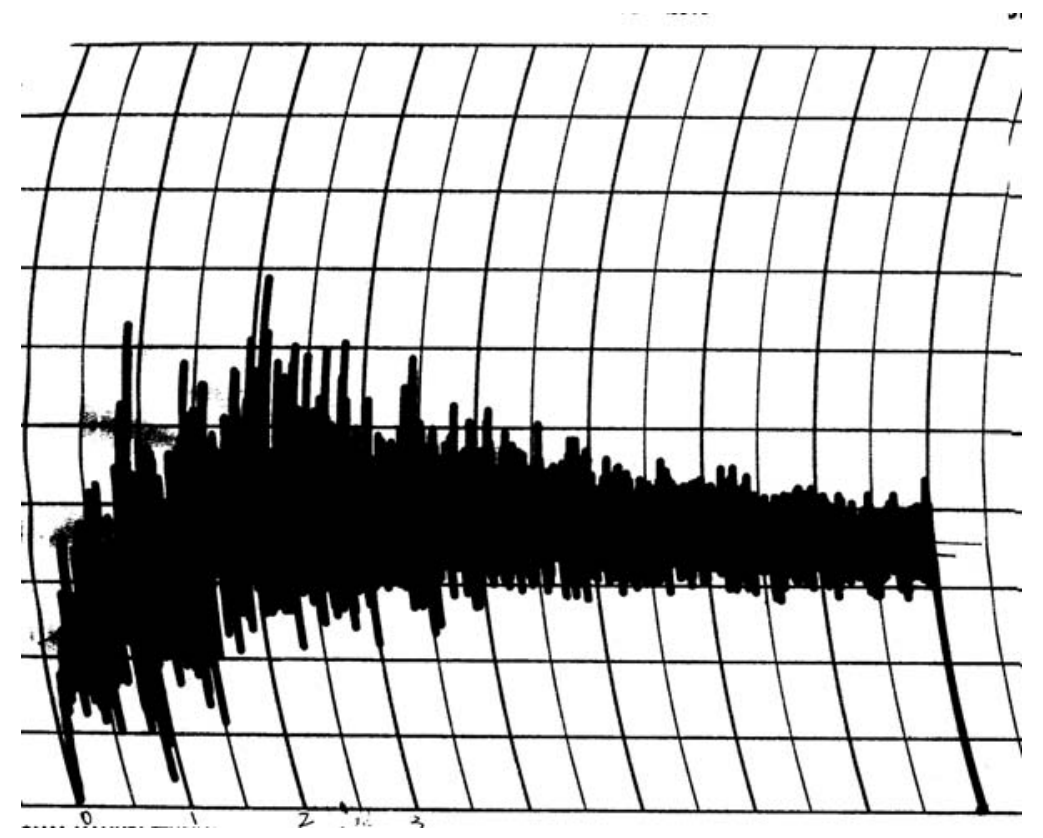

Figure 3.13 Mixograph measurement for soft wheat flour

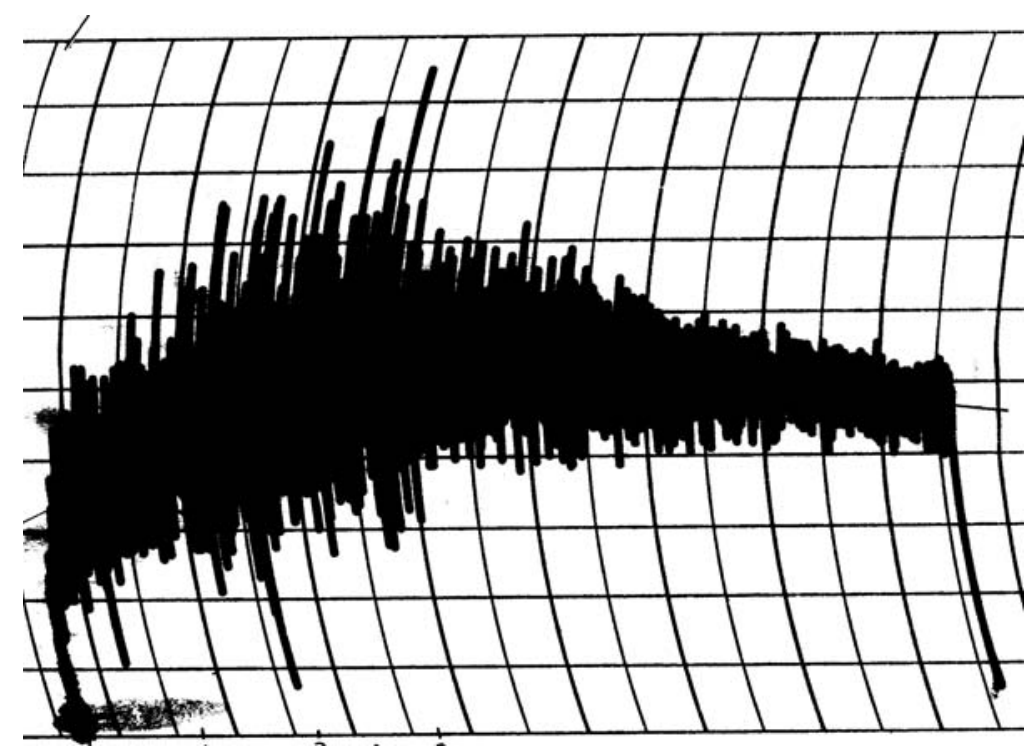

Figure 3.14 Mixograph measurement for commercial flour 
Alveograph Measurements for three flour sets

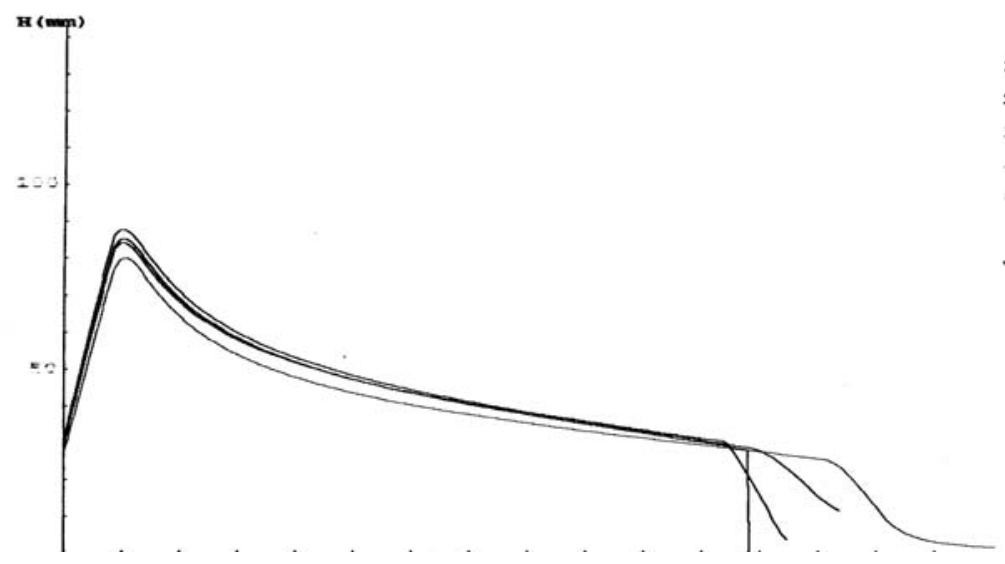

Figure 3.15 Alveograph measurement for bread flour

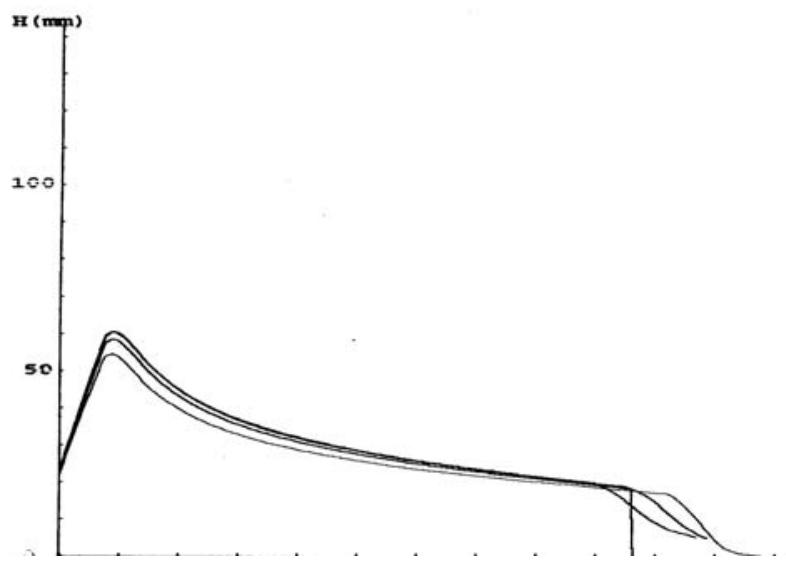

Figure 3.16 Alveograph measurement for 50/50 blended bread/pastry flour

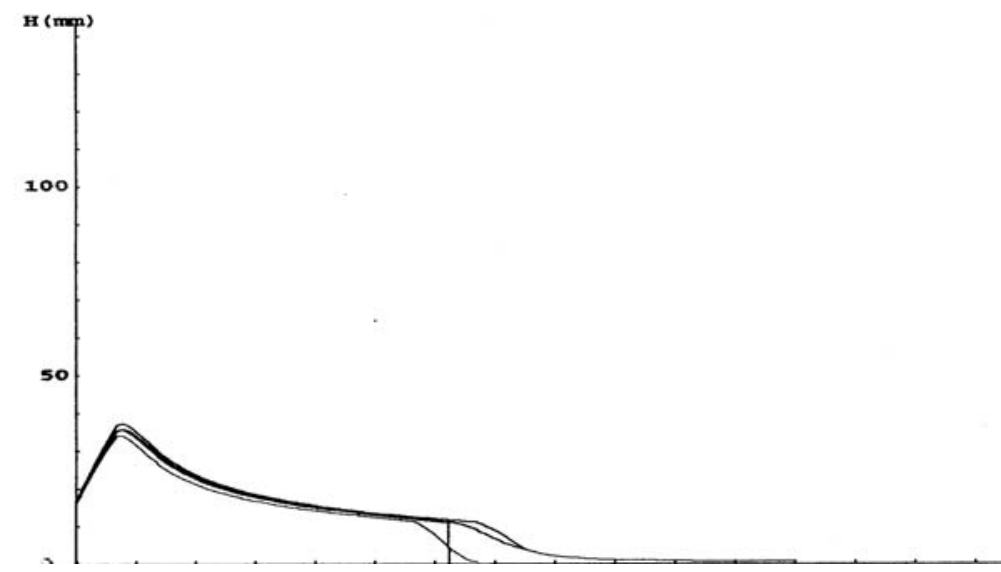

Figure 3.17 Alveograph measurement for pastry flour 


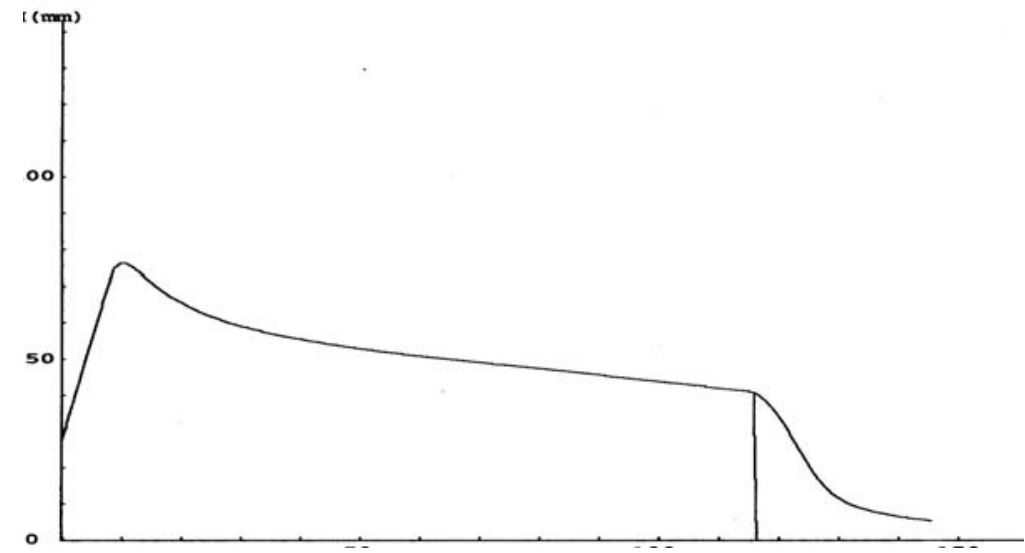

Figure 3.18 Alveograph measurement for hard wheat flour

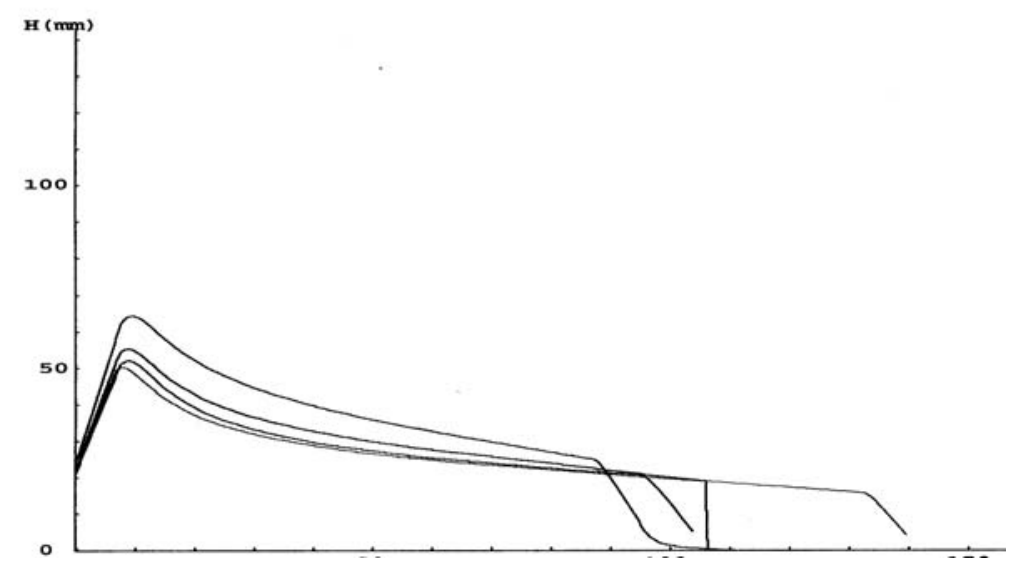

Figure 3.19 Alveograph measurement for 50/50 blended hard/soft wheat flour

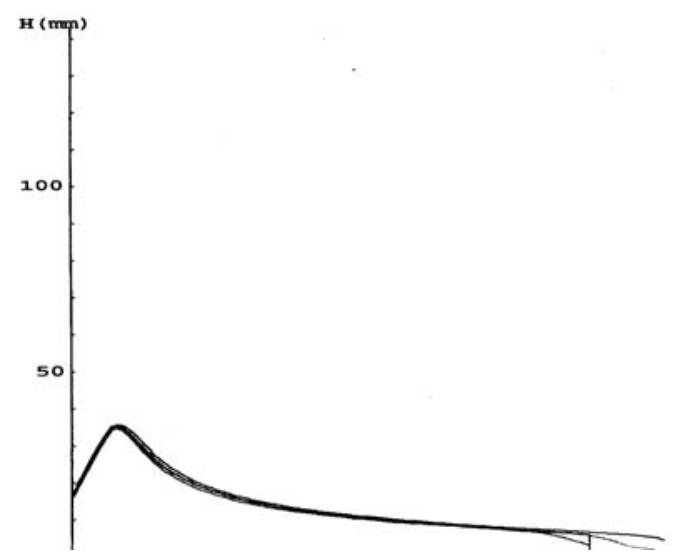

Figure 3.20 Alveograph measurement for soft wheat flour 


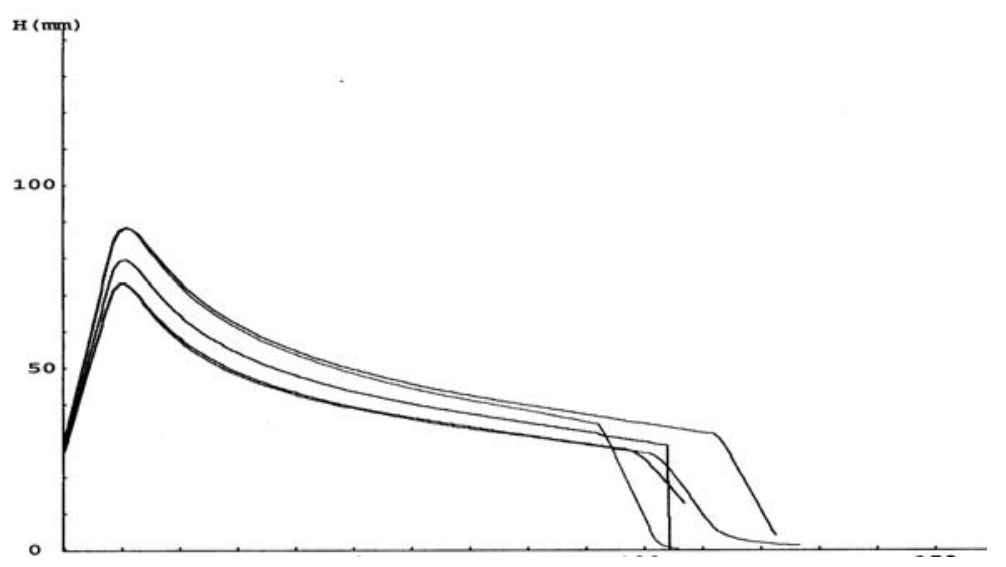

Figure 3.21 Alveograph measurement for commercial flour

Three different empirical instruments were used to test the bread, 50/50 blended, and pastry flours of Set I to quantify common flour characteristics commonly associated with dough physical properties. The bread flour had the higher protein content and water absorption, usually indicative of strong flour properties. The results from the dough physical tests support that. Bread flour had the larger values for Mixograph peak height, mixing time, and work, Farinograph water absorption and mixing time, and Alveograph $\mathrm{P} / \mathrm{L}$ and work (Table 3.1). In contrast to bread flour, the pastry flour had much weaker dough strength, indicated by the smaller values found for these empirical test results. The 50/50 blended flour had intermediate values between these of its parent flours. The results suggest that the bread and pastry flour proteins do not interact significantly but rather combine linearly, and further suggest that the mixing and dough quality of the blended flour depends largely on the protein content, though perhaps also influenced by other factors not measured.

From observation, Set II shows the same pattern as Set I. 


\section{The snapback for three flour sets studied}

The snapback for bread, 50/50 blended, pastry flours of Set I, correlated with their reduction ratio and rest time changes

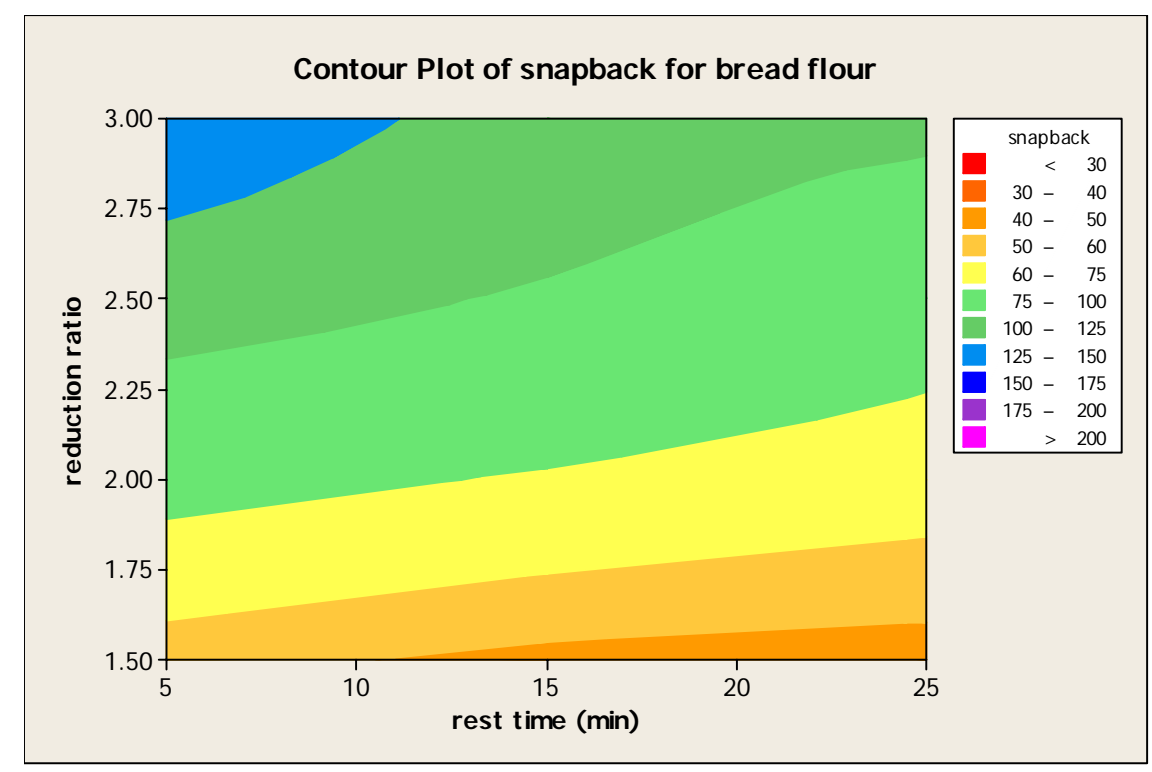

Figure 3.22 The snapback (\%) for bread flour, correlated with different reduction ratios and rest times

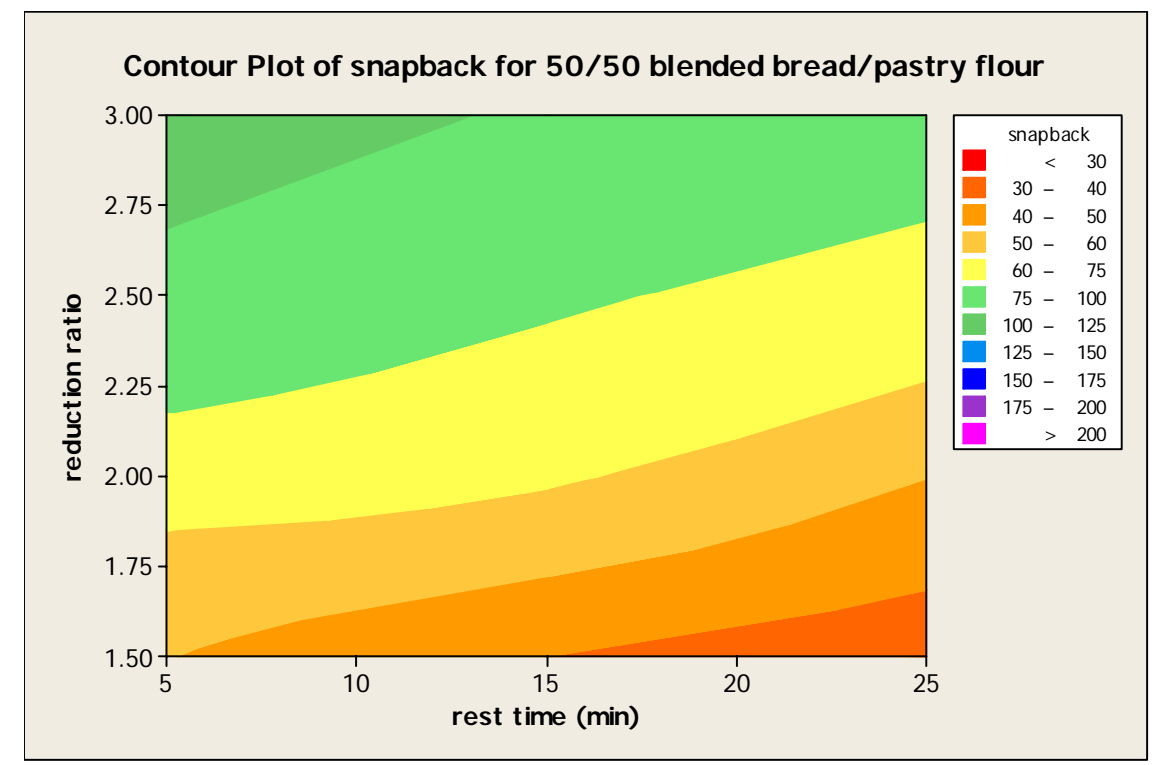

Figure 3.23 The snapback (\%) for 50/50 blended bread/pastry flours, correlated with different reduction ratios and rest times 


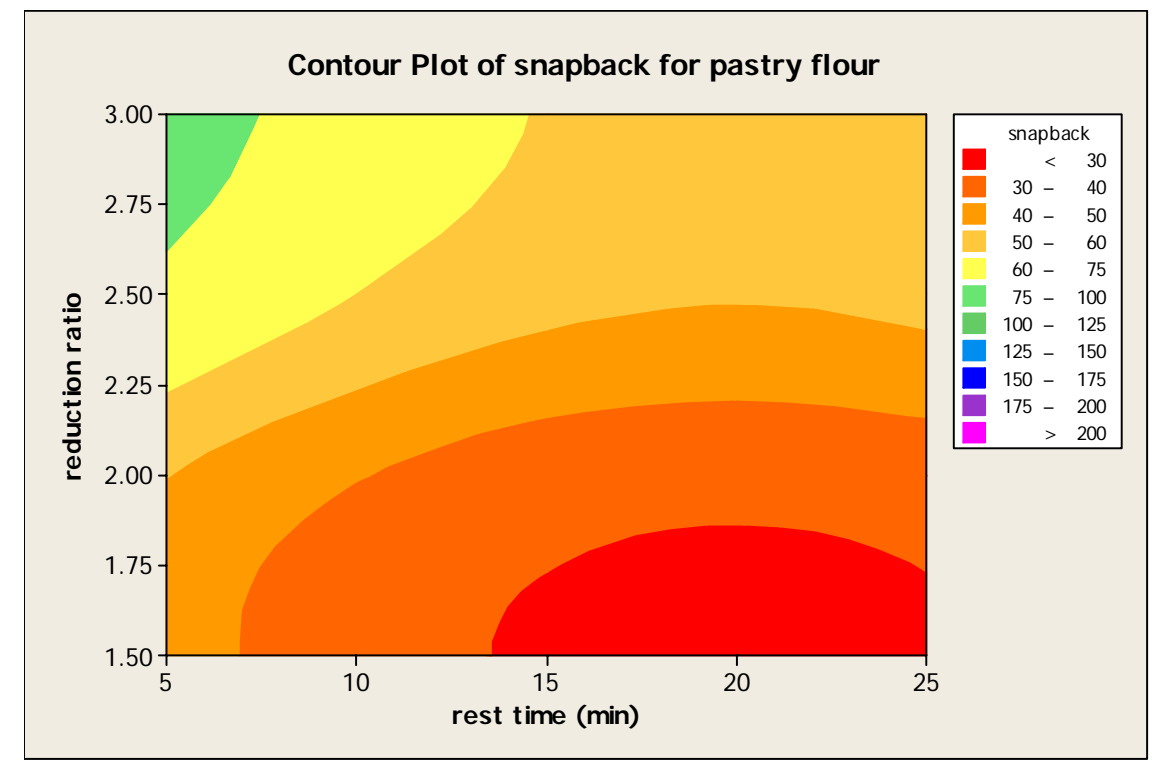

Figure 3.24 The snapback (\%) for pastry flour, correlated with different reduction ratios and rest times

In these three charts, the bread flour snapback is from 40-50 to 125-150 (Figure 3.22). The 50/50 blended bread/pastry flour snapback is from 30-40 to 100-125 (Figure 3.23). The pastry flour snapback is from 0-30 to 75-100 (Figure 3.24). The snapback ranges one level higher from pastry flour, to blended flour, then to bread flour. It was observed that when the reduction ratio was increased, the degree of snapback also increased for the same rest time. If the reduction ratio is kept the same, the degree of snapback decreases as the rest time increases. After the dough is sheeted, part of the energy stored in the dough must be released, so the dough springs back. With time, the dough returns to the original energy condition. The dough is under greater stress when sheeted with a larger reduction ratio, so there is more energy transferred to the dough and more energy could be released back to balance the system by snapback. The higher value of snapback is concentrated in the upper left chart corner (maximum reduction ration and minimum relaxation time). A smaller snapback can result from either choosing a smaller reduction ratio or increasing the rest time, or both, for the same flour type.

The trend of snapback for the 50/50 blended flour (Figure 3.23) is quite similar to that for the bread flour (Figure 3.22). With increased reduction ratio and decreased rest time, the blended flour snapback is increased proportionally. 
The trend in snapback for pastry flour (Figure 3.24) is a little different from that for bread and blended flours (Figure 3.22, 3.23). When the reduction ratio is small, the short rest time period does not affect the dough's elastic properties. As the rest time extends, the dough relaxes and becomes much softer so that it doesn't contain the energy to spring back. But when the reduction ratio is increased, the rest time has a larger influence on dough's elastic properties, especially at the time when the dough has just exited from the sheeter. Because the dough made by pastry flour does not have a strong protein network to support the cell structure, the dough is quite soft. But when the reduction ratio is increased, if the great pressure is applied harshly, the dough gives the response of snapback in a shorter time and releases the energy quickly. But compared to the doughs made with bread flour, the short period rest time has a less effect just after the dough exits from the sheeter with a larger reduction ratio. Because the dough made with bread flour has stronger rheological properties, it responds faster to the changes in shape. It shows a different extent of elastic properties in different flours. 
The snapback for hard wheat, 50/50 blended, soft wheat flours of Set II, correlated with their reduction ratio and rest time changes

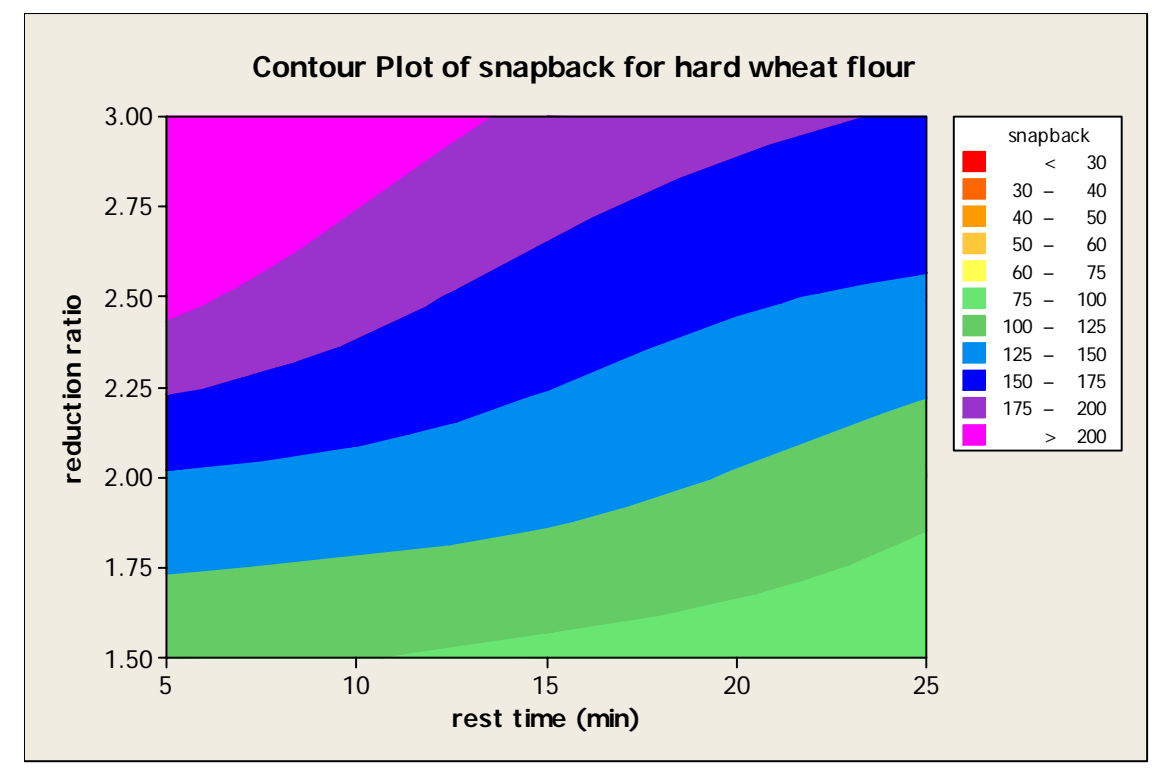

Figure 3.25 The snapback (\%) for hard wheat flour, correlated with different reduction ratios and rest times

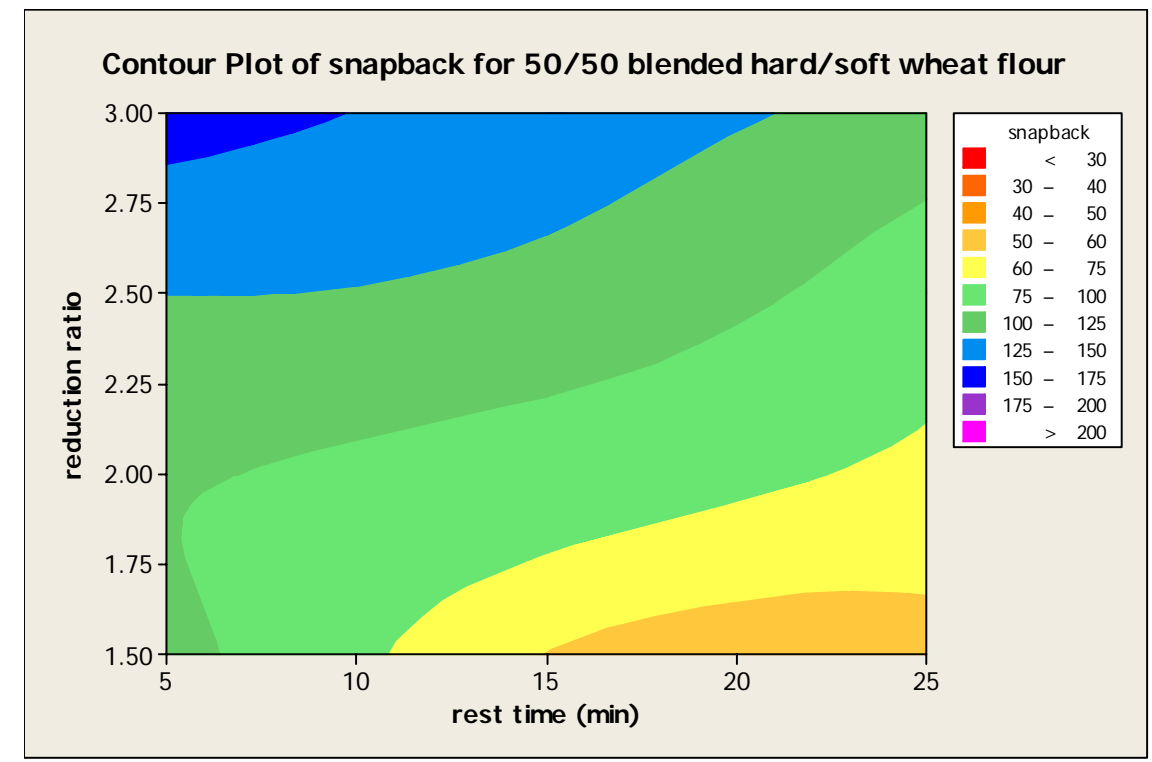

Figure 3.26 The snapback (\%) for 50/50 blended hard/soft wheat flour, correlated with different reduction ratios and rest times 


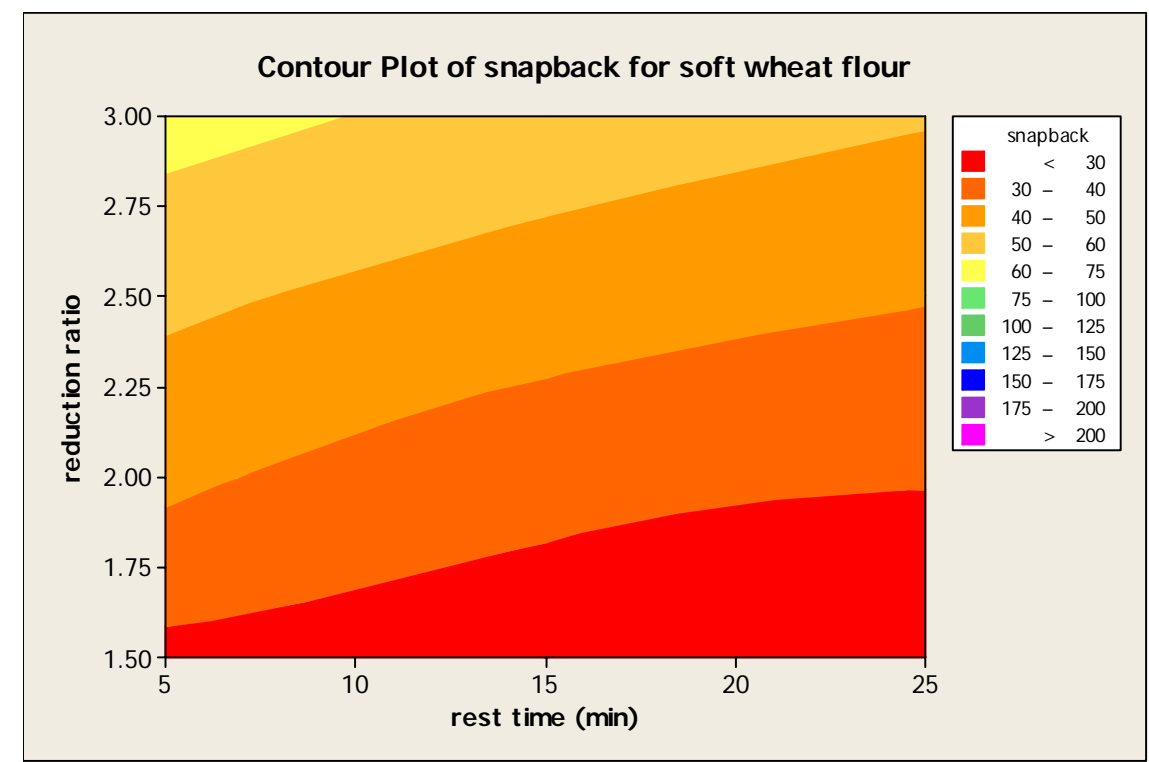

Figure 3.27 The snapback (\%) for soft wheat flour, correlated with different reduction ratios and rest times

In these three charts, the hard wheat flour snapback is from 75-100 to more than 200 (Figure 3.25). The 50/50 blended hard/soft wheat flour snapback is from 50-60 to 150-175 (Figure 3.26). The soft wheat flour snapback is from 0-30 to 60-75 (Figure 3.27). The snapback has much higher and wider ranges from the soft wheat flour, to blended flour, then to the hard wheat flour. The hard wheat flour had a similar protein content as did the bread flour, but the value of snapback (75-200) shows much larger values than that (40-150) for bread flour. It indicates that the snapback is affected by both protein quantity and quality. But the trend for snapback of hard wheat flour is similar to that for bread flour. The larger snapback is obtained by either choosing a larger reduction ratio or reducing the rest time for the same flour type. The higher protein content flours give the stronger dough rheological properties.

The trend of snapback for the second flour set (Figure 3.26) is quite similar to that for the $50 / 50$ blended flour of the first flour set (Figure 3.23), but the values are just a little bit larger than those for the first flour set.

The values for the snapback of soft wheat flour are quite similar, but the protein quality is much stronger than that of pastry flour in the first set. So the trend of snapback for soft wheat 
flour (Figure 3.27) is different from that for pastry flour (Figure 3.24), even though most pastry flours are produced from soft wheat. The reduction ratio and rest time both contribute to the snapback. The snapback increases diagonally across the contour plot. This property is quite similar to the one for bread flour, so it shows that the snapback is affected by both the protein quantity and quality. 
The snapback for the first and second flour sets receiving 5 min rest time, correlated with their reduction ratio and protein content changes

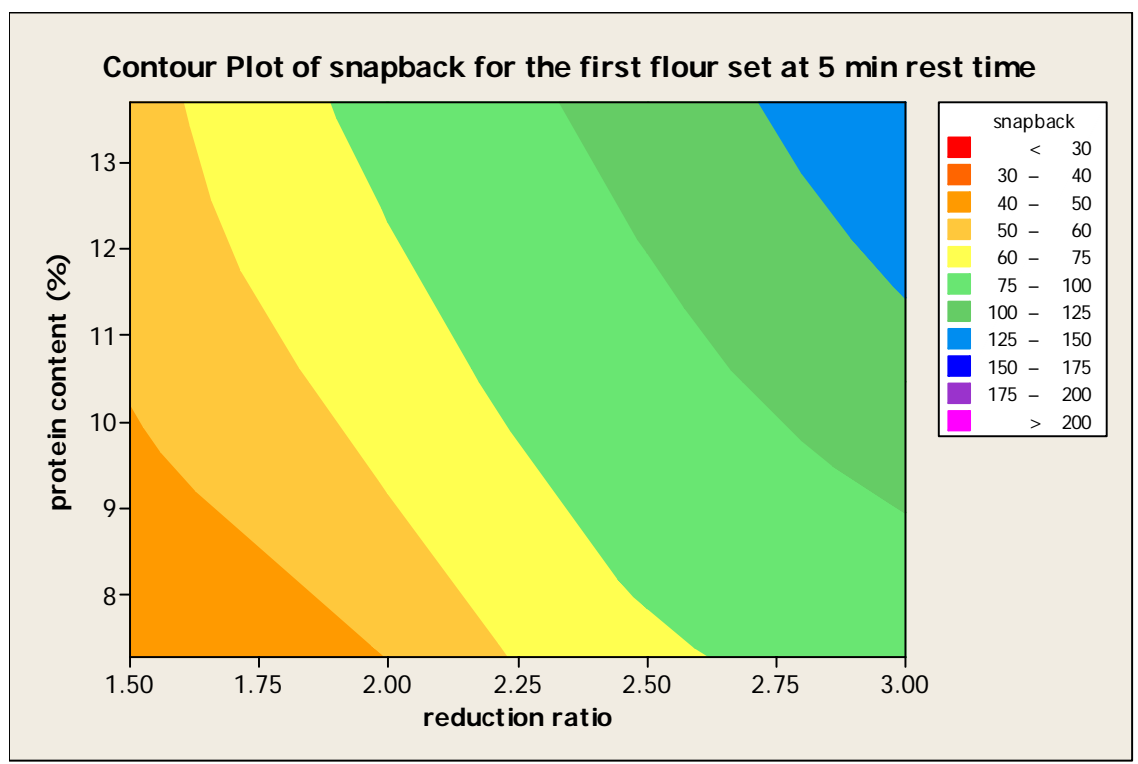

Figure 3.28 The snapback (\%) for the first flour set, correlated with protein content using different reduction ratios at 5 min rest time

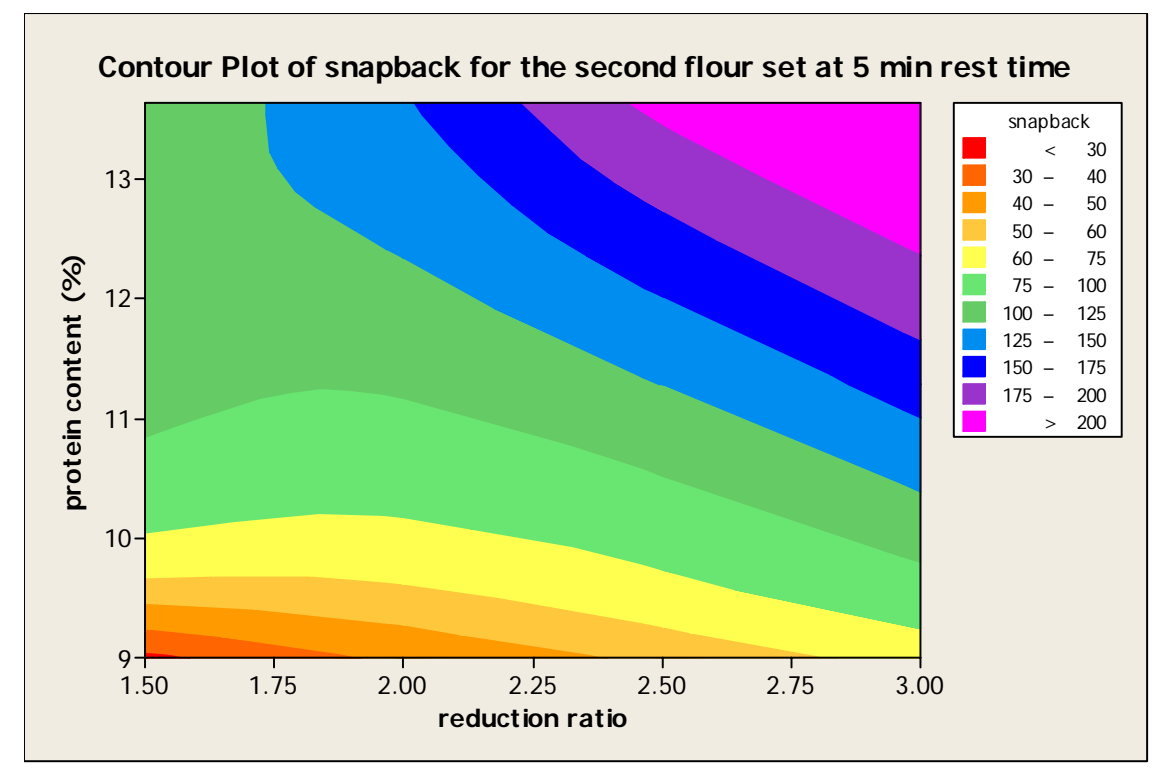

Figure 3.29 The snapback (\%) for the second flour set, correlated with protein content using different reduction ratios at $5 \mathrm{~min}$ rest time 
In these two charts, the snapback for the first flour set is from 40-50 to $125-150$ at 5 min rest time (Figure 3.28). The snapback for the second flour set is from 30-40 to more than 200 at 5 min rest time (Figure 3.29). The snapback range for the second flour set (Figure 3.29) is much wider than that for the first flour set (Figure 3.28). The snapback will increase proportionally, either with increased reduction ratio or with protein content. At the same time, we see that the protein content and reduction ratio are two important factors, both of which influence the snapback. The snapback for the first flour set increases along the opposed angle line from point $(1.5,8)$ to point $(3.0,13)$, which means that the snapback is affected by both of those factors in a positive way.

The second set flour snapback (Figure 3.29) has a different pattern than the first set ones (Figure 3.28) at $5 \mathrm{~min}$ rest time. When the protein content is low, the snapback for the second flour set does not change much with increased reduction ratio. And as the protein content reaches a high level, the second flour set snapback changes rapidly from the low reduction ratio to the high one. But when the reduction ratio is increased, the snapback for the second flour set jumps a lot from low to high. In addition, the snapback in the second set is much larger than that in the first set when the protein content is increased to medium or high level. This shows that even when both flour sets have similar protein ranges, the protein for the second set has a stronger quality. 
The snapback for the first and second flour sets receiving 15 min rest time, correlated with their reduction ratio and protein content changes

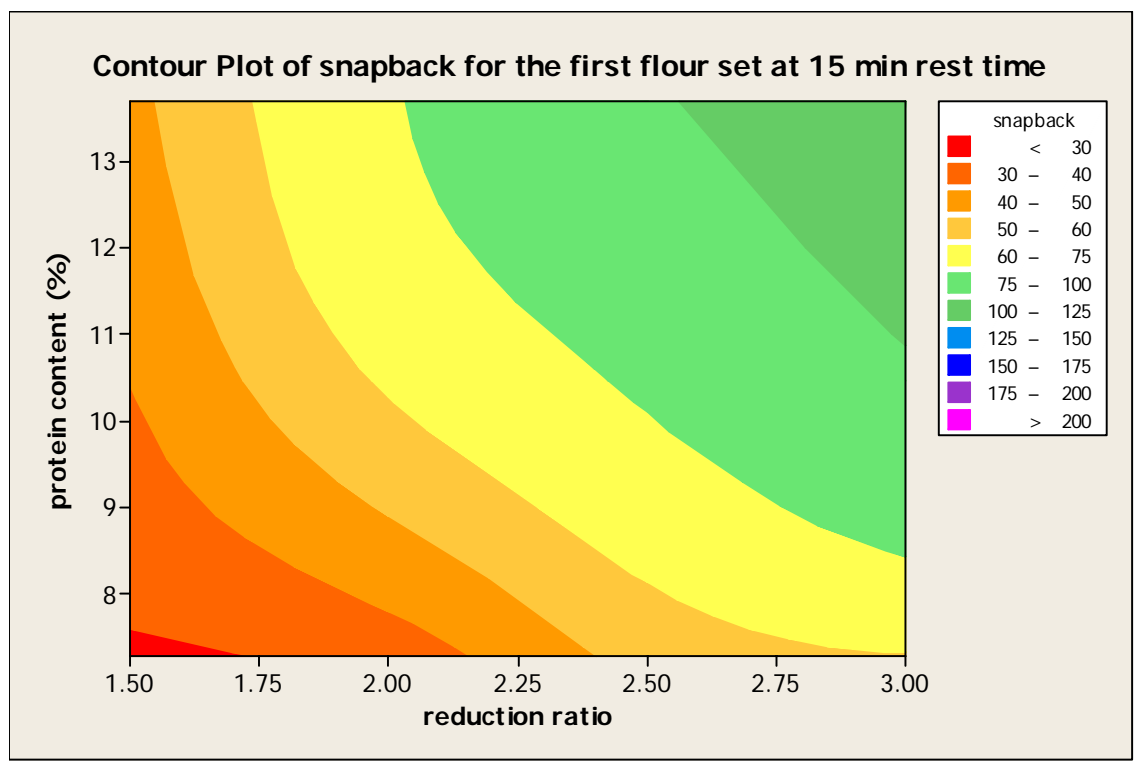

Figure 3.30 The snapback (\%) for the first flour set, correlated with protein content using different reduction ratios at $15 \mathrm{~min}$ rest time

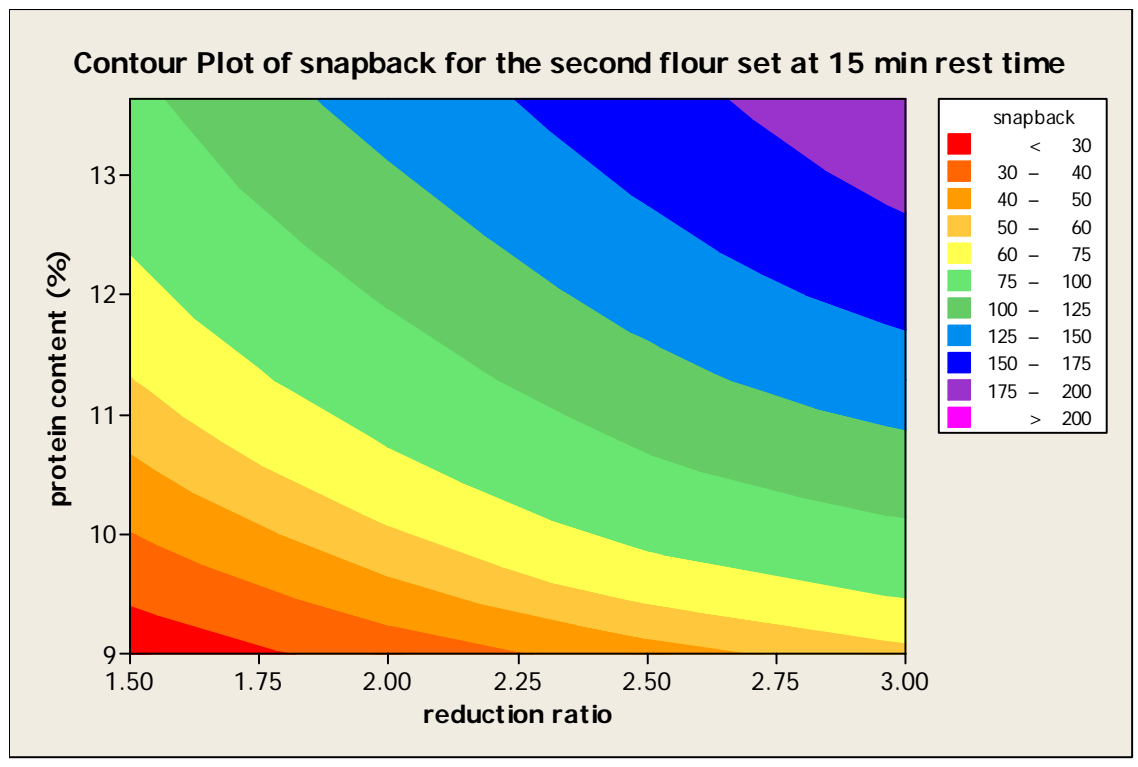

Figure 3.31 The snapback (\%) for the second flour set, correlated with protein content using different reduction ratio at $15 \mathrm{~min}$ rest time 
In these two charts, the snapback for the first flour set varies from less than 30 to $100-125$ at $15 \mathrm{~min}$ rest time (Figure 3.30). The snapback for the second flour set is from less than 30 to more than 200 at $15 \mathrm{~min}$ rest time (Figure 3.31). This trend is similar to the snapback at 5-min rest time (Figure 3.28, 3.29), in that the range of snapback values for the second flour set (Figure 3.31) is more extended than for the first flour set (Figure 3.30) and the increases in both the protein content and reduction ratio increase the snapback. There are some differences in snapback for different protein levels at $15 \mathrm{~min}$ rest time. We can see that the snapback changes quite slowly with increased reduction ratio when the protein content is low. The snapback changes faster for the medium protein level as compared with flour with low protein content. At a high protein level, the snapback changes very rapidly at all reduction ratios. 
The snapback for the first and second flour sets receiving $\mathbf{2 5}$ min rest time, correlated with their reduction ratio and protein content changes

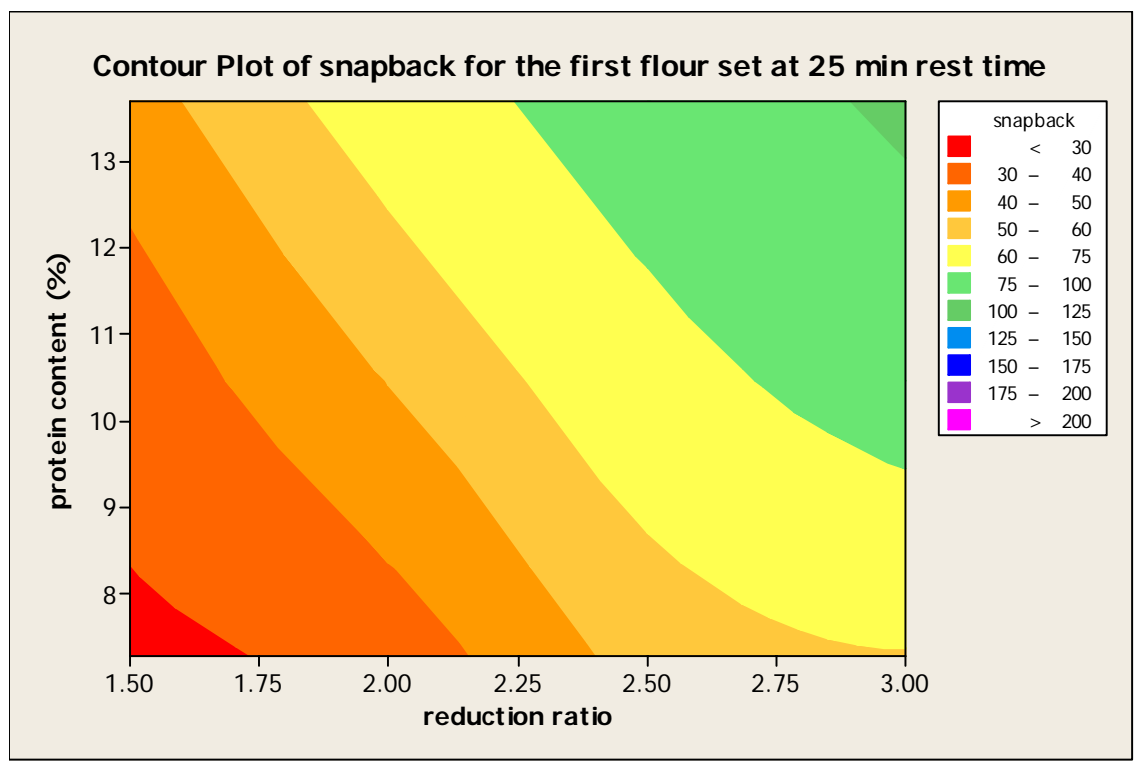

Figure 3.32 The snapback (\%) for the first flour set, correlated with protein content using different reduction ratios at $25 \mathrm{~min}$ rest time

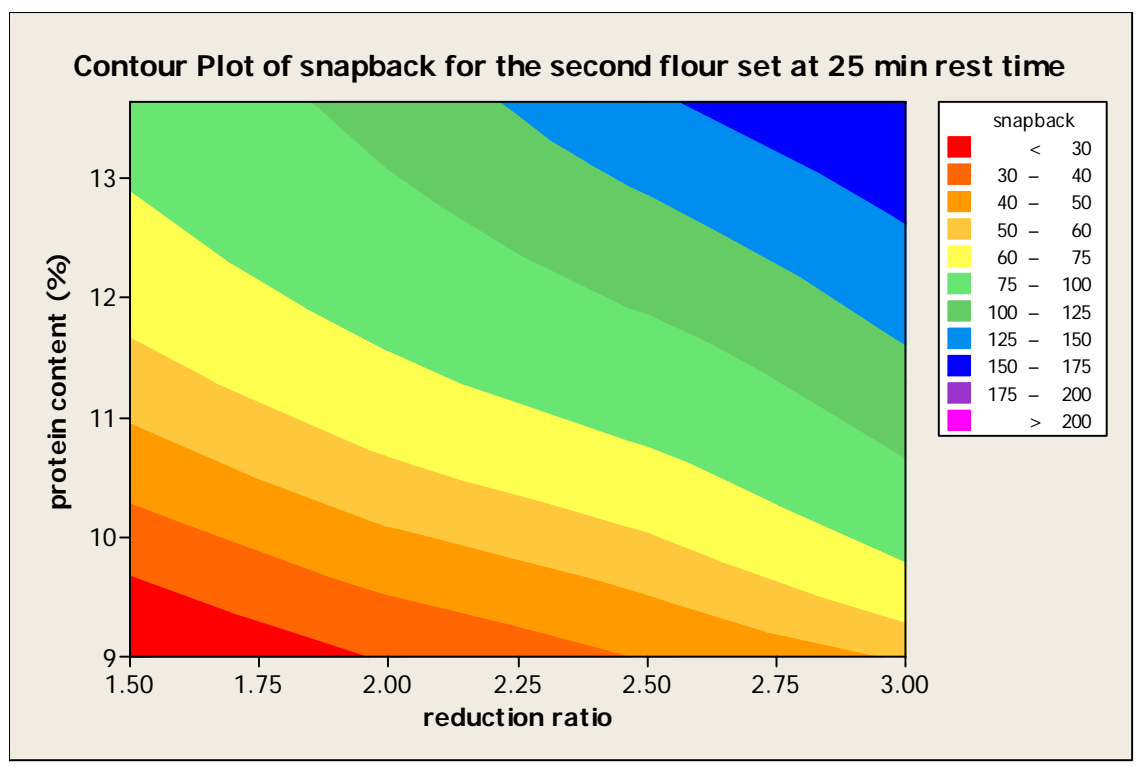

Figure 3.33 The snapback (\%) for the second flour set, correlated with protein content using different reduction ratios at 25 min rest time 
In these two charts, the snapback for the first flour set is from less than 30 to 100-125 at 25 min rest time (Figure 3.32). The snapback for the second flour set is from less than 30 to 150-175 at 25 min rest time (Figure 3.33). The snapback for 25 min rest time (Figure 3.32, 3.33) is much lower than that after only a $5 \mathrm{~min}$ rest time (Figure $3.28,3.29$ ) for both flour sets.

The last two sections of snapback values for the second set (Figure 3.33) are larger than the snapback of the first set flour (Figure 3.32) at 25 min rest time. When the reduction ratio is kept the same for both set flours, the snapback in the second set is much larger than that in the first set, when the protein content is increased to median or high levels. It shows that even if both flour sets have similar protein ranges, the protein for the second set apparently has a better quality. Through observing two sets of flour charts, the second set flour snapback shows a similar trend to the snapback for the first set. This indicates that even when the protein quantity has similar numbers and protein quality has difference between both sets, the trend for both sets shows consistent results. 
The snapback for the first and second flour sets, correlated with their protein content and rest time changes for a reduction ratio of 1.5

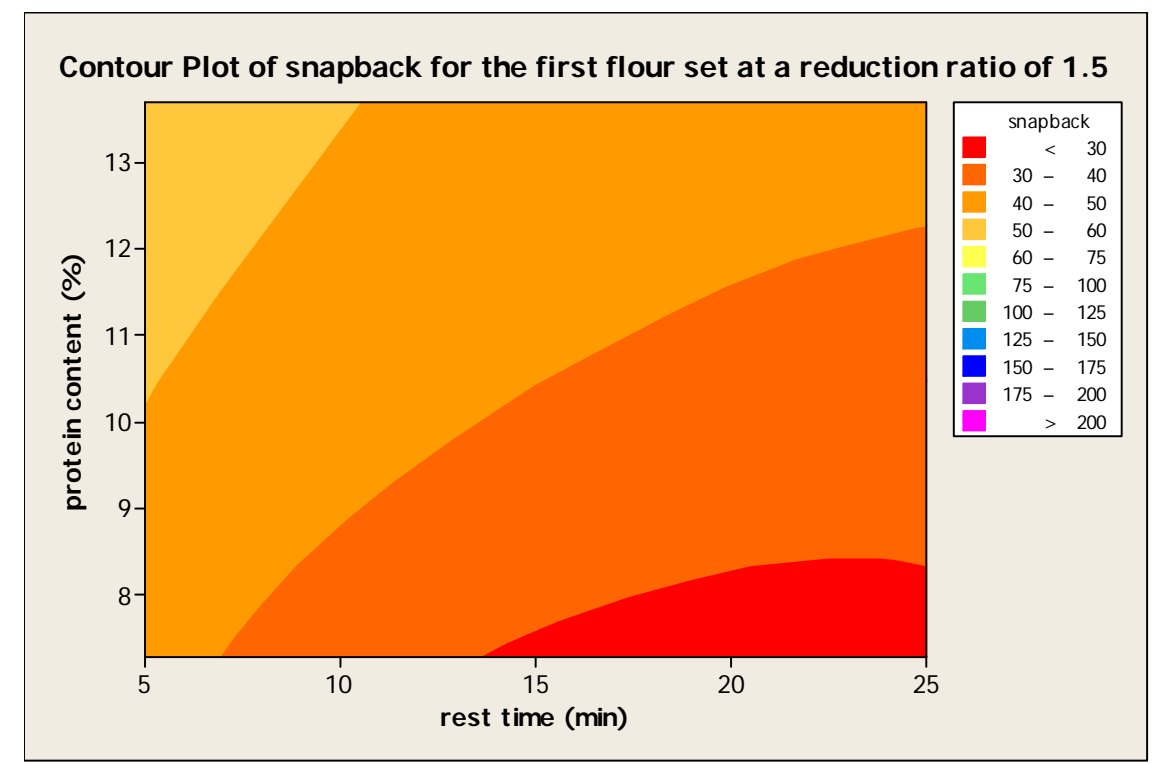

Figure 3.34 The snapback (\%) for the first flour set, correlated with protein content using different rest times for a reduction ratio of $\mathbf{1 . 5}$

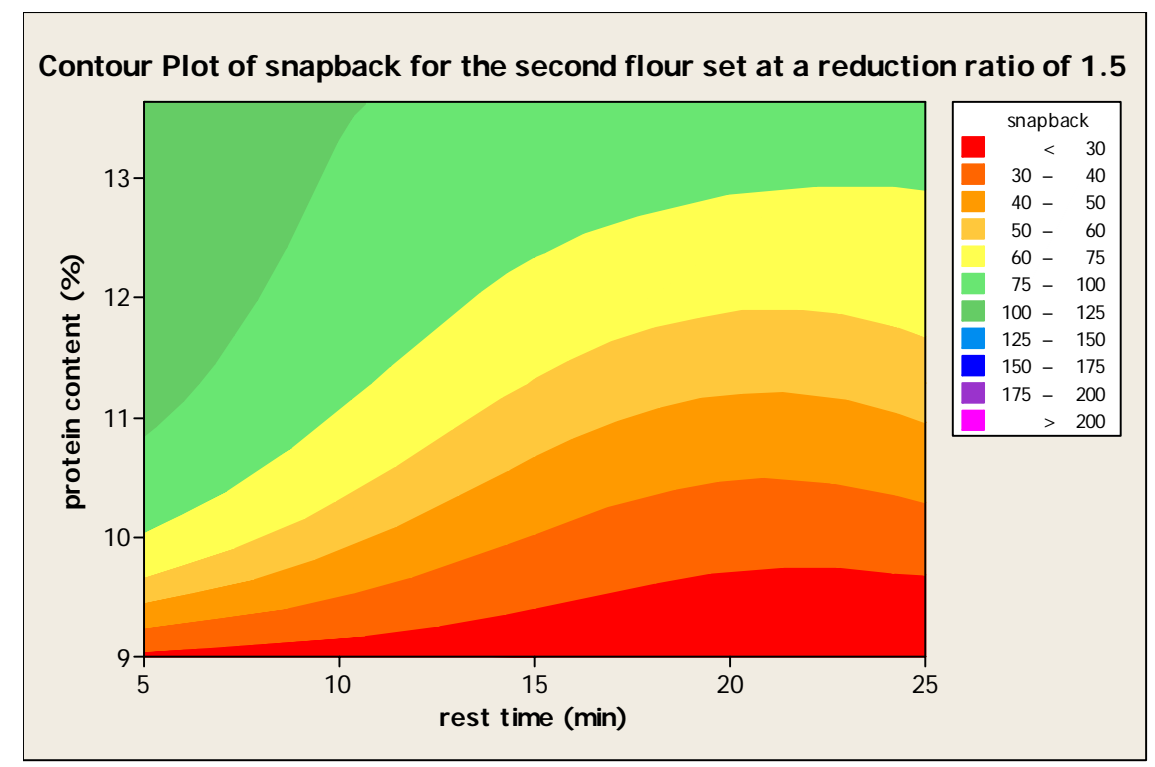

Figure 3.35 The snapback (\%) for the second flour set, correlated with protein content using different rest times for a reduction ratio of 1.5 
In these two charts, the snapback for the first flour set is from less than 30 to 50-60 for a reduction ratio of 1.5 (Figure 3.34). The snapback for the second flour set is from less than 30 to $100-125$ for a reduction ratio of 1.5 (Figure 3.35). In general, the overall snapback is quite small when the reduction ratio is only 1.5. The number for the second set snapback (Figure 3.35) is nearly doubled compared with the first set snapback (Figure 3.34). The snapback increases either with shortened rest time or increased protein content. We can see that the snapback changes quite slowly at longer rest times than at shorter rest times. The snapback changes faster at higher protein levels as compared with that at lower protein levels. Again, the snapback change rate depends on the range of protein content and the rest time. 
The snapback for the first and second flour sets, correlated with their protein content and rest time changes for a reduction ratio of 2

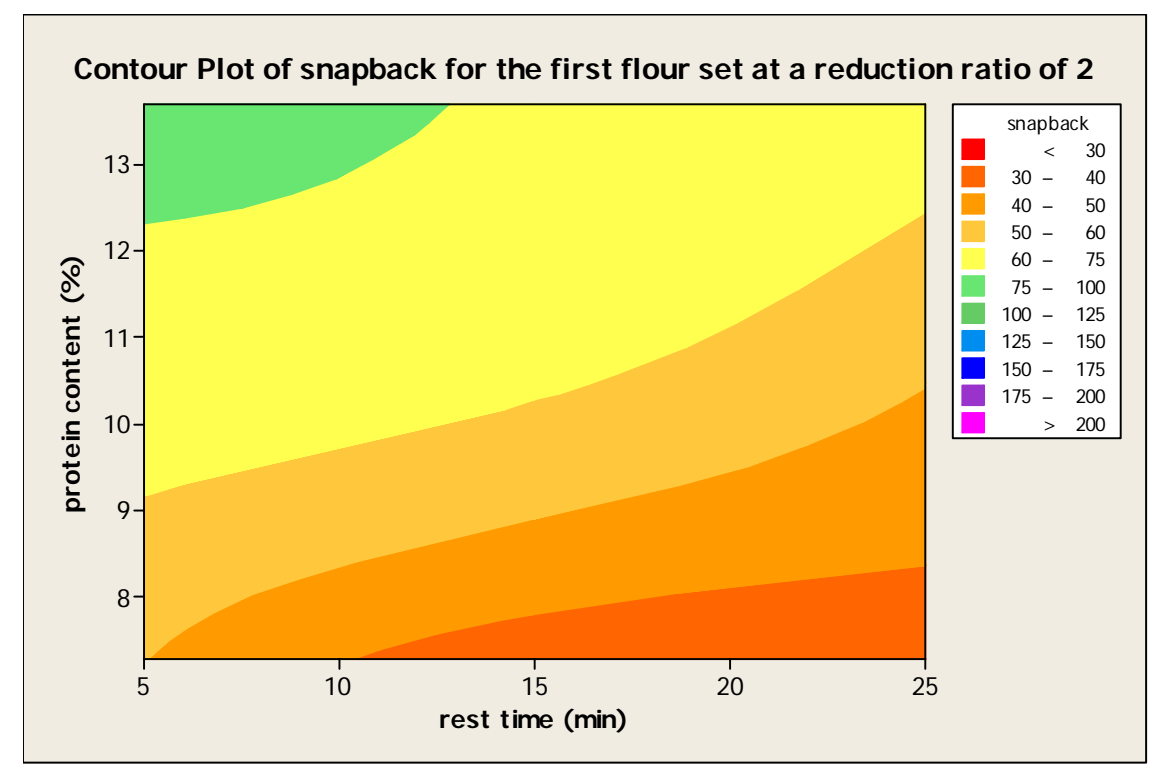

Figure 3.36 The snapback (\%) for the first flour set, correlated with protein content using different rest times for a reduction ratio of 2

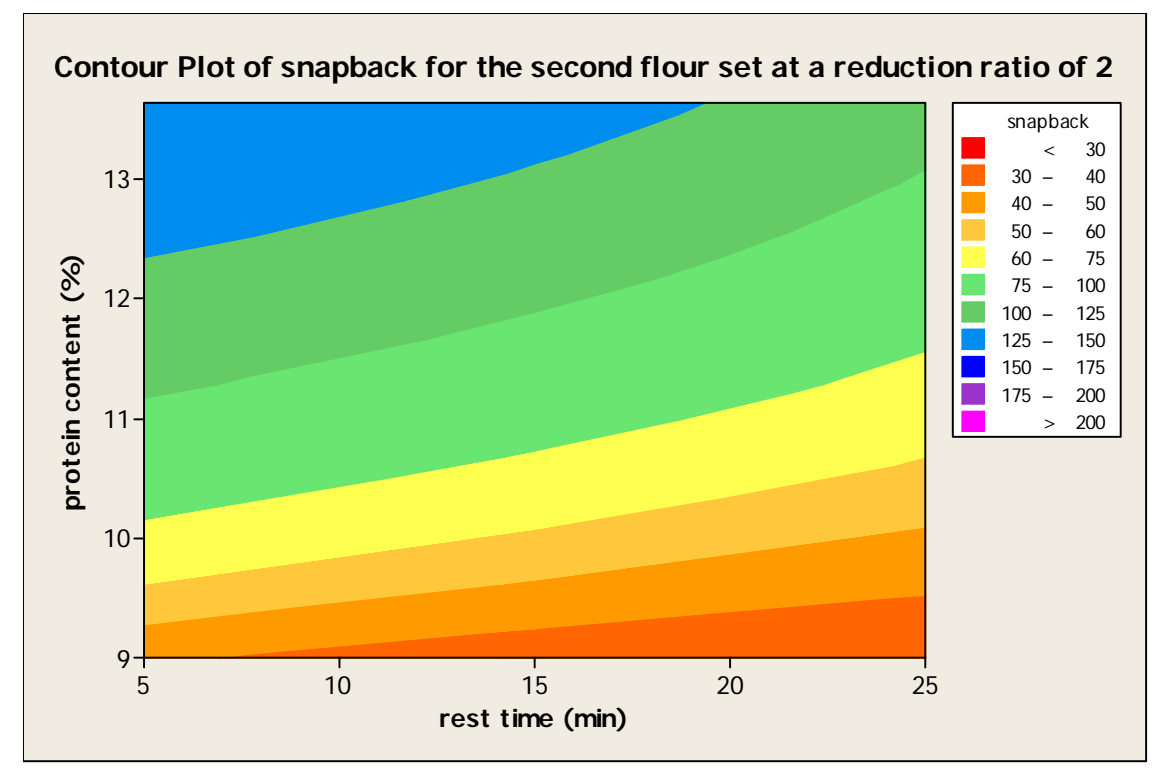

Figure 3.37 The snapback (\%) for the second flour set, correlated with protein content using different rest times for a reduction ratio of 2 
In these two charts, the snapback for the first flour set is from 30-40 to 75-100 for a reduction ratio of 2 (Figure 3.36). The snapback for the second flour set is from 30-40 to 125150 for a reduction ratio of 2 (Figure 3.37). In general, the overall snapback is quite modest when the reduction ratio is 2 . The snapback for a reduction of 2 (Figure 3.36, 3.37) is one or two ranges larger than that for the reduction of 1.5 (Figure 3.34, 3.35). We could see the snapback has less change at a longer rest time when the protein content is low. The snapback for the medium protein level at longer rest time changes faster, compared with the one at a shorter rest time. When the protein level becomes high, the snapback changes very rapidly, compared with the snapback with lower protein content.

The number for the second set snapback (Figure 3.37) is a little bit larger compared with the first set snapback (Figure 3.36) for a reduction ratio of 2. The protein content for the second flour set has larger effect on the snapback. Because the protein quality in the second set flour is much stronger, the dough rheological properties are different. 
The snapback for the first and second flour sets, correlated with their protein content and rest time changes for a reduction ratio of 2.5

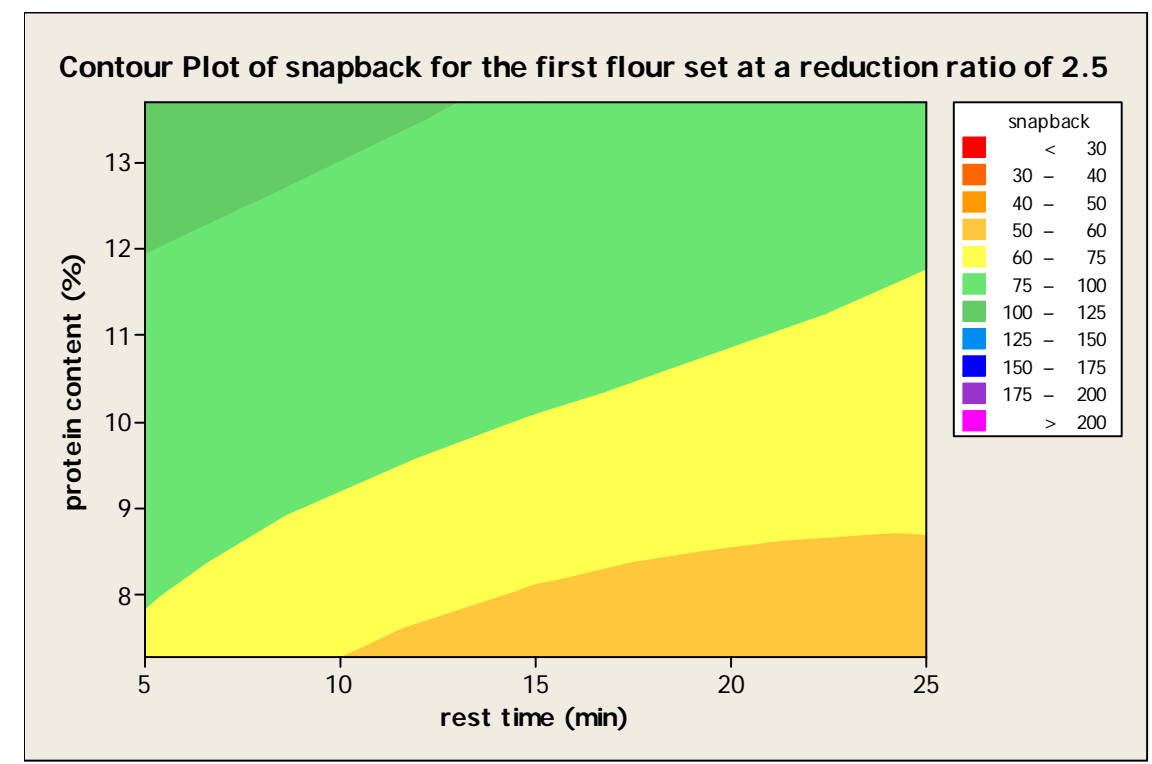

Figure 3.38 The snapback (\%) for the first flour set, correlated with protein content using different rest times for a reduction ratio of 2.5

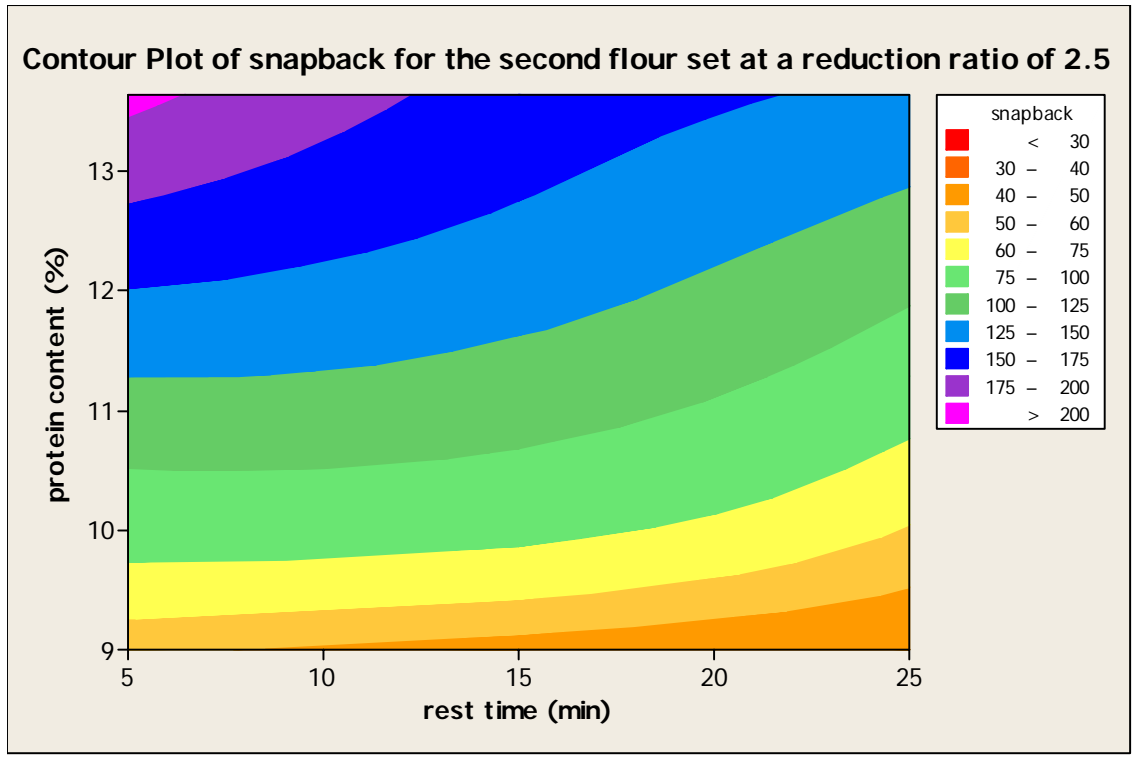

Figure 3.39 The snapback (\%) for the second flour set, correlated with protein content using different rest times for a reduction ratio of 2.5 
In these two charts, the snapback for the first flour set is from 50-60 to 100-125 for a reduction ratio of 2.5 (Figure 3.38). The snapback for the second flour set is from 40-50 to more than 200 for a reduction ratio of 2.5 (Figure 3.39). In general, the overall snapback is quite large when the reduction ratio is 2.5. Also the snapback for a reduction ratio of 2.5 (Figure 3.38, 3.39) has bigger jump than that for a reduction ratio of 2 (Figure 3.36, 3.37) for the second flour set. The snapback increases proportionally, either with shortened rest time or increased protein content.

The number for the second set snapback (Figure 3.39) is much greater compared with the first set snapback (Figure 3.38) for a reduction ratio of 2.5. The trends between the two sets had some differences. When the protein content was low, the effect of rest time on the snapback was not obvious. When the protein level was increased, rest time had an increased effect on the snapback as is to be expected. The protein content for the second flour set (Figure 3.39) had a larger effect on the snapback compared as with the first flour set (Figure 3.38). 
The snapback for the first and second flour sets, correlated with their protein content and rest time changes for a reduction ratio of 3

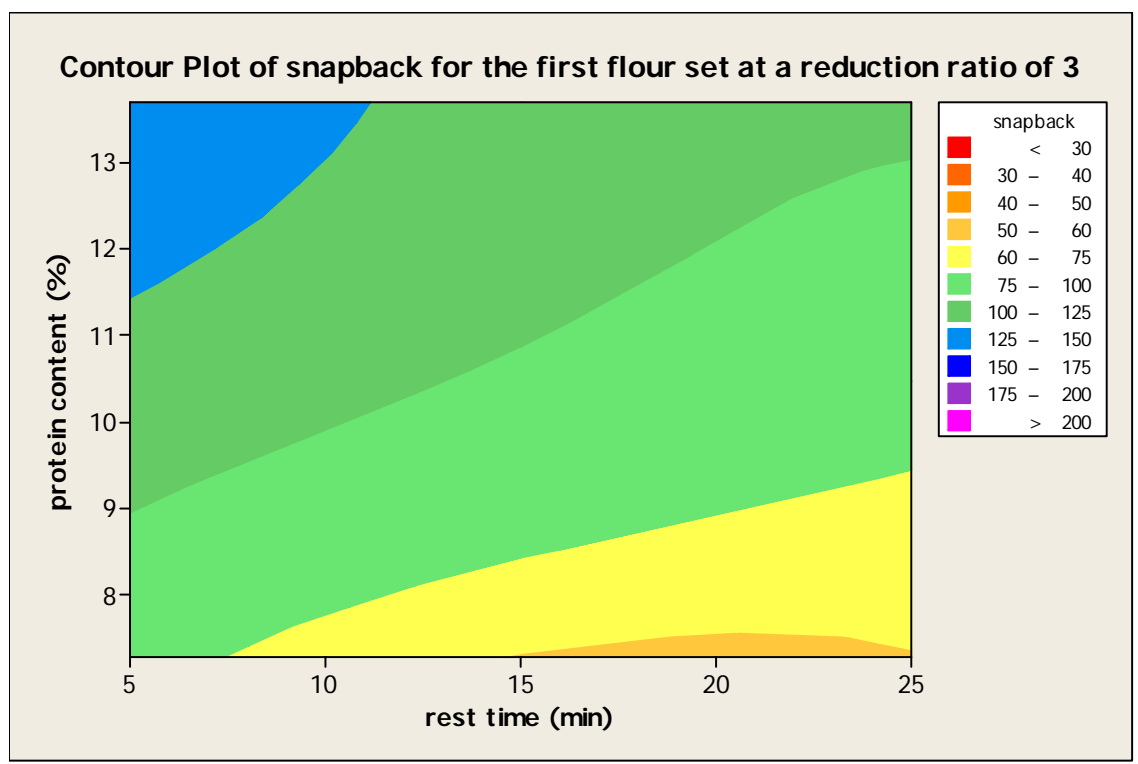

Figure 3.40 The snapback (\%) for the first flour set, correlated with protein content using different rest times for a reduction ratio of 3

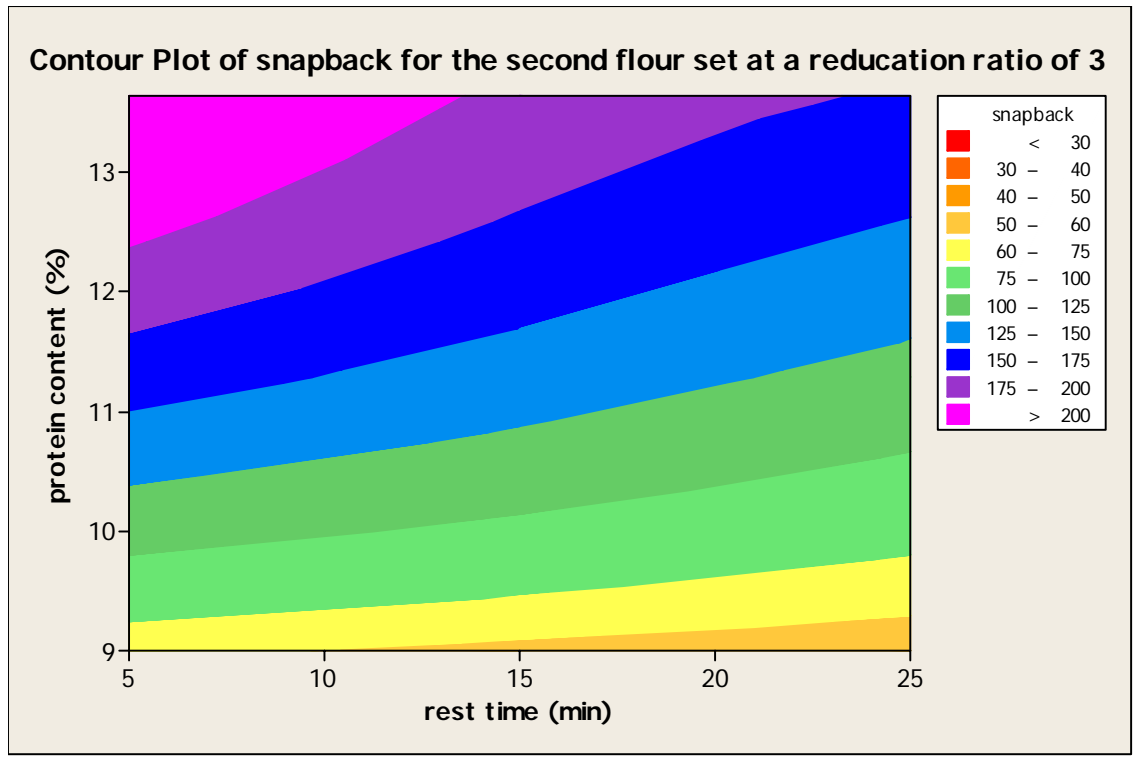

Figure 3.41 The snapback (\%) for the second flour set, correlated with protein content using different rest times for a reduction ratio of 3 
In these two charts, the snapback for the first flour set is from 50-60 to 125-150 for a reduction ratio of 3 (Figure 3.40). The snapback for the second flour set is from 50-60 to more than 200 for a reduction ratio of 3 (Figure 3.41). In general, the overall snapback is much larger when the reduction ratio is 3 . The snapback for a reduction ratio of 3 (Figure $3.40,3.41$ ) has quite similar values and pattern as that for a reduction ratio of 2.5 (Figure 3.38, 3.39).

In summary, there were the flour set's analyses derived from the results of using three different pieces of equipment to characterize the flour's rheological behavior. The chart analyses are based on the snapback changes in the flours. Protein content is most typically used to explain the relationship among the factors affecting snapback. Other parameters such as Mixograph peak height and work, and Alveograph work, correlate similarly as does the protein content. The second set of flours showed about the same tendencies as did the first set flour, indicating that this is probably not a unique happening, applicable only to select flours. The following stepwise analyses (Table 3.2, 3.3) are based upon both sets of flours, illustrating that the two flour sets behave similarly. 


\section{LINEAR STEPWISE REGRESSION ANALYSIS}

\section{LINEAR STEPWISE REGRESSION ANALYSIS FOR THE FIRST FLOUR SET}

Table 3.2 Linear stepwise regression analysis for snapback in the first flour set

\begin{tabular}{|c|c|c|c|}
\hline Step & 1 & 2 & 3 \\
\hline Constant & -14.32 & -72.43 & -56.6 \\
\hline Reduction Ratio & 36.7 & 36.7 & 36.7 \\
\hline Protein Content & & 5.55 & 5.55 \\
\hline Rest Time & & & -1.06 \\
\hline $\mathrm{s}$ & 19.0 & 12.1 & 8.46 \\
\hline R-Sq (\%) & 54.40 & 81.55 & 91.12 \\
\hline
\end{tabular}

The linear stepwise regression, based upon 108 data points from the first set of flours (Table 3.2), is designed to predict the snapback by an equation using the main chosen parameters and estimates how well the equation fits the data. If only the reduction ratio is used (Kempt, 2006) to predict snapback, only $54.40 \%$ of the variability in the response is explained by the equation. By adding protein content as an independent variable, $81.55 \%$ of the variation in the independent variable is explained by the two factors of data used to fit the equation. The degree of prediction has been greatly enhanced. If the three factors of reduction ratio, protein content, and rest time, are combined, $91.12 \%$ of the variation in the response data is explained by the three independent variables chosen to fit the equation. 


\section{LINEAR STEPWISE REGRESSION ANALYSIS FOR THE SECOND FLOUR SET}

Table 3.3 Linear stepwise regression analysis for snapback in the second flour set

\begin{tabular}{|l|c|c|c|}
\hline Step & 1 & 2 & 3 \\
\hline Constant & -171.2 & -275.1 & -249.4 \\
\hline & & & \\
\hline Protein Content & 23.79 & 23.79 & 23.79 \\
\hline Reduction Ratio & & 46.2 & 46.2 \\
\hline Rest Time & & & -1.71 \\
\hline & & & \\
\hline S & 34.0 & 21.9 & 16.8 \\
\hline R-Sq (\%) & 64.08 & 85.21 & 91.43 \\
\hline
\end{tabular}

The linear stepwise regression, based on 108 data points from the second set of flours likewise (Table 3.3) predicts the snapback with an equation using the main chosen parameters and estimates how well the regression equation fits the data. The results are similar to the results from the first flour set. The equation uses the same parameters to predict the snapback, and the data show a similar percentage of fit to the equation. If only using one factor, protein content, to predict the results, the data is only explained $64.08 \%$ by the equation. Likewise, the data shows only $54.40 \%$ fit to the equation for one factor prediction in the first set of flours (Table 3.2). If one more factor, reduction ratio, is added as a variable, there is an $85.21 \%$ fit to the equation, compared with $81.55 \%$ with two factors for the first flour set (Table 3.2). The degree of prediction has been greatly enhanced. Again, when combining the three factors of reduction ratio, protein content, and rest time, the data fit the equation pretty well (91.43\% explained), compared with $91.12 \%$ with the same three independent variables for the first flour set. These results are quite similar to that from the first flour set. 


\section{LINEAR STEPWISE REGRESSION ANALYSIS FOR THREE FLOUR SETS COMBINED}

The linear regression equation for snapback using seven factors is Snapback $=233.8+5.5 \times$ Mixo Work $+44.5 \times$ Reduction Ratio $-1.37 \times$ Rest Time $-11.23 \times$ Mixo Peak Height $-189 \times$ Mixo Mixing Time $-222 \times$ Alveo P/L $+34 \times$ Protein Content

Table 3.4 Linear first order stepwise regression analysis for snapback-including all 7 flours

\begin{tabular}{|l|c|c|c|c|c|c|c|}
\hline Step & 1 & 2 & 3 & 4 & 5 & 6 & 7 \\
\hline Constant & 9.348 & -90.766 & -70.219 & -22.986 & 50.317 & 121.633 & 233.8 \\
\hline Mixo Work & & & & & & & \\
\hline Reduction Ratio & & 44.5 & 44.5 & 44.5 & 44.5 & 44.5 & 44.5 \\
\hline Rest Time & & & -1.37 & -1.37 & -1.37 & -1.37 & -1.37 \\
\hline Mixo Peak Height & & & & -1.79 & -3.14 & -3.67 & -11.23 \\
\hline Mixo Mixing Time & & & & & -64.7 & -103.2 & -189 \\
\hline Alveo P/L & & & & & & -73 & -222 \\
\hline Protein Content & & & & & & & 34 \\
\hline & & & & & & & \\
\hline s & 33.7 & 22.7 & 19.8 & 18.9 & 16.7 & 15.8 & 13.6 \\
\hline R-Sq (\%) & 49.57 & 77.18 & 82.77 & 84.45 & 87.88 & 89.13 & 92.01 \\
\hline
\end{tabular}

All data tabulated is in Appendix B.

The linear stepwise regression based on combining the 252 data points from three sets of flours predicts the snapback by an equation using chosen parameters and estimating how well the equation fits the data (Table 3.4). When including more flours with different properties, more than three variables are needed to make the equation sufficiently robust to predict the snapback 
to the same closeness of fit as for a single flour set. The three different sets of flours came from different wheats, different mills and processing procedures, and had different protein contents and quality. The first set of flours was from commercial blends, so there are more uncertain factors which may have affected the properties. The second set of flours was from pure varieties milled under controlled conditions, not commercial blends. The third flour was a typical commercial bread flour.

As seen from Table 3.4, when only using one factor (Mixo work) to predict the fit, the equation explained only $49.57 \%$ of the variability in the results. By adding reduction ratio as a variable, there is a $77.18 \%$ fit to the equation. By adding more factors, the degree of prediction can be continually enhanced. Thus, by combining several factors of Mixograph work, reduction ratio, rest time, Mixograph peak height and mixing time, Alveograph $\mathrm{P} / \mathrm{L}$, and protein content, the equation accounts for $92.01 \%$ of the variability in the dependent variable, snapback. This would suggest a 7-factor equation that appears to be reasonably robust for the range of flour types tested here. It does, however, require more information on the flours and their properties.

Note that when studying flours of more widely different characteristics, the 'protein' term was replaced by Mixograph work, as an important factor affecting snapback. Work and protein are clearly related, but by a different ratio for each variety. When different flours with different protein qualities as well as different quantities are grouped together, the work is a function of both protein quantity and quality and therefore more difficult to predict. 

FLOUR SETS COMBINED

Since many relationships in nature are not linear, and this has frequently been observed to be the case with flour properties and performance, an alternate approach was to consider using Response Surface Analysis, or multiple, second order, regression, similar to the method which generated the colored contour figures shown earlier in this thesis. This equation was created by 'RSMPlus' (AEW Consulting, Lincoln, NE, 1992) developed by A. E. Walker and C. E. Walker (Walker and Parkhurst, 1984).

Using Model: STD 3_VAR |C 123122313112233

Coefficient of Determination $\left(\mathrm{R}^{\wedge} 2\right)=0.90012$

Coefficient of Multiple Correlation $=0.94874$

Standard Error of Estimate 15.26598

The second order regression equation for 3 factors is

$$
\begin{aligned}
\text { SNAPBACK }= & +22.8437474 \\
& -0.6005180 * \text { MIX-WORK } \\
& +8.2650851 * \text { RED-RATIO } \\
& -0.2326954 * \text { REST-TIME } \\
& +0.3654636 * \text { MIX-WORK * RED-RATIO } \\
& -0.5406127 * \text { RED-RATIO * REST-TIME } \\
& -0.0102471 * \text { MIX-WORK * REST-TIME } \\
& +0.0032125 * \text { MIX-WORK * MIX-WORK } \\
& +1.0712917 * \text { RED-RATIO * RED-RATIO } \\
& +0.0396248 * \text { REST-TIME * REST-TIME }
\end{aligned}
$$

A total of 252 data points were used with different combinations of Mixo Work, Red Ratio, and Rest Time to develop a second order equation predicting snapback (Appendix C). 
The equation included the three independent variables as first and second order terms as well as the three interaction terms.

Using the first three variables, Mixograph Work, Reduction Ratio, and Rest Time, the linear equation for Table 3.4 successfully predicted about $83 \%$ of the variability in the data (correlation coefficient $\mathrm{R}=0.910$ and $\mathrm{s}=19.8$ ). By extending to a total of 7 variables, the prediction was about $92 \%(\mathrm{R}=0.959$ and $\mathrm{s}=13.6)$.

The Mixograph Work input (area under the curve from start to peak) is an indicator of how much energy is required to develop the dough to the optimum strength during mixing. The sheeting Reduction Ratio indicates the relative stress applied to the dough during the actual sheeting operation, and the Rest Time following initial mixing indicates the time available for the dough to relax the stresses induced during mixing before it is sheeted. All of these are understood to be strongly affected by the four protein quantity and quality.

Following the second order regression approach, the resulting equation predicted about $90 \%$ of the snapback variability $(\mathrm{R}=0.949$ and $\mathrm{s}=15.3)$ with only three rather than 7 input variables. At the very least, this approach eliminates the need to obtain Alveograph data, with Mixograph data being sufficient. 


\section{CHAPTER 4 - CONCLUSIONS}

A combination of several chemical and physical flour properties can predict the relationship of the snapback to processing parameters and flour characteristics. The snapback will increase either with increased protein content and strength, or reduction ratio, or reduced rest time. This result was shown in the prediction of snapback for several flour samples. Mixograph work, reduction ratio, and dough rest time were the main factors affecting the snapback.

When including more flours with more widely different properties, more than three variables were needed to make the equation sufficiently robust to predict the snapback to the desired closeness to fit to the equation. By combining several factors such as Mixograph work, reduction ratio, rest time, Mixograph peak height and mixing time, Alveo P/L, and protein content, the equation accounted for $92.01 \%$ of the variability in the dependent variable, snapback. This would suggest that a 7-factor equation is reasonably robust for several flour types.

This research could be used to control the dough piece size and shape at bakeries, using various flour properties and under different circumstances. Since these relationships are empirical, bakeries and production lines would probably need to develop their own equation coefficients to fit their specific formulas, processing conditions, and equipment specifies. Opportunities for future research include the effects of roll speed and diameter on dough elastic snapback as well as the effects of yeast concentration, fermentation time and temperature. Also a direct measurement of dough elastic properties should be tested. 


\section{References}

AACC Methods (46-30, 44-15A, 54-21, 54-40A, 54-30A). Approved Methods of the American Association of Cereal Chemists, $9^{\text {th }}$ ed. The Association, St. Paul, 2000

Beckwith, A.C., Wall, J.S. and Dimler, R.J. Amide groups as interaction sites in wheat gluten proteins: effects of amide-ester conversion. Archives of Biochemistry and Biophysics. 103(3):319-330, 1963

Bernardin, J.E., and Kasarda, D.D. The microstructure of wheat protein fibrils. Cereal Chemistry. 50(6):735-745, 1973

Bloksma, A.H. Dough Structure, dough rheology, and baking quality. Cereal Foods World. 35(2):237-244, 1990

Bloksma, A.H., and Nieman, W. The effect of temperature on some rheological properties of wheat flour doughs. Journal of Texture Studies. 6(3):343-361, 1975

Cauvain, S.P. and Young, L.S. Technology of Breadmaking. Blackie Academic and Professional, London, UK, 1998

Cauvain, S.P. Bread Making: Improving Quality. CRC Press, Boca Raton, 2003

Casier, J.P.J., de Paepe, G., and Bruemmer, J.M. Einfluss der wasserunloeslichen Weizen- und Roggen- Pentosane auf die Backeigenschaften von Weizenmehlen und anderen Rohstoffen. (Effect of water-insoluble pentosans from wheat and rye on the baking properties of wheat flour and other raw materials. Getreide, Mehl und Brot. 27(1):36-44, 1973

Casier, J.P.J. Effect of water-insoluble endosperm pentosans of wheat and rye on baking and dough properties of soft wheat and other starch-rich raw materials, e.g. manioc, rice, sorghum, millet. Fermentatio. 71(3): 117-134, 1975

Dobraszczyk, B.J. Development of a new dough inflation system to evaluate doughs. Cereal Foods World. 42(7):516-519, 1997

Dorrington, K.L. and McCrum, N.G. Elastin as a rubber. Biopolymers. 16(6):1201-1222, 1977

Ewart, J.A.D. A hypothesis for the structure and rheology of glutenin. Journal of the Science of Food and Agriculture. 19(11):617-623, 1968 
Ewart, J.A.D. A modified hypothesis for the structure and rheology of glutelins. Journal of the Science of Food and Agriculture. 23(6):687-699, 1972

Ewart, J.A.D. Re-examination of the linear glutenin hypothesis. Journal of the Science of Food and Agriculture. 28(2):191-199, 1977

Ewart, J.A.D. Glutenin and dough tenacity. Journal of the Science of Food and Agriculture. 29(6):551-556, 1978

Ewart, J.A.D. Glutenin structure. Journal of the Science of Food and Agriculture. 30(5):482-492, 1979

Ewart, J.A.D. Calculated molecular weight distribution for glutenin. Journal of the Science of Food and Agriculture. 38(3):277-289, 1987

Faridi, H. and Faubion, J.M. Dough Rheology and Baked Product Texture. Van Nostrand Reinhold, New York, 1990

Farrand, E.A. Flour properties in relation to modern bread processes in the United Kingdom, with special reference to alpha-amylase and starch damage. Cereal Chemistry. 41:98111,1964

Greenwood, C.T. and Ewart, J.A.D. Hypothesis for the structure of glutenin in relation to rheological properties of gluten and dough. Cereal Chemistry. 52:146r-153r, 1975

Hibberd, G.E. and Parker, N.S. Measurement of the fundamental rheological properties of wheat-flour doughs. Cereal Chemistry. 52(3, part II):1r-23r, 1975

Holas, J. and Tipples, K.H. Factors affecting farinograph and baking absorption. I. Quality characteristics of flour streams. Cereal Chemistry. 55(5):637-652, 1978

Hoseney, R.C. Functional properties of pentosans in baked foods. Food Technology. 38(1):114-117, 1984

Hoseney, R.C. and Faubion, J.M. A mechanism of the oxidative gelation of wheat flour wheat-soluble pentosans. Cereal Chemistry. 58(5):421-424, 1981

Hoseney, R.C. and Rogers, D.E. The formation and properties of wheat flour doughs. Critical Reviews in Food Science and Nutrition. 29(2):73-93, 1990

Jelaca, S.L. and Hlynka, I. Water-binding capacity of wheat flour crude pentosans and their relation to mixing characteristics of dough. Cereal Chemistry. 48(3):211-222, 1971

Kempf, T. P., Labuza, T. P., and Levine, L. Elastic recovery of a wheat flour dough during sheeting. Cereal Foods World. 50(6):316-320, 2006 
Kim, S.K. and D’Appolonia, B.L. Bread staling studies. III. Effect of pentosans on dough, bread and bread staling rate. Cereal Chemistry. 54:225-229, 1977

Kokelaar, J.J., Vliet, T.V., and Prins, A. Strain hardening properties and extensibility of flour and gluten doughs in relation to breadmaking performance. Journal of Cereal Science. 24(3):199-214, 1996

Michniewicz, J., Biliaderis, C.G. and Bushuk, W. Water-insoluble pentosans of wheat: composition and some physical properties. Cereal Chemistry. 67(5): 434-439, 1990.

Orth, R.A. and Bushuk, W. A comparative study of the proteins of wheats of diverse baking qualities. Cereal Chemistry. 49(3):268-275, 1972.

Sidhu, J.S., Hoseney, R.C., Faubion, J. and Nordin, P. Reaction of ${ }^{14}$ C-cysteine with wheat flour water solubles under ultraviolet light. Cereal Chemistry. 57(6):380-382, 1980.

Singh, N.K., Donovan, R. and MacRitchie, F. Use of sonication and size-execlusion highperformance liquid chromatography in the study of wheat flour proteins. II. Relative quantity of glutenin as a measure of breadmaking quality. Cereal Chemistry. 67(2):161-170, 1990

Tatham, A.S., Miflin, B.J. and Shewry, P.R. The beta-turn conformation in wheat gluten protein: Relationship to gluten elasticity. Cereal Chemistry. 62(5):405-412, 1985

Tipples, K.H. and Kilborn, R.H. Factors affecting mechanical dough development V. Influence of rest period on mixing and "unmixing" characteristics of dough. Cereal Chemistry. 54(1):92-109, 1977

Walker, C. E. and Parkhurst, A. M. Response surface analysis of bake-lab data with a personal computer. Cereal Foods World. 29(10):662-665, 1984

Wall, J.S. and Beckwith, A.C. Relationship between structure and rheological properties of gluten proteins. Cereal Science today. 14(1):16-18, 20-21, 1969 


\section{Appendix A - Tables}

\section{The first flour set}

The snapback for the first flour set, correlated with their protein content using different reduction ratios

Table A. 1 The snapback for the first flour set, correlated with protein content using different reduction ratios at 5 min rest time

\begin{tabular}{|c|c|c|c|c|c|}
\hline \multirow{2}{*}{ Flour Type } & \multirow{2}{*}{ Protein Content (14\%) } & \multicolumn{4}{|c|}{ Reduction Ratio } \\
\cline { 3 - 6 } & & 1.5 & 2 & 2.5 & 3 \\
\hline bread flour & 13.69 & 55.7 & 84.3 & 113.7 & 151.2 \\
\hline bread flour & 13.69 & 50.6 & 77.0 & 100.5 & 141.4 \\
\hline bread flour & 13.69 & 57.4 & 81.9 & 116.6 & 149.1 \\
\hline 50/50 PB flour & 10.49 & 54.1 & 70.7 & 91.3 & 115.3 \\
\hline 50/50 PB flour & 10.49 & 49.1 & 62.9 & 91.1 & 121.7 \\
\hline 50/50 PB flour & 10.49 & 48.0 & 65.5 & 90.5 & 109.0 \\
\hline pastry flour & 7.28 & 44.2 & 48.8 & 72.8 & 77.3 \\
\hline pastry flour & 7.28 & 44.0 & 45.8 & 70.1 & 83.0 \\
\hline pastry flour & 7.28 & 44.3 & 56.0 & 71.6 & 88.1 \\
\hline
\end{tabular}

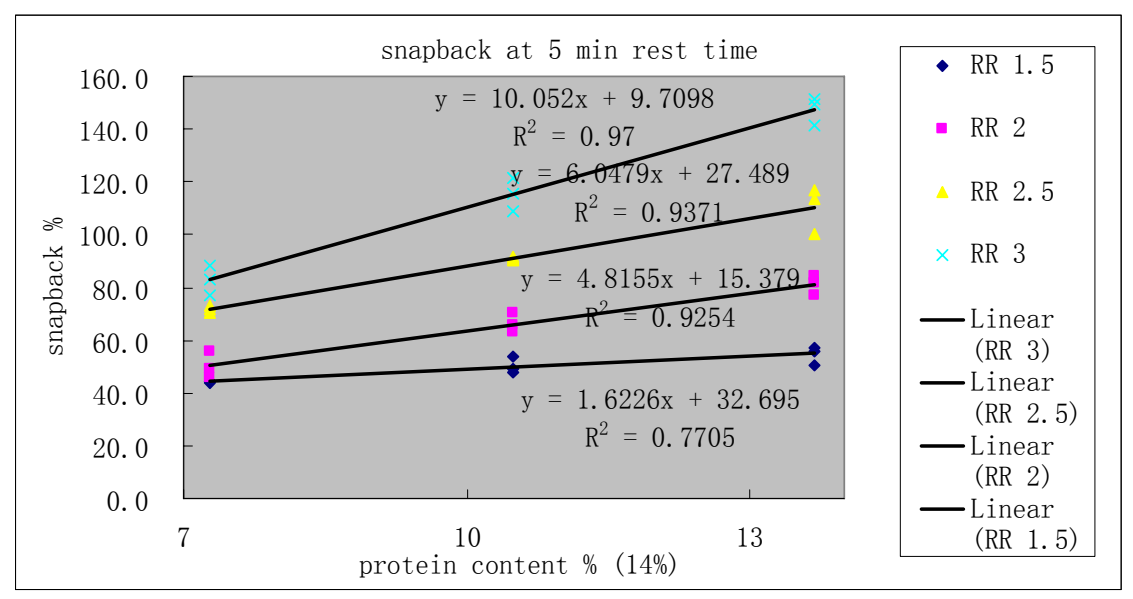

Figure A. 1 The snapback for the first flour set, correlated with protein content using different reduction ratios at 5 min rest time 
Table A. 2 The snapback for the first flour set, correlated with protein content using different reduction ratios at $15 \mathrm{~min}$ rest time

\begin{tabular}{|c|c|c|c|c|c|}
\hline \multirow{2}{*}{ Flour Type } & \multirow{2}{*}{ Protein Content (14\%) } & \multicolumn{4}{|c|}{ Reduction Ratio } \\
\cline { 2 - 6 } & & 1.5 & 2 & 2.5 & 3 \\
\hline bread flour & 13.69 & 48.5 & 70.7 & 99.9 & 118.5 \\
\hline bread flour & 13.69 & 48.5 & 74.1 & 95.6 & 109.3 \\
\hline bread flour & 13.69 & 45.3 & 75.2 & 96.5 & 117.5 \\
\hline 50/50 PB flour & 10.49 & 42.3 & 57.9 & 75.6 & 95.5 \\
\hline 50/50 PB flour & 10.49 & 39.1 & 62.0 & 80.9 & 94.8 \\
\hline 50/50 PB flour & 10.49 & 38.9 & 63.6 & 76.3 & 99.5 \\
\hline pastry flour & 7.28 & 27.2 & 38.3 & 56.4 & 60.0 \\
\hline pastry flour & 7.28 & 28.9 & 33.2 & 47.4 & 51.0 \\
\hline pastry flour & 7.28 & 30.0 & 32.7 & 54.9 & 67.2 \\
\hline
\end{tabular}

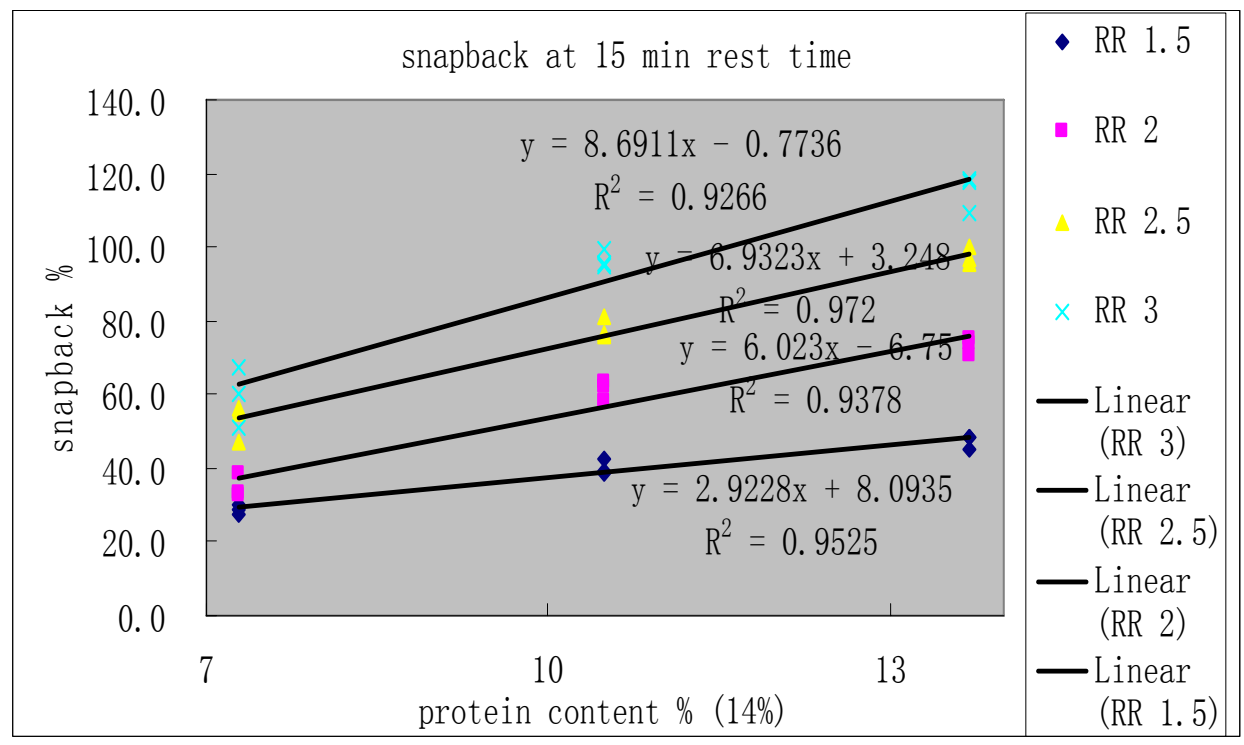

Figure A. 2 The snapback for the first flour set, correlated with protein content using different reduction ratios at $15 \mathrm{~min}$ rest time 
Table A. 3 The snapback for the first flour set, correlated with protein content using different reduction ratios at $25 \mathrm{~min}$ rest time

\begin{tabular}{|c|c|c|c|c|c|}
\hline \multirow{2}{*}{ Flour Type } & \multirow{2}{*}{ Protein Content (14\%) } & \multicolumn{4}{|c|}{ Reduction Ratio } \\
\cline { 3 - 6 } & & 1.5 & 2 & 2.5 & 3 \\
\hline bread flour & 13.69 & 41.2 & 67.1 & 80.9 & 108.3 \\
\hline bread flour & 13.69 & 47.5 & 67.3 & 84.4 & 104.8 \\
\hline bread flour & 13.69 & 48.1 & 64.2 & 87.7 & 100.0 \\
\hline $50 / 50$ PB flour & 10.49 & 35.8 & 53.8 & 68.0 & 83.0 \\
\hline $50 / 50$ PB flour & 10.49 & 32.8 & 47.2 & 66.0 & 78.1 \\
\hline $50 / 50$ PB flour & 10.49 & 34.6 & 49.5 & 71.8 & 85.6 \\
\hline pastry flour & 7.28 & 27.2 & 38.3 & 56.4 & 60.0 \\
\hline pastry flour & 7.28 & 28.9 & 33.2 & 47.4 & 51.0 \\
\hline pastry flour & 7.28 & 30.0 & 32.7 & 54.9 & 67.2 \\
\hline
\end{tabular}

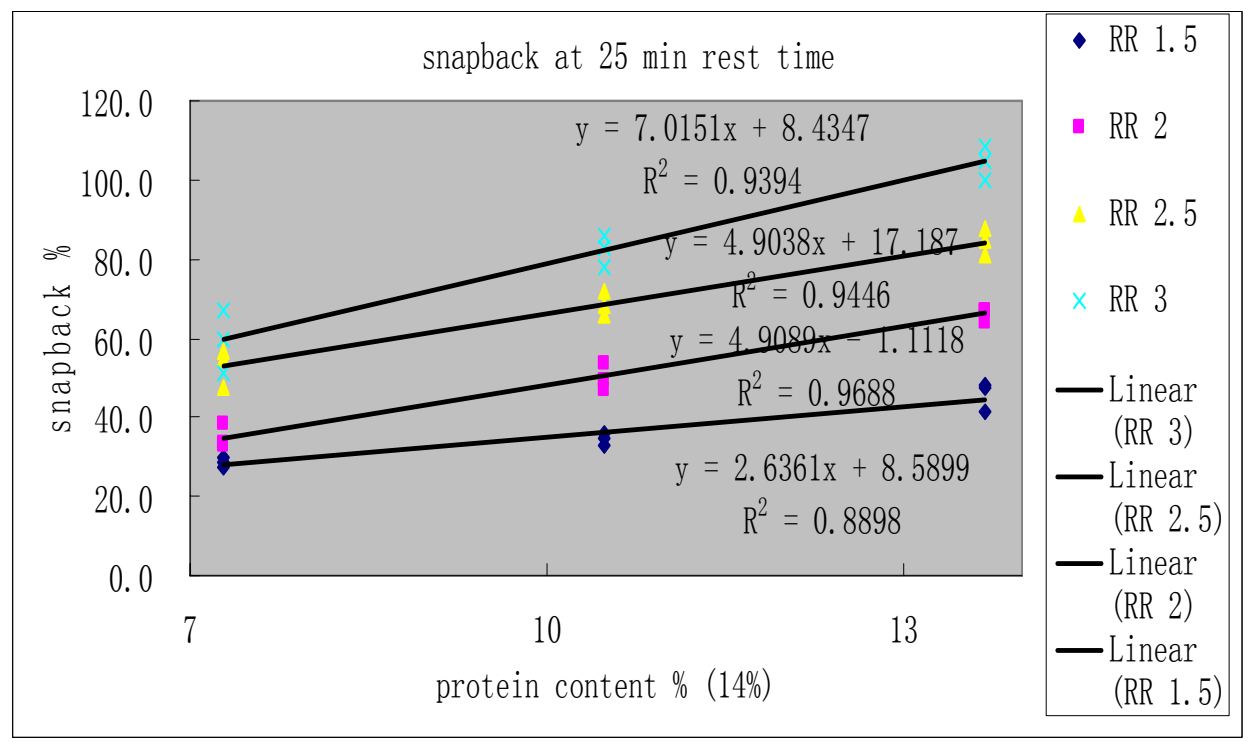

Figure A. 3 The snapback for the first flour set, correlated with protein content using different reduction ratios at $25 \mathrm{~min}$ rest time 
The snapback for the first flour set, correlated with protein content using different rest times

Table A. 4 The snapback for the first flour set, correlated with protein content using different rest times at RR 1.5

\begin{tabular}{|c|c|c|c|c|}
\hline \multirow{2}{*}{ Flour Type } & \multirow{2}{*}{ Protein Content (14\%) } & \multicolumn{3}{|c|}{ Rest Time (min) } \\
\cline { 3 - 5 } & & 5 & 15 & 25 \\
\hline bread flour & 13.69 & 55.7 & 48.5 & 41.2 \\
\hline bread flour & 13.69 & 50.6 & 48.5 & 47.5 \\
\hline bread flour & 13.69 & 57.4 & 45.3 & 48.1 \\
\hline 50/50 PB flour & 10.49 & 54.1 & 42.3 & 35.8 \\
\hline 50/50 PB flour & 10.49 & 49.1 & 39.1 & 32.8 \\
\hline 50/50 PB flour & 10.49 & 48.0 & 38.9 & 34.6 \\
\hline pastry flour & 7.28 & 44.2 & 29.9 & 27.2 \\
\hline pastry flour & 7.28 & 44.0 & 33.6 & 28.9 \\
\hline pastry flour & 7.28 & 44.3 & 33.7 & 30.0 \\
\hline
\end{tabular}

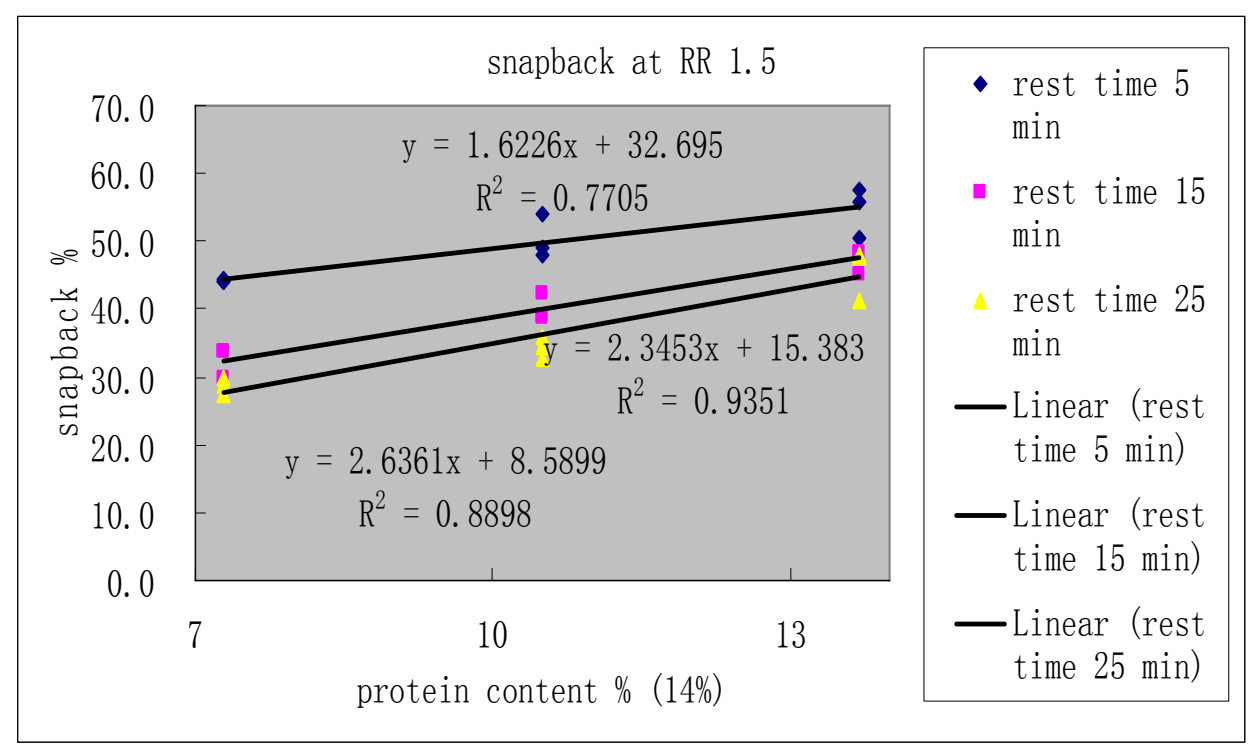

Figure A. 4 The snapback for the first flour set, correlated with protein content using different rest times at $R R 1.5$ 
Table A. 5 The snapback for the first flour set, correlated with protein content using different rest times at $\mathbf{R R} 2$

\begin{tabular}{|c|c|c|c|c|}
\hline \multirow{2}{*}{ Flour Type } & \multirow{2}{*}{ Protein Content (14\%) } & \multicolumn{3}{|c|}{ Rest Time (min) } \\
\cline { 3 - 5 } & & 5 & 15 & 25 \\
\hline bread flour & 13.69 & 84.3 & 70.7 & 67.1 \\
\hline bread flour & 13.69 & 77.0 & 74.1 & 67.3 \\
\hline bread flour & 13.69 & 81.9 & 75.2 & 64.2 \\
\hline 50/50 PB flour & 10.49 & 70.7 & 57.9 & 53.8 \\
\hline 50/50 PB flour & 10.49 & 62.9 & 62.0 & 47.2 \\
\hline 50/50 PB flour & 10.49 & 65.5 & 63.6 & 49.5 \\
\hline pastry flour & 7.28 & 48.8 & 47.4 & 38.3 \\
\hline pastry flour & 7.28 & 45.8 & 44.3 & 33.2 \\
\hline pastry flour & 7.28 & 56.0 & 43.3 & 32.7 \\
\hline
\end{tabular}

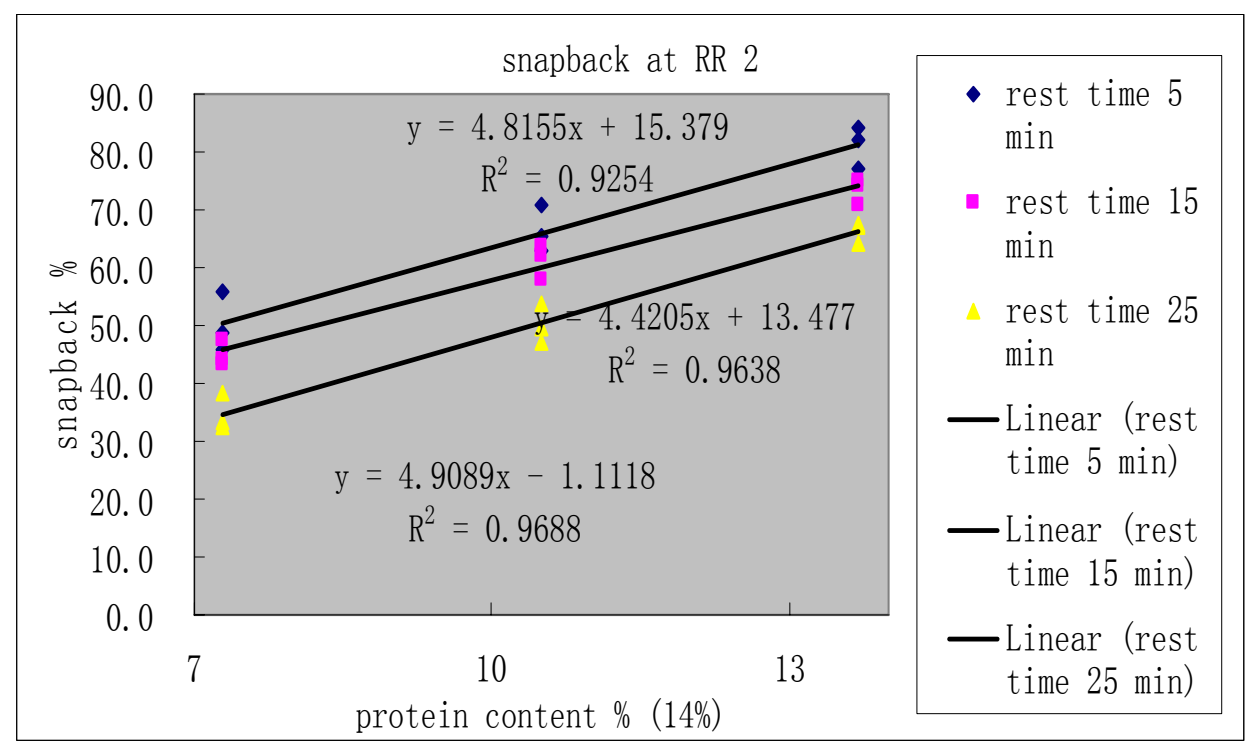

Figure A. 5 The snapback for the first flour set, correlated with protein content using different rest times at $\mathbf{R R} 2$ 
Table A. 6 The snapback for the first flour set, correlated with protein content using different rest times at $R R 2.5$

\begin{tabular}{|c|c|c|c|c|}
\hline \multirow{2}{*}{ Flour Type } & \multirow{2}{*}{ Protein Content (14\%) } & \multicolumn{3}{|c|}{ Rest Time (min) } \\
\cline { 3 - 5 } & & 5 & 15 & 25 \\
\hline bread flour & 13.69 & 113.7 & 99.9 & 80.9 \\
\hline bread flour & 13.69 & 100.5 & 95.6 & 84.4 \\
\hline bread flour & 13.69 & 116.6 & 96.5 & 87.7 \\
\hline 50/50 PB flour & 10.49 & 91.3 & 75.6 & 68.0 \\
\hline 50/50 PB flour & 10.49 & 91.1 & 80.9 & 66.0 \\
\hline 50/50 PB flour & 10.49 & 90.5 & 76.3 & 71.8 \\
\hline pastry flour & 7.28 & 72.8 & 60.7 & 56.4 \\
\hline pastry flour & 7.28 & 70.1 & 58.1 & 47.4 \\
\hline pastry flour & 7.28 & 71.6 & 61.7 & 54.9 \\
\hline
\end{tabular}

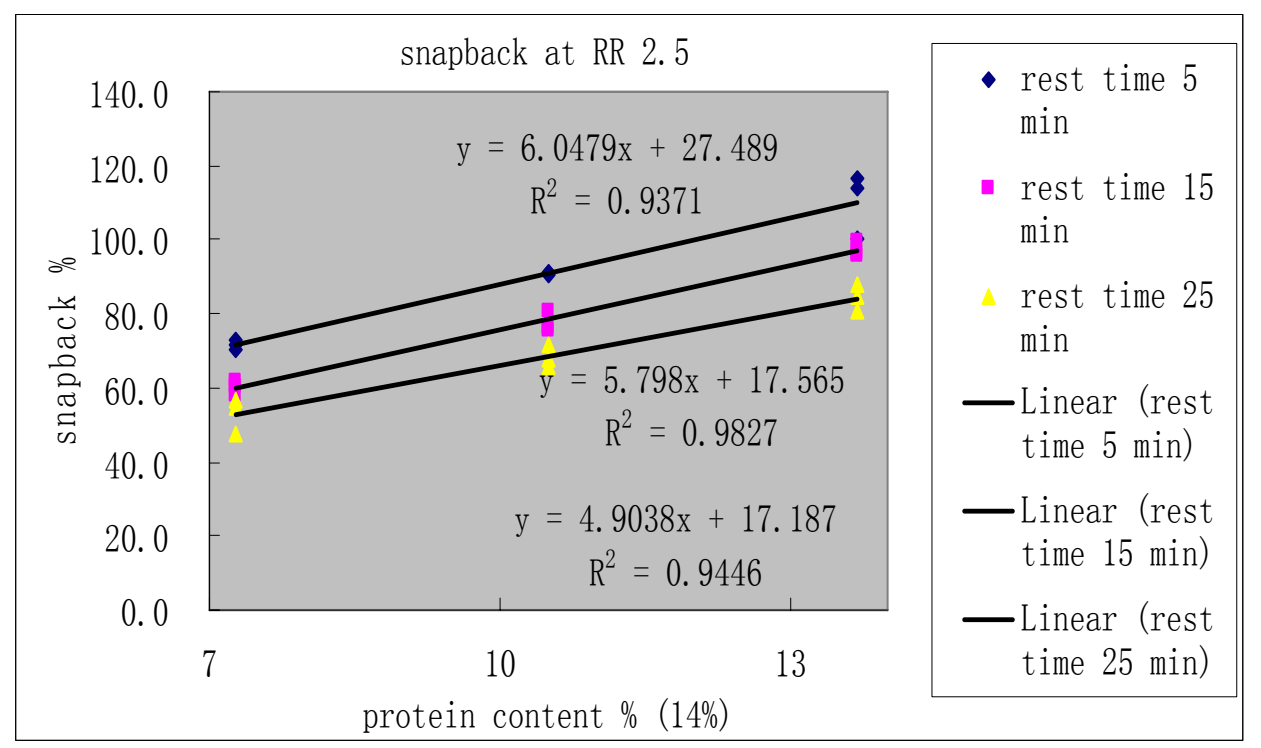

Figure A. 6 The snapback for the first flour set, correlated with protein content using different rest times at $R R 2.5$ 
Table A. 7 The snapback for the first flour set, correlated with protein content using different rest times at $\mathbf{R R} 3$

\begin{tabular}{|c|c|c|c|c|}
\hline \multirow{2}{*}{ Flour Type } & \multirow{2}{*}{ Protein Content (14\%) } & \multicolumn{3}{|c|}{ Rest Time (min) } \\
\cline { 3 - 5 } & & 5 & 15 & 25 \\
\hline bread flour & 13.69 & 151.2 & 118.5 & 108.3 \\
\hline bread flour & 13.69 & 141.4 & 109.3 & 104.8 \\
\hline bread flour & 13.69 & 149.1 & 117.5 & 100.0 \\
\hline 50/50 PB flour & 10.49 & 115.3 & 95.5 & 83.0 \\
\hline 50/50 PB flour & 10.49 & 121.7 & 94.8 & 78.1 \\
\hline 50/50 PB flour & 10.49 & 109.0 & 99.5 & 85.6 \\
\hline pastry flour & 7.28 & 77.3 & 74.2 & 60.0 \\
\hline pastry flour & 7.28 & 83.0 & 75.5 & 51.0 \\
\hline pastry flour & 7.28 & 88.1 & 72.1 & 67.2 \\
\hline
\end{tabular}

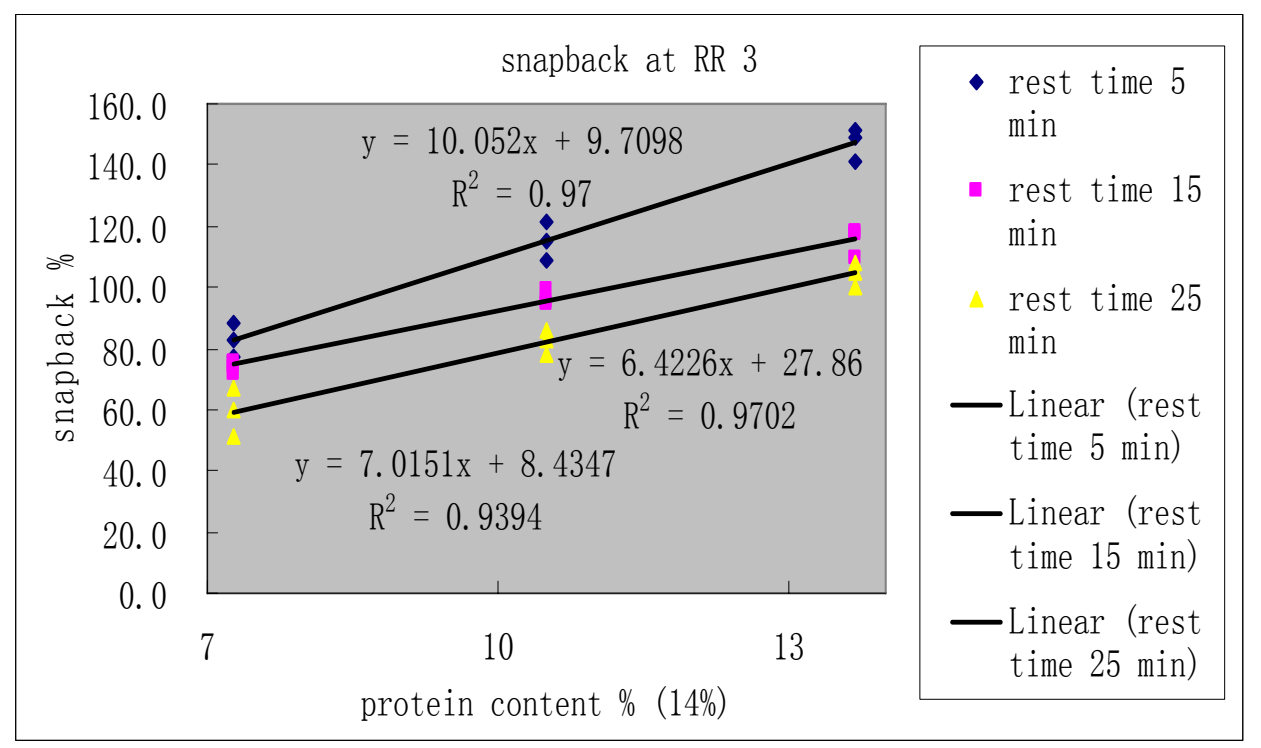

Figure A. 7 The snapback for the first flour set, correlated with protein content using different rest times at $R R 3$ 
The snapback for the first flour set, correlated with Mixograph peak height using different reduction ratios

Table A. 8 The snapback for the first flour set, correlated with Mixograph peak height using different reduction ratios at $5 \mathrm{~min}$ rest time

\begin{tabular}{|c|c|c|c|c|c|}
\hline \multirow{2}{*}{ Flour Type } & \multirow{2}{*}{ Peak Height $\%$} & \multicolumn{4}{|c|}{ Reduction Ratio } \\
\cline { 3 - 6 } & & 1.5 & 2 & 2.5 & 3 \\
\hline bread flour & 54.67 & 48.5 & 70.7 & 99.9 & 118.5 \\
\hline bread flour & 54.67 & 48.5 & 74.1 & 95.6 & 109.3 \\
\hline bread flour & 54.67 & 45.3 & 75.2 & 96.5 & 117.5 \\
\hline 50/50 PB flour & 45.00 & 42.3 & 57.9 & 75.6 & 95.5 \\
\hline 50/50 PB flour & 45.00 & 39.1 & 62.0 & 80.9 & 94.8 \\
\hline 50/50 PB flour & 45.00 & 38.9 & 63.6 & 76.3 & 99.5 \\
\hline pastry flour & 28.33 & 27.2 & 38.3 & 56.4 & 60.0 \\
\hline pastry flour & 28.33 & 28.9 & 33.2 & 47.4 & 51.0 \\
\hline pastry flour & 28.33 & 30.0 & 32.7 & 54.9 & 67.2 \\
\hline
\end{tabular}

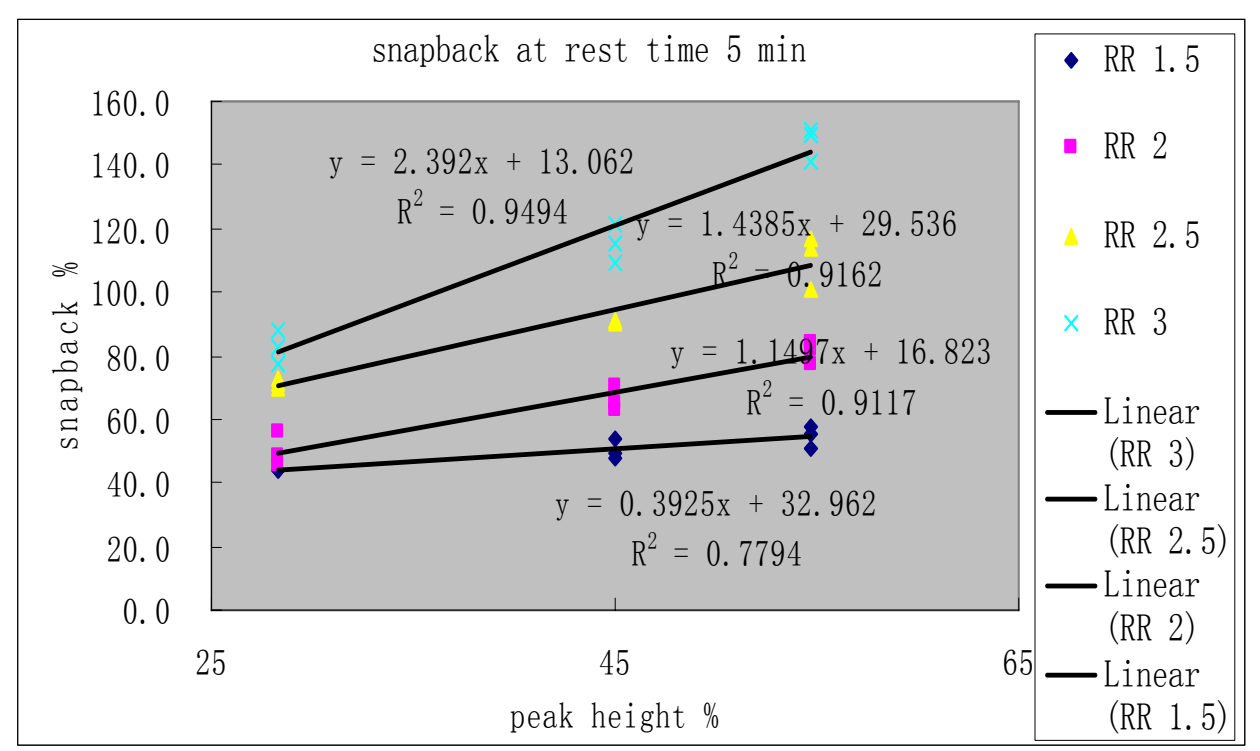

Figure A. 8 The snapback for the first flour set, correlated with Mixograph peak height using different reduction ratios at $5 \mathrm{~min}$ rest time 
Table A. 9 The snapback for the first flour set, correlated with Mixograph peak height using different reduction ratios at 15 min rest time

\begin{tabular}{|c|c|c|c|c|c|}
\hline \multirow{2}{*}{ Flour Type } & \multirow{2}{*}{ Peak Height \% } & \multicolumn{4}{|c|}{ Reduction Ratio } \\
\cline { 3 - 6 } & & 1.5 & 2 & 2.5 & 3 \\
\hline bread flour & 54.67 & 48.5 & 70.7 & 99.9 & 118.5 \\
\hline bread flour & 54.67 & 48.5 & 74.1 & 95.6 & 109.3 \\
\hline bread flour & 54.67 & 45.3 & 75.2 & 96.5 & 117.5 \\
\hline 50/50 PB flour & 45.00 & 42.3 & 57.9 & 75.6 & 95.5 \\
\hline 50/50 PB flour & 45.00 & 39.1 & 62.0 & 80.9 & 94.8 \\
\hline 50/50 PB flour & 45.00 & 38.9 & 63.6 & 76.3 & 99.5 \\
\hline pastry flour & 28.33 & 27.2 & 38.3 & 56.4 & 60.0 \\
\hline pastry flour & 28.33 & 28.9 & 33.2 & 47.4 & 51.0 \\
\hline pastry flour & 28.33 & 30.0 & 32.7 & 54.9 & 67.2 \\
\hline
\end{tabular}

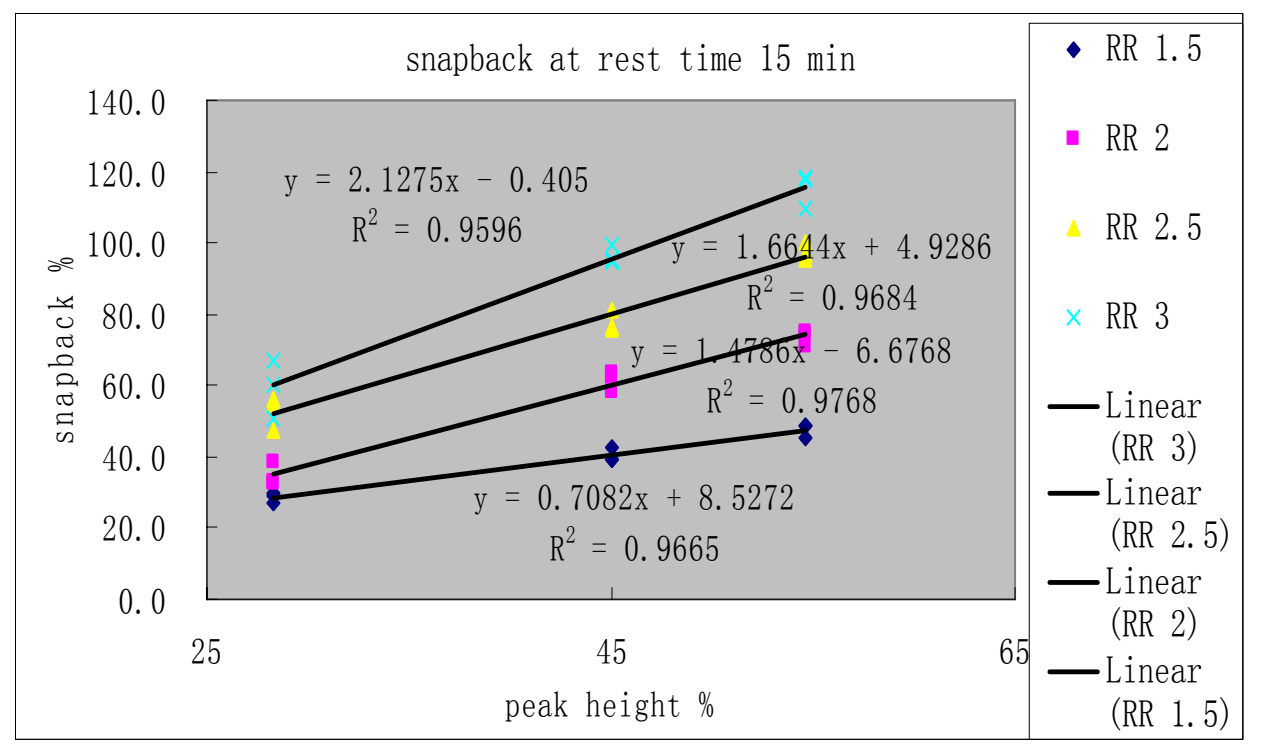

Figure A. 9 The snapback for the first flour set, correlated with Mixograph peak height using different reduction ratios at 15 min rest time 
Table A. 10 The snapback for the first flour set, correlated with Mixograph peak height using different reduction ratios at 25 min rest time

\begin{tabular}{|c|c|c|c|c|c|}
\hline \multirow{2}{*}{ Flour Type } & \multirow{2}{*}{ Peak Height $\%$} & \multicolumn{4}{|c|}{ Reduction Ratio } \\
\cline { 3 - 6 } & & 1.5 & 2 & 2.5 & 3 \\
\hline bread flour & 54.67 & 41.2 & 67.1 & 80.9 & 108.3 \\
\hline bread flour & 54.67 & 47.5 & 67.3 & 84.4 & 104.8 \\
\hline bread flour & 54.67 & 48.1 & 64.2 & 87.7 & 100.0 \\
\hline 50/50 PB flour & 45.00 & 35.8 & 53.8 & 68.0 & 83.0 \\
\hline 50/50 PB flour & 45.00 & 32.8 & 47.2 & 66.0 & 78.1 \\
\hline 50/50 PB flour & 45.00 & 34.6 & 49.5 & 71.8 & 85.6 \\
\hline pastry flour & 28.33 & 27.2 & 38.3 & 56.4 & 60.0 \\
\hline pastry flour & 28.33 & 28.9 & 33.2 & 47.4 & 51.0 \\
\hline pastry flour & 28.33 & 30.0 & 32.7 & 54.9 & 67.2 \\
\hline
\end{tabular}

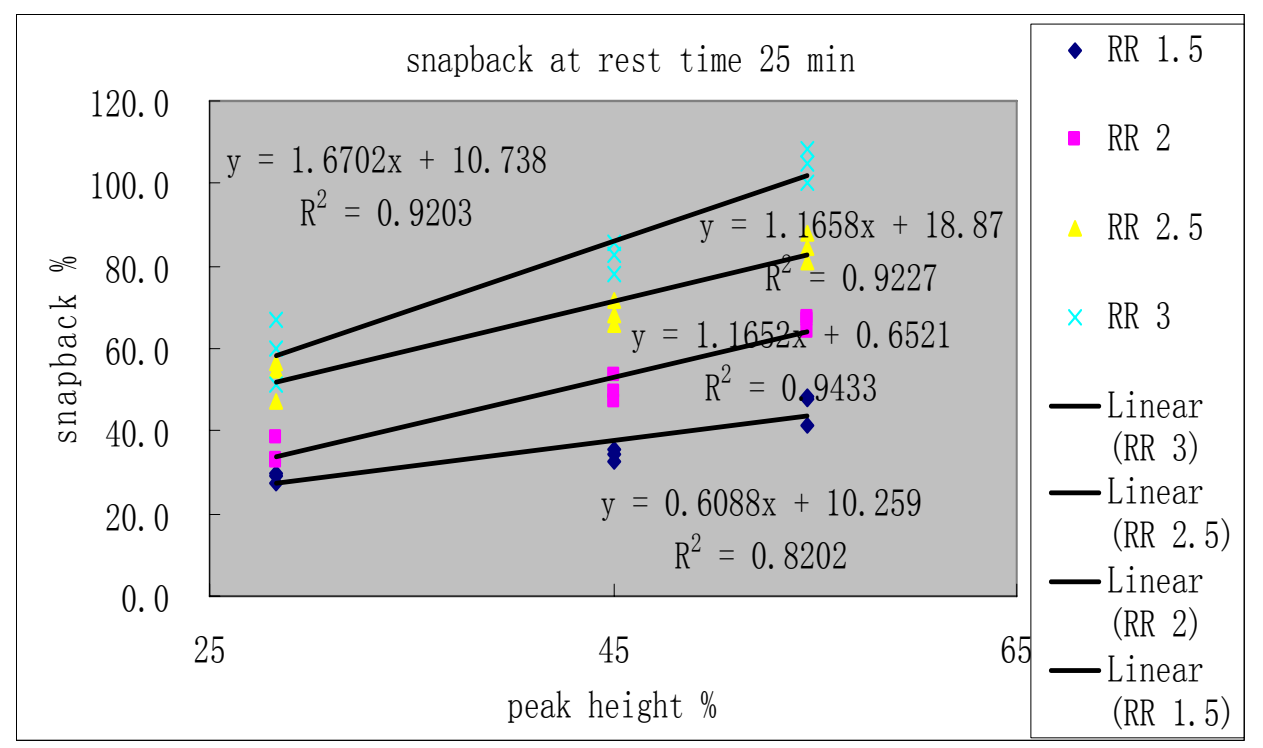

Figure A. 10 The snapback for the first flour set, correlated with Mixograph peak height using different reduction ratios at 25 min rest time 
The snapback for the first flour set, correlated with Mixograph peak height using different rest times

Table A. 11 The snapback for the first flour set, correlated with Mixograph peak height using different rest times at RR 1.5

\begin{tabular}{|c|c|c|c|c|}
\hline & peak height \% & 5 & 15 & 25 \\
\hline bread flour & 54.67 & 55.7 & 48.5 & 41.2 \\
\hline bread flour & 54.67 & 50.6 & 48.5 & 47.5 \\
\hline bread flour & 54.67 & 57.4 & 45.3 & 48.1 \\
\hline $50 / 50$ PB flour & 45.00 & 54.1 & 42.3 & 35.8 \\
\hline 50/50 PB flour & 45.00 & 49.1 & 39.1 & 32.8 \\
\hline 50/50 PB flour & 45.00 & 48.0 & 38.9 & 34.6 \\
\hline pastry flour & 28.33 & 44.2 & 29.9 & 27.2 \\
\hline pastry flour & 28.33 & 44.0 & 33.6 & 28.9 \\
\hline pastry flour & 28.33 & 44.3 & 33.7 & 30.0 \\
\hline
\end{tabular}

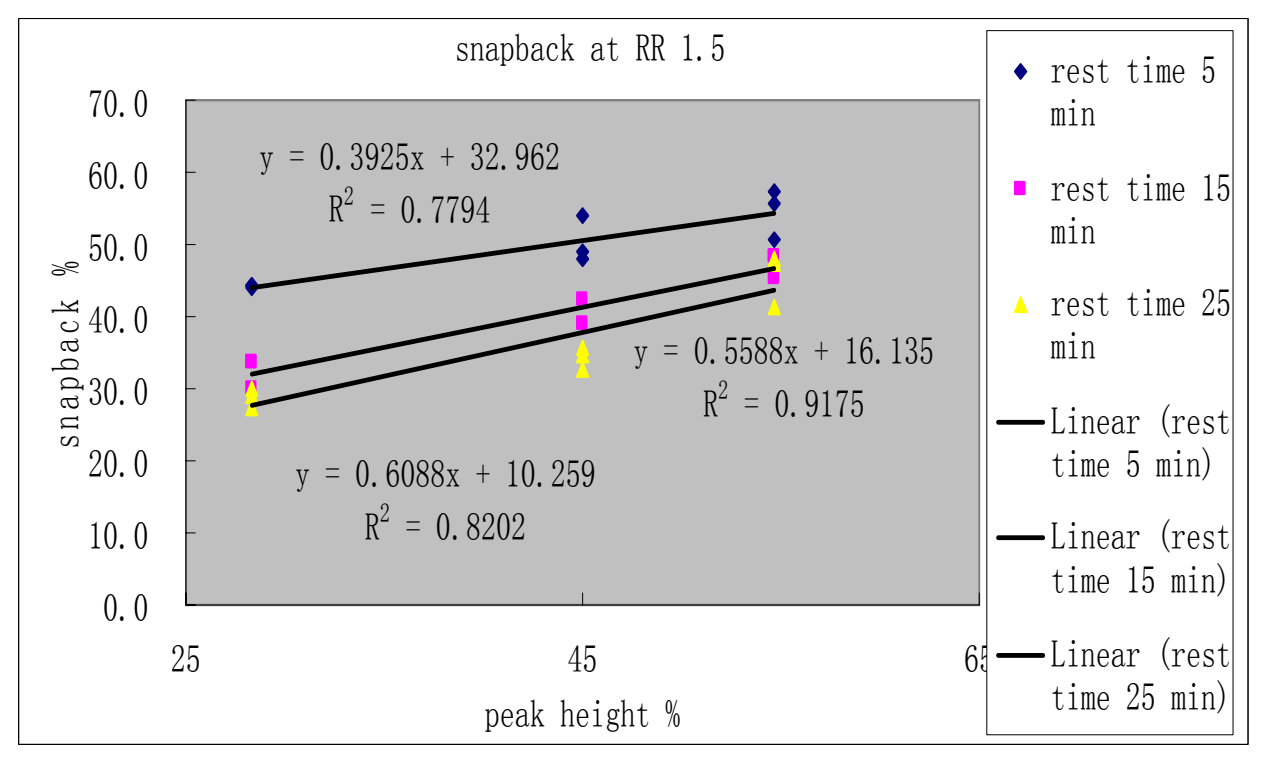

Figure A. 11 The snapback for the first flour set, correlated with Mixograph peak height using different rest times at $R R 1.5$ 
Table A. 12 The snapback for the first flour set, correlated with Mixograph peak height using different rest times at RR 2

\begin{tabular}{|c|c|c|c|c|}
\hline & peak height \% & 5 & 15 & 25 \\
\hline bread flour & 54.67 & 84.3 & 70.7 & 67.1 \\
\hline bread flour & 54.67 & 77.0 & 74.1 & 67.3 \\
\hline bread flour & 54.67 & 81.9 & 75.2 & 64.2 \\
\hline $50 / 50$ PB flour & 45.00 & 70.7 & 57.9 & 53.8 \\
\hline 50/50 PB flour & 45.00 & 62.9 & 62.0 & 47.2 \\
\hline 50/50 PB flour & 45.00 & 65.5 & 63.6 & 49.5 \\
\hline pastry flour & 28.33 & 48.8 & 47.4 & 38.3 \\
\hline pastry flour & 28.33 & 45.8 & 44.3 & 33.2 \\
\hline pastry flour & 28.33 & 56.0 & 43.3 & 32.7 \\
\hline
\end{tabular}

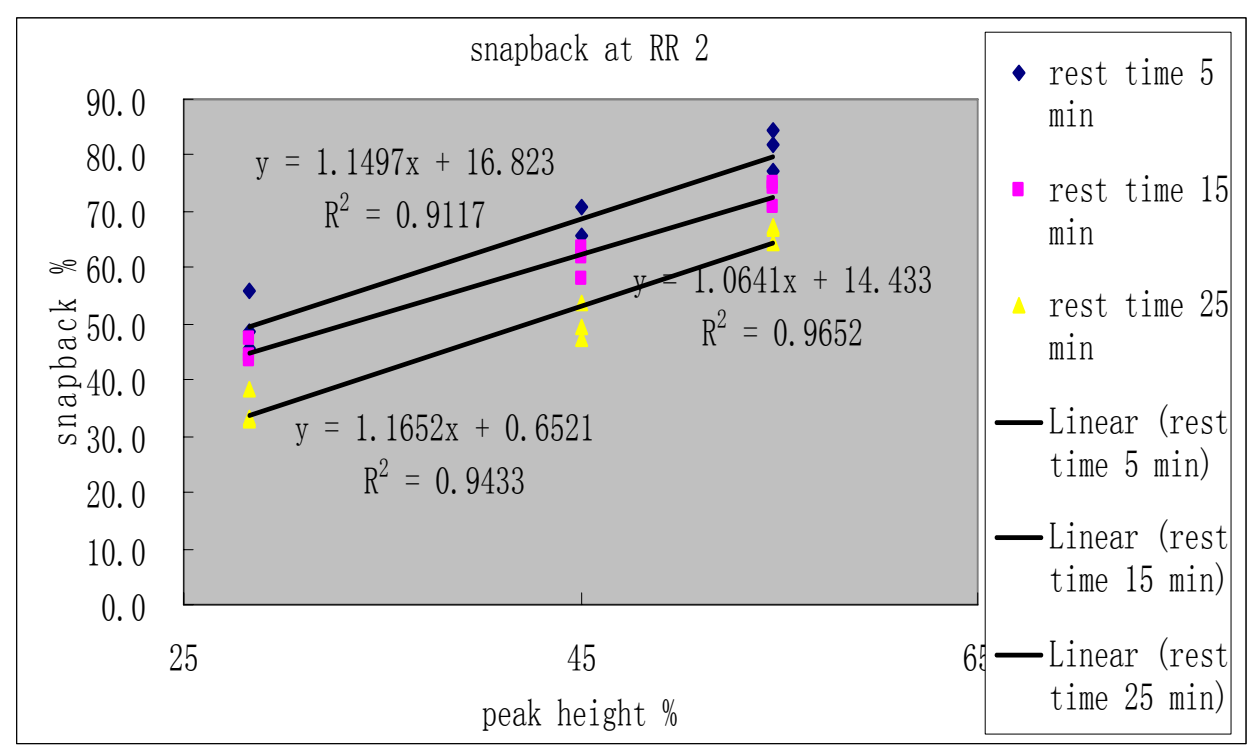

Figure A. 12 The snapback for the first flour set, correlated with Mixograph peak height using different rest times at $R R 2$ 
Table A. 13 The snapback for the first flour set, correlated with Mixograph peak height using different rest times at $\mathrm{RR} 2.5$

\begin{tabular}{|c|c|c|c|c|}
\hline & peak height \% & 5 & 15 & 25 \\
\hline bread flour & 54.67 & 113.7 & 99.9 & 80.9 \\
\hline bread flour & 54.67 & 100.5 & 95.6 & 84.4 \\
\hline bread flour & 54.67 & 116.6 & 96.5 & 87.7 \\
\hline 50/50 PB flour & 45.00 & 91.3 & 75.6 & 68.0 \\
\hline 50/50 PB flour & 45.00 & 91.1 & 80.9 & 66.0 \\
\hline 50/50 PB flour & 45.00 & 90.5 & 76.3 & 71.8 \\
\hline pastry flour & 28.33 & 72.8 & 60.7 & 56.4 \\
\hline pastry flour & 28.33 & 70.1 & 58.1 & 47.4 \\
\hline pastry flour & 28.33 & 71.6 & 61.7 & 54.9 \\
\hline
\end{tabular}

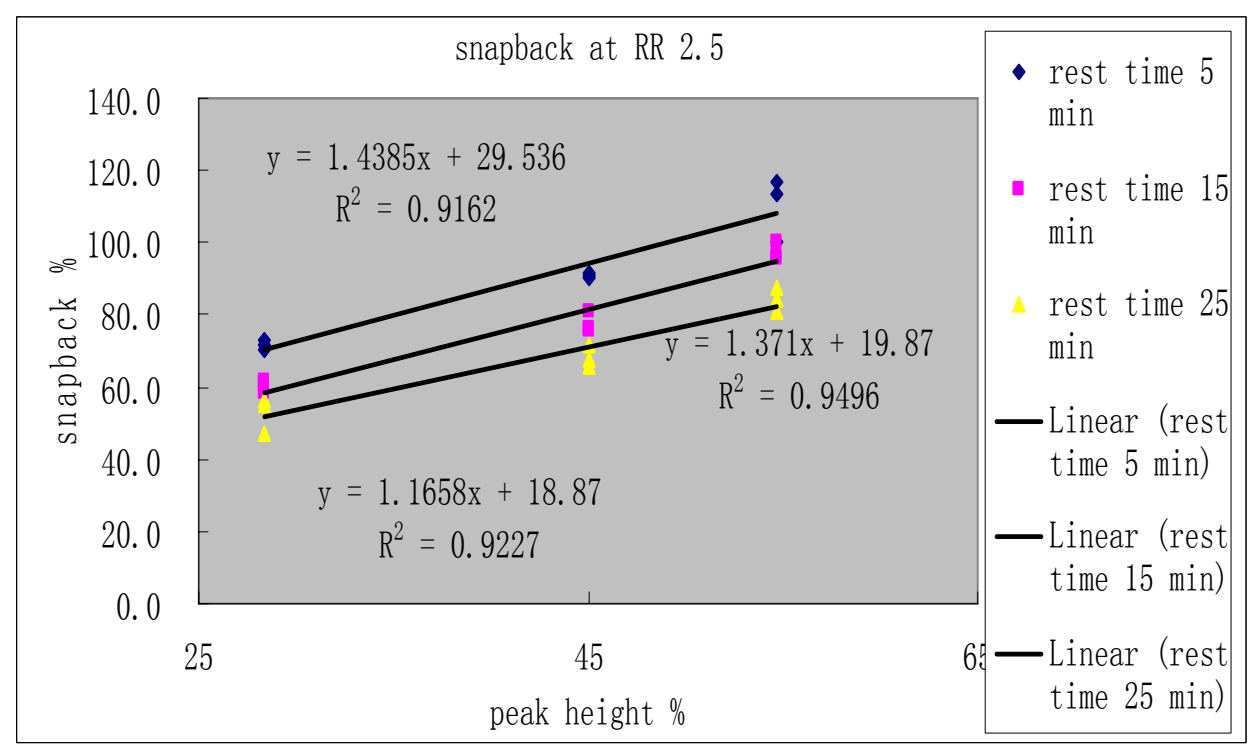

Figure A. 13 The snapback for the first flour set, correlated with Mixograph peak height using different rest times at $R R 2.5$ 
Table A. 14 The snapback for the first flour set, correlated with Mixograph peak height using different rest times at RR 3

\begin{tabular}{|c|c|c|c|c|}
\hline & peak height \% & 5 & 15 & 25 \\
\hline bread flour & 54.67 & 151.2 & 118.5 & 108.3 \\
\hline bread flour & 54.67 & 141.4 & 109.3 & 104.8 \\
\hline bread flour & 54.67 & 149.1 & 117.5 & 100.0 \\
\hline $50 / 50$ PB flour & 45.00 & 115.3 & 95.5 & 83.0 \\
\hline 50/50 PB flour & 45.00 & 121.7 & 94.8 & 78.1 \\
\hline 50/50 PB flour & 45.00 & 109.0 & 99.5 & 85.6 \\
\hline pastry flour & 28.33 & 77.3 & 74.2 & 60.0 \\
\hline pastry flour & 28.33 & 83.0 & 75.5 & 51.0 \\
\hline pastry flour & 28.33 & 88.1 & 72.1 & 67.2 \\
\hline
\end{tabular}

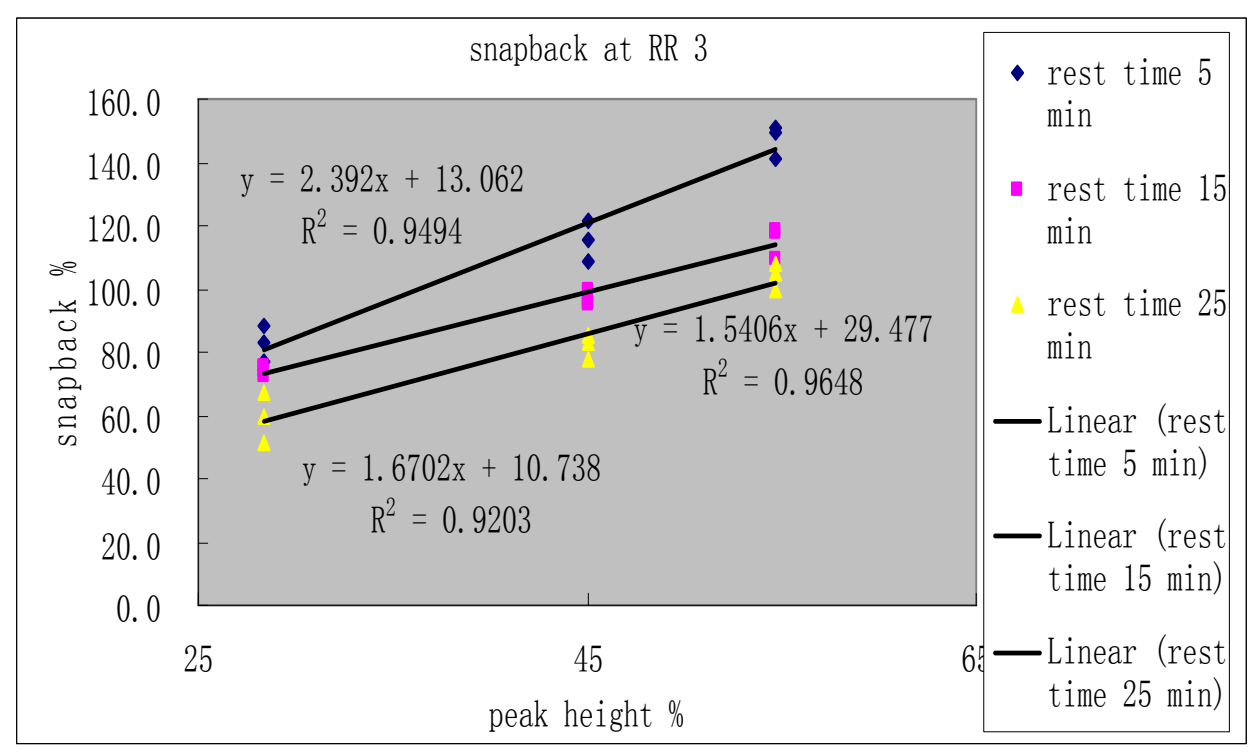

Figure A. 14 The snapback for the first flour set, correlated with Mixograph peak height using different rest times at $R R 3$ 
The snapback for the first flour set, correlated with Mixograph mixing time using different reduction ratios

Table A. 15 The snapback for the first flour set, correlated with Mixograph mixing time using different reduction ratios at $5 \mathrm{~min}$ rest time

\begin{tabular}{|c|c|c|c|c|c|}
\hline & mixing time $(\mathrm{min})$ & 1.5 & 2 & 2.5 & 3 \\
\hline bread flour & 3.25 & 55.7 & 84.3 & 113.7 & 151.2 \\
\hline bread flour & 3.25 & 50.6 & 77.0 & 100.5 & 141.4 \\
\hline bread flour & 3.25 & 57.4 & 81.9 & 116.6 & 149.1 \\
\hline $50 / 50$ PB flour & 2.82 & 54.1 & 70.7 & 91.3 & 115.3 \\
\hline $50 / 50$ PB flour & 2.82 & 49.1 & 62.9 & 91.1 & 121.7 \\
\hline $50 / 50$ PB flour & 2.82 & 48.0 & 65.5 & 90.5 & 109.0 \\
\hline pastry flour & 1.25 & 44.2 & 48.8 & 72.8 & 77.3 \\
\hline pastry flour & 1.25 & 44.0 & 45.8 & 70.1 & 83.0 \\
\hline pastry flour & 1.25 & 44.3 & 56.0 & 71.6 & 88.1 \\
\hline
\end{tabular}

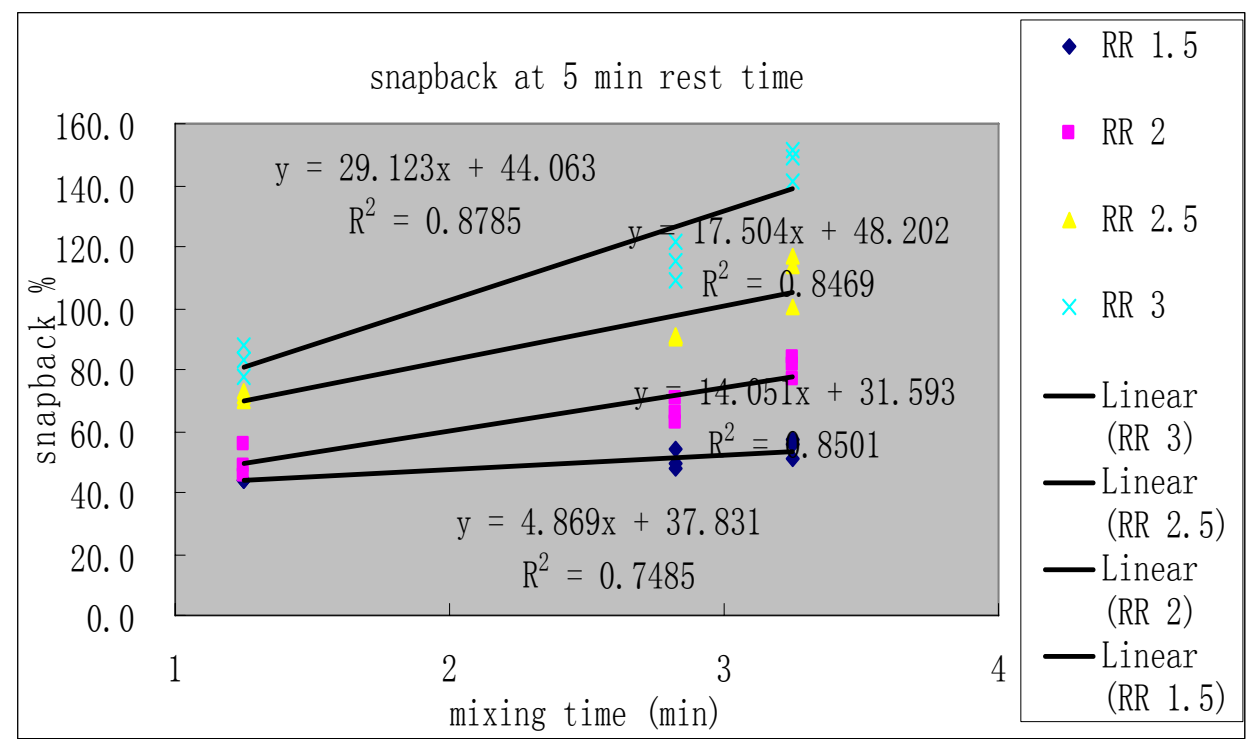

Figure A. 15 The snapback for the first flour set, correlated with Mixograph mixing time using different reduction ratios at 5 min rest time 
Table A. 16 The snapback for the first flour set, correlated with Mixograph mixing time using different reduction ratios at 15 min rest time

\begin{tabular}{|c|c|c|c|c|c|}
\hline & mixing time (min) & 1.5 & 2 & 2.5 & 3 \\
\hline bread flour & 3.25 & 48.5 & 70.7 & 99.9 & 118.5 \\
\hline bread flour & 3.25 & 48.5 & 74.1 & 95.6 & 109.3 \\
\hline bread flour & 3.25 & 45.3 & 75.2 & 96.5 & 117.5 \\
\hline 50/50 PB flour & 2.82 & 42.3 & 57.9 & 75.6 & 95.5 \\
\hline 50/50 PB flour & 2.82 & 39.1 & 62.0 & 80.9 & 94.8 \\
\hline 50/50 PB flour & 2.82 & 38.9 & 63.6 & 76.3 & 99.5 \\
\hline pastry flour & 1.25 & 27.2 & 38.3 & 56.4 & 60.0 \\
\hline pastry flour & 1.25 & 28.9 & 33.2 & 47.4 & 51.0 \\
\hline pastry flour & 1.25 & 30.0 & 32.7 & 54.9 & 67.2 \\
\hline
\end{tabular}

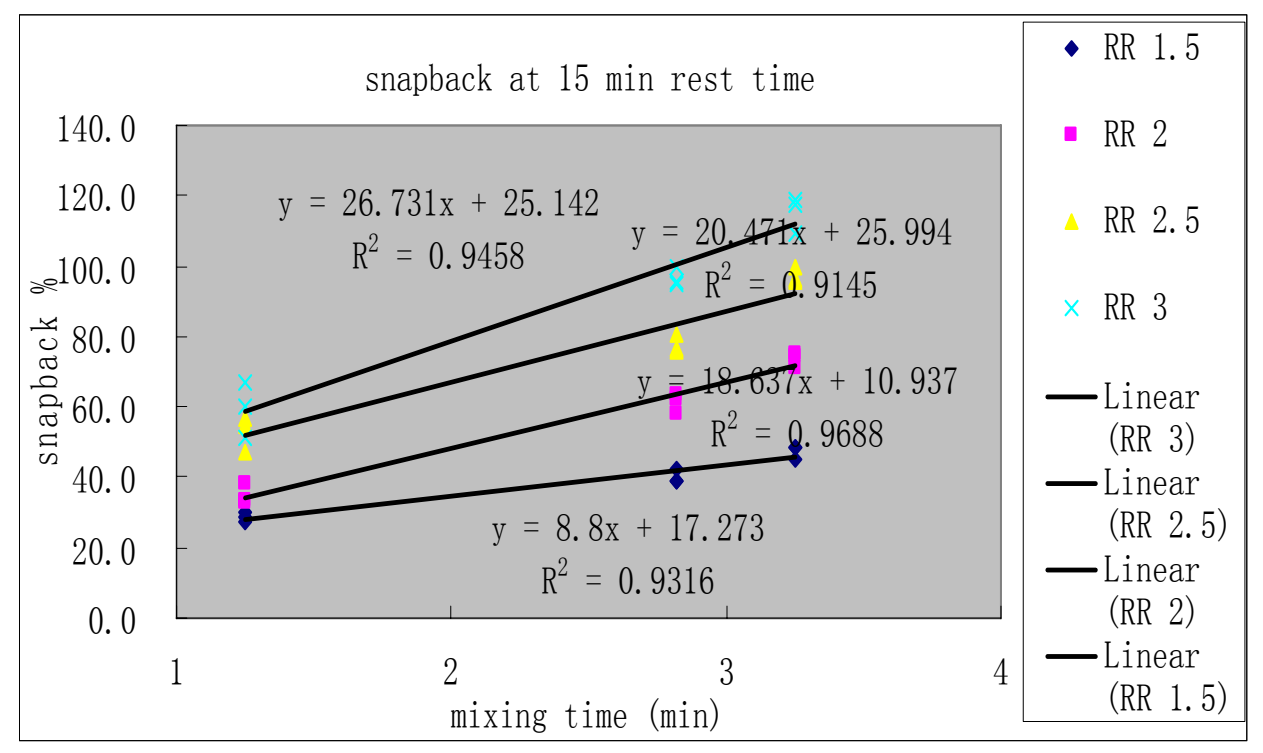

Figure A. 16 The snapback for the first flour set, correlated with Mixograph mixing time using different reduction ratios at 15 min rest time 
Table A. 17 The snapback for the first flour set, correlated with Mixograph mixing time using different reduction ratios at 25 min rest time

\begin{tabular}{|c|c|c|c|c|c|}
\hline & mixing time $(\mathrm{min})$ & 1.5 & 2 & 2.5 & 3 \\
\hline bread flour & 3.25 & 41.2 & 67.1 & 80.9 & 108.3 \\
\hline bread flour & 3.25 & 47.5 & 67.3 & 84.4 & 104.8 \\
\hline bread flour & 3.25 & 48.1 & 64.2 & 87.7 & 100.0 \\
\hline $50 / 50$ PB flour & 2.82 & 35.8 & 53.8 & 68.0 & 83.0 \\
\hline $50 / 50$ PB flour & 2.82 & 32.8 & 47.2 & 66.0 & 78.1 \\
\hline $50 / 50$ PB flour & 2.82 & 34.6 & 49.5 & 71.8 & 85.6 \\
\hline pastry flour & 1.25 & 27.2 & 38.3 & 56.4 & 60.0 \\
\hline pastry flour & 1.25 & 28.9 & 33.2 & 47.4 & 51.0 \\
\hline pastry flour & 1.25 & 30.0 & 32.7 & 54.9 & 67.2 \\
\hline
\end{tabular}

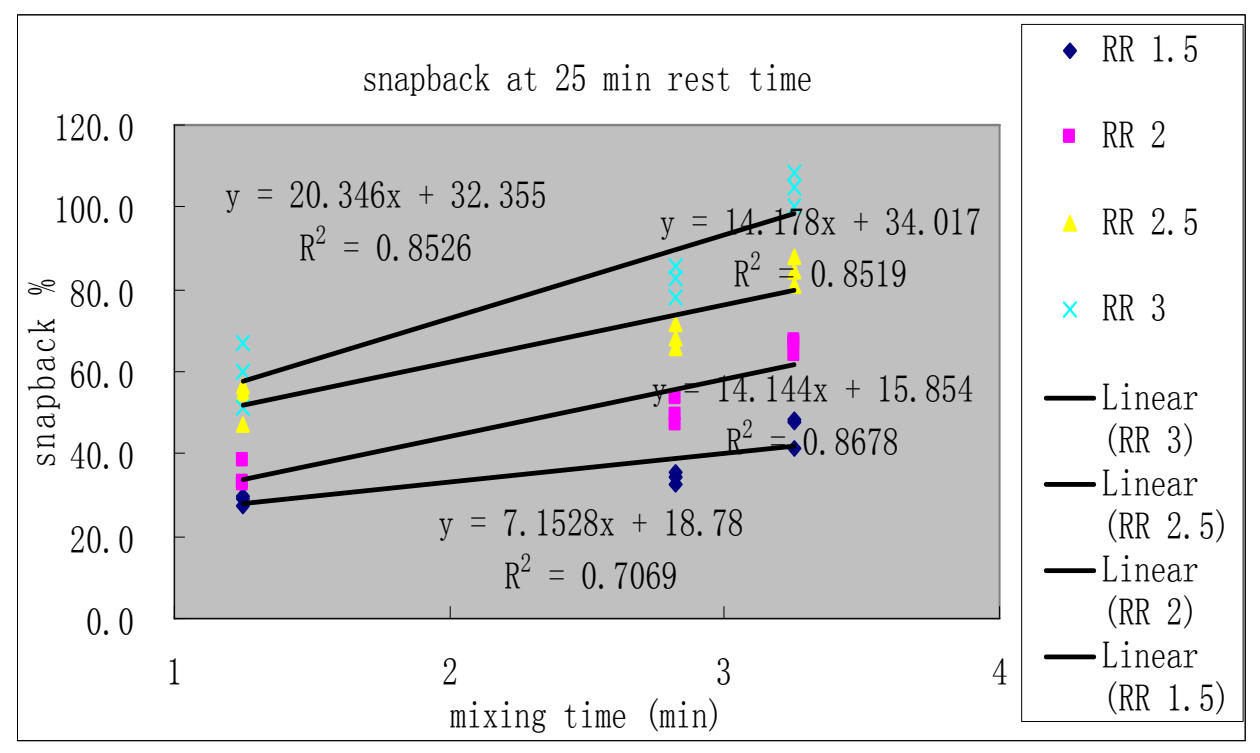

Figure A. 17 The snapback for the first flour set, correlated with Mixograph mixing time using different reduction ratios at 25 min rest time 
The snapback for the first flour set, correlated with Mixograph mixing time using different rest times

Table A. 18 The snapback for the first flour set, correlated with Mixograph mixing time using different rest times at RR 1.5

\begin{tabular}{|c|c|c|c|c|}
\hline & mixing time (min) & 5 & 15 & 25 \\
\hline bread flour & 3.25 & 55.7 & 48.5 & 41.2 \\
\hline bread flour & 3.25 & 50.6 & 48.5 & 47.5 \\
\hline bread flour & 3.25 & 57.4 & 45.3 & 48.1 \\
\hline $50 / 50$ PB flour & 2.82 & 54.1 & 42.3 & 35.8 \\
\hline $50 / 50$ PB flour & 2.82 & 49.1 & 39.1 & 32.8 \\
\hline $50 / 50$ PB flour & 2.82 & 48.0 & 38.9 & 34.6 \\
\hline pastry flour & 1.25 & 44.2 & 29.9 & 27.2 \\
\hline pastry flour & 1.25 & 44.0 & 33.6 & 28.9 \\
\hline pastry flour & 1.25 & 44.3 & 33.7 & 30.0 \\
\hline
\end{tabular}

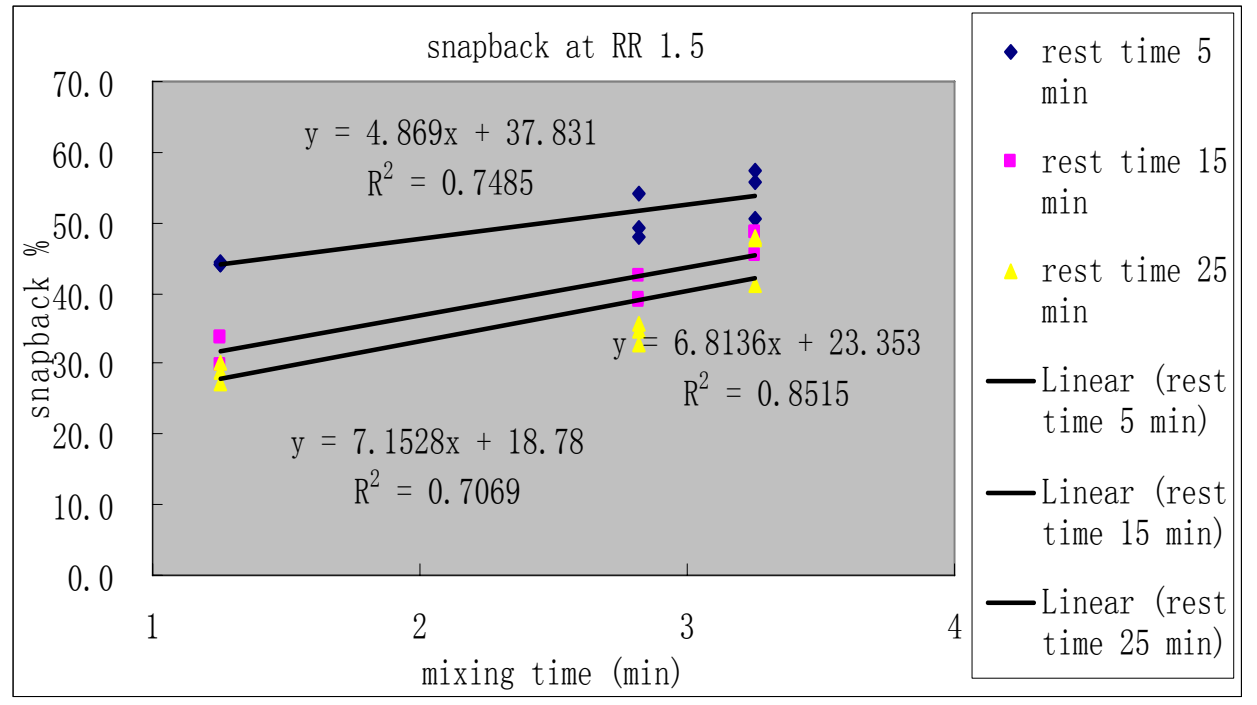

Figure A. 18 The snapback for the first flour set, correlated with Mixograph mixing time using different rest times at RR 1.5 
Table A. 19 The snapback for the first flour set, correlated with Mixograph mixing time using different rest times at $R R 2$

\begin{tabular}{|c|c|c|c|c|}
\hline & mixing time (min) & 5 & 15 & 25 \\
\hline bread flour & 3.25 & 84.3 & 70.7 & 67.1 \\
\hline bread flour & 3.25 & 77.0 & 74.1 & 67.3 \\
\hline bread flour & 3.25 & 81.9 & 75.2 & 64.2 \\
\hline 50/50 PB flour & 2.82 & 70.7 & 57.9 & 53.8 \\
\hline 50/50 PB flour & 2.82 & 62.9 & 62.0 & 47.2 \\
\hline 50/50 PB flour & 2.82 & 65.5 & 63.6 & 49.5 \\
\hline pastry flour & 1.25 & 48.8 & 47.4 & 38.3 \\
\hline pastry flour & 1.25 & 45.8 & 44.3 & 33.2 \\
\hline pastry flour & 1.25 & 56.0 & 43.3 & 32.7 \\
\hline
\end{tabular}

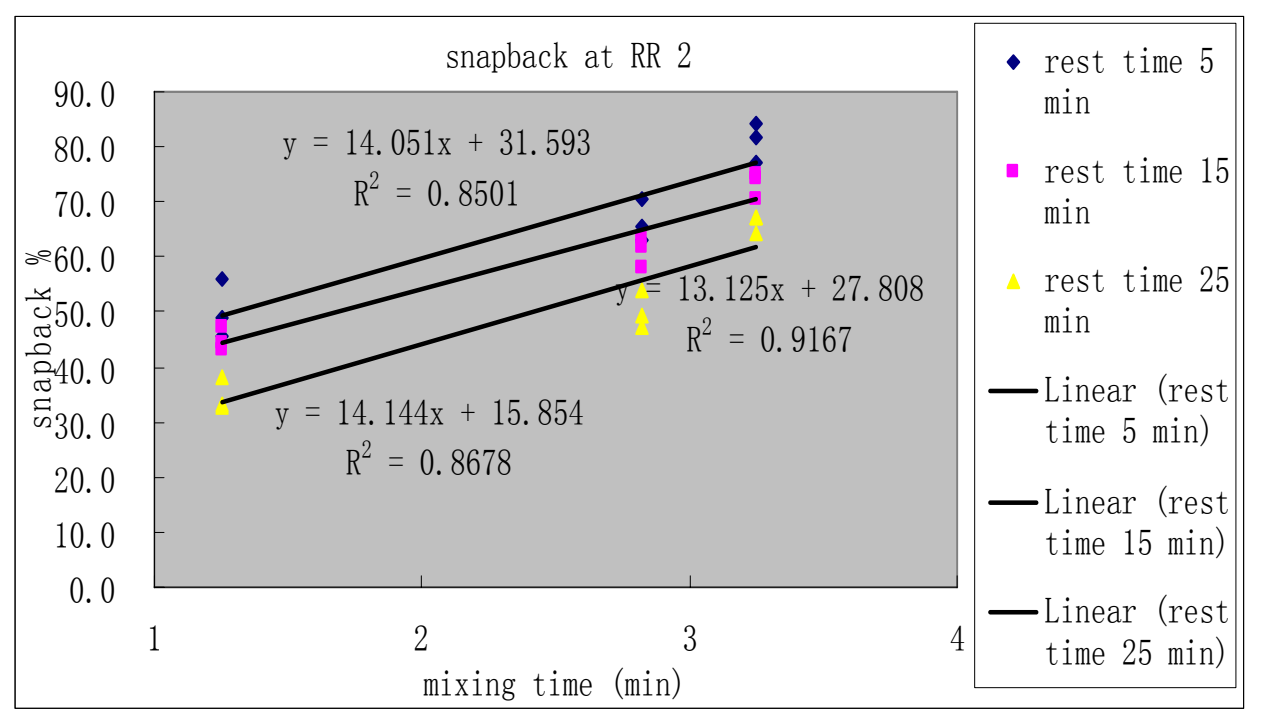

Figure A. 19 The snapback for the first flour set, correlated with Mixograph mixing time using different rest times at RR 2 
Table A. 20 The snapback for the first flour set, correlated with Mixograph mixing time using different rest times at $\mathrm{RR} 2.5$

\begin{tabular}{|c|c|c|c|c|}
\hline & mixing time (min) & 5 & 15 & 25 \\
\hline bread flour & 3.25 & 113.7 & 99.9 & 80.9 \\
\hline bread flour & 3.25 & 100.5 & 95.6 & 84.4 \\
\hline bread flour & 3.25 & 116.6 & 96.5 & 87.7 \\
\hline 50/50 PB flour & 2.82 & 91.3 & 75.6 & 68.0 \\
\hline 50/50 PB flour & 2.82 & 91.1 & 80.9 & 66.0 \\
\hline 50/50 PB flour & 2.82 & 90.5 & 76.3 & 71.8 \\
\hline pastry flour & 1.25 & 72.8 & 60.7 & 56.4 \\
\hline pastry flour & 1.25 & 70.1 & 58.1 & 47.4 \\
\hline pastry flour & 1.25 & 71.6 & 61.7 & 54.9 \\
\hline
\end{tabular}

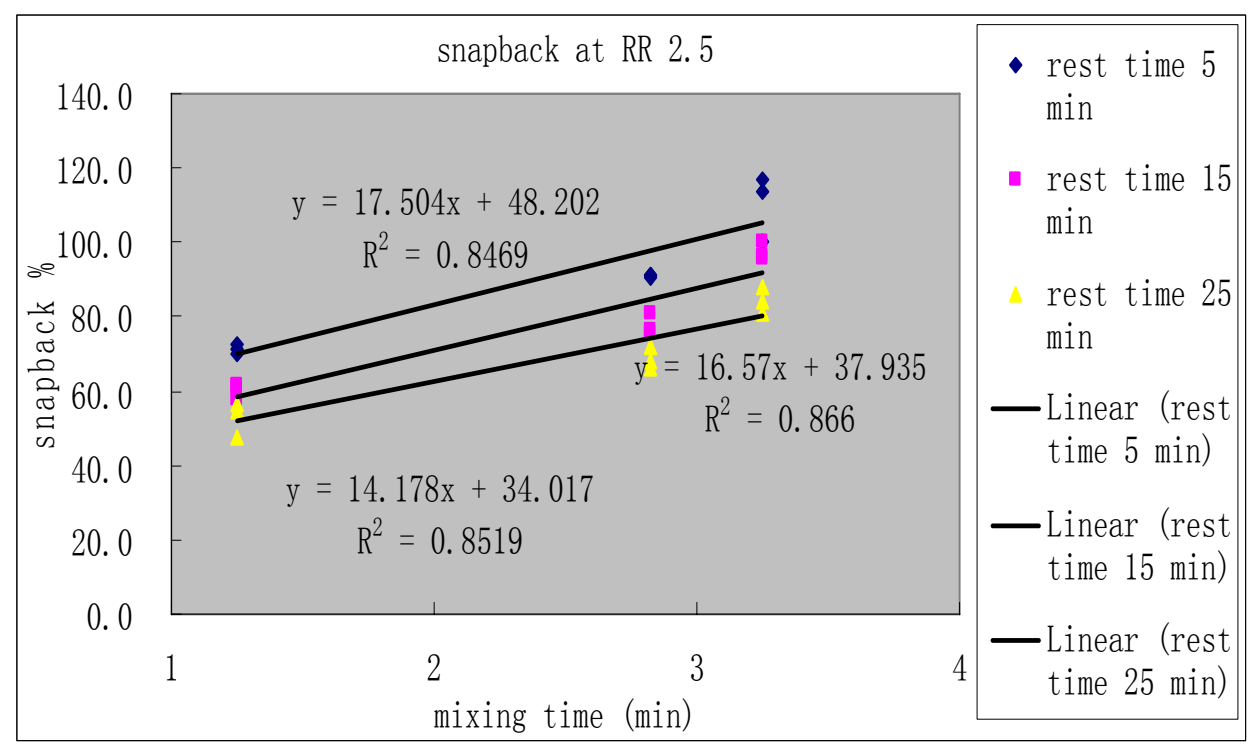

Figure A. 20 The snapback for the first flour set, correlated with Mixograph mixing time using different rest times at $R R 2.5$ 
Table A. 21 The snapback for the first flour set, correlated with Mixograph mixing time using different rest times at RR 3

\begin{tabular}{|c|c|c|c|c|}
\hline & mixing time (min) & 5 & 15 & 25 \\
\hline bread flour & 3.25 & 151.2 & 118.5 & 108.3 \\
\hline bread flour & 3.25 & 141.4 & 109.3 & 104.8 \\
\hline bread flour & 3.25 & 149.1 & 117.5 & 100.0 \\
\hline 50/50 PB flour & 2.82 & 115.3 & 95.5 & 83.0 \\
\hline 50/50 PB flour & 2.82 & 121.7 & 94.8 & 78.1 \\
\hline 50/50 PB flour & 2.82 & 109.0 & 99.5 & 85.6 \\
\hline pastry flour & 1.25 & 77.3 & 74.2 & 60.0 \\
\hline pastry flour & 1.25 & 83.0 & 75.5 & 51.0 \\
\hline pastry flour & 1.25 & 88.1 & 72.1 & 67.2 \\
\hline
\end{tabular}

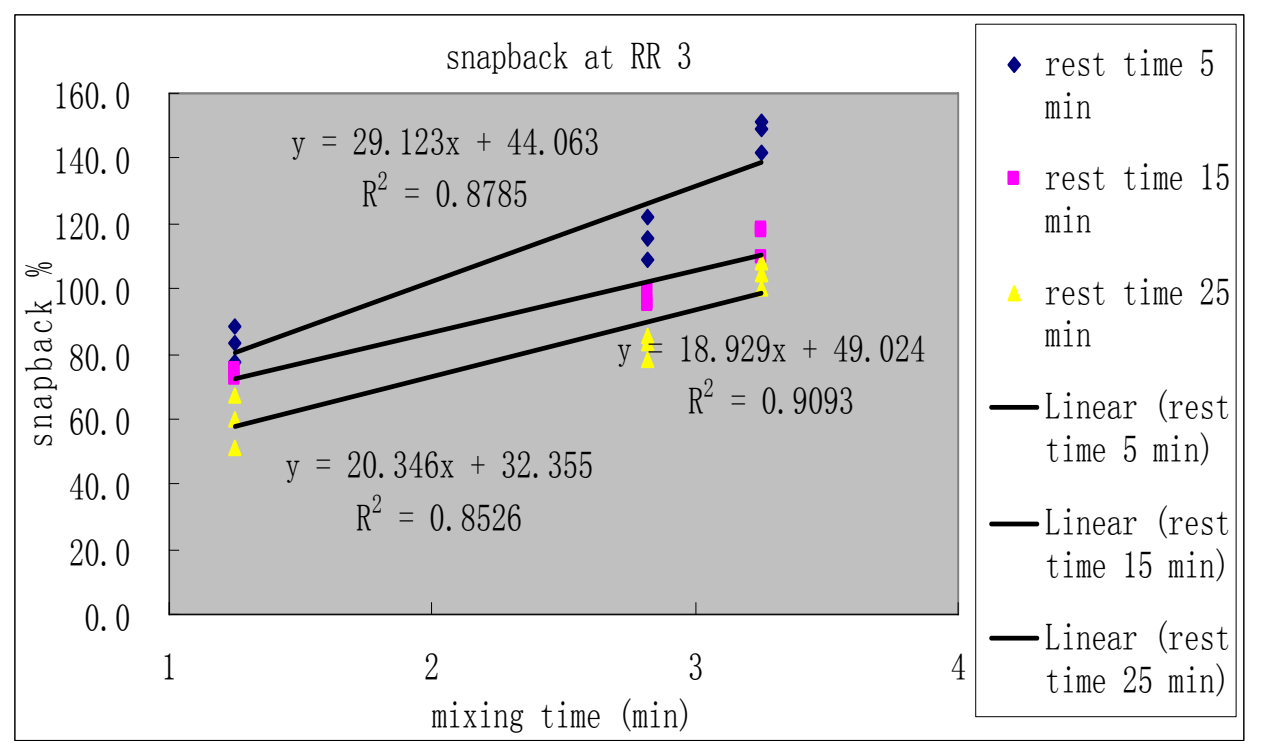

Figure A. 21 The snapback for the first flour set, correlated with Mixograph mixing time using different rest times at RR 3 


\title{
Appendix B - ALL RAW DATA
}

\author{
The first flour set
}

Table B.1 The snapback relative to flour properties and process conditions for the first flour set

The second flour set

Table B.2 The snapback relative to flour properties and process conditions for the first flour set

\section{The third flour set}

Table B.3 The snapback relative to flour properties and process conditions for the first flour set 
Table B. 1 The snapback relative to flour properties and process conditions for the first flour set

\begin{tabular}{|c|c|c|c|c|c|c|c|c|c|c|}
\hline & snapback & $\begin{array}{l}\text { rest } \\
\text { time }\end{array}$ & $\begin{array}{l}\text { reduction } \\
\text { ratio }\end{array}$ & $\begin{array}{l}\text { Mixo } \\
\text { Work }\end{array}$ & $\begin{array}{l}\text { Mixo peak } \\
\text { height }\end{array}$ & $\begin{array}{l}\text { protein } \\
\text { content }\end{array}$ & $\begin{array}{l}\text { Alveo } \\
\mathrm{P} / \mathrm{L}\end{array}$ & $\begin{array}{l}\text { Alveo } \\
\text { work }\end{array}$ & $\begin{array}{c}\text { Mixo } \\
\text { mixing time }\end{array}$ & $\begin{array}{c}\text { Farino water } \\
\text { absorption }\end{array}$ \\
\hline 1 & 55.7 & 5 & 1.5 & 129.46 & 54.67 & 13.69 & 0.8 & 366 & 3.25 & 64.73 \\
\hline 2 & 50.6 & 5 & 1.5 & 129.46 & 54.67 & 13.69 & 0.8 & 366 & 3.25 & 64.73 \\
\hline 3 & 57.4 & 5 & 1.5 & 129.46 & 54.67 & 13.69 & 0.8 & 366 & 3.25 & 64.73 \\
\hline 4 & 54.1 & 5 & 1.5 & 107.16 & 45 & 10.46 & 0.68 & 197 & 2.82 & 57.93 \\
\hline 5 & 49.1 & 5 & 1.5 & 107.16 & 45 & 10.46 & 0.68 & 197 & 2.82 & 57.93 \\
\hline 6 & 48 & 5 & 1.5 & 107.16 & 45 & 10.46 & 0.68 & 197 & 2.82 & 57.93 \\
\hline 7 & 44.2 & 5 & 1.5 & 33.33 & 28.33 & 7.28 & 0.63 & 81 & 1.25 & 53.5 \\
\hline 8 & 44 & 5 & 1.5 & 33.33 & 28.33 & 7.28 & 0.63 & 81 & 1.25 & 53.5 \\
\hline 9 & 44.3 & 5 & 1.5 & 33.33 & 28.33 & 7.28 & 0.63 & 81 & 1.25 & 53.5 \\
\hline 10 & 84.3 & 5 & 2 & 129.46 & 54.67 & 13.69 & 0.8 & 366 & 3.25 & 64.73 \\
\hline 11 & 77 & 5 & 2 & 129.46 & 54.67 & 13.69 & 0.8 & 366 & 3.25 & 64.73 \\
\hline 12 & 81.9 & 5 & 2 & 129.46 & 54.67 & 13.69 & 0.8 & 366 & 3.25 & 64.73 \\
\hline 13 & 70.7 & 5 & 2 & 107.16 & 45 & 10.46 & 0.68 & 197 & 2.82 & 57.93 \\
\hline 14 & 62.9 & 5 & 2 & 107.16 & 45 & 10.46 & 0.68 & 197 & 2.82 & 57.93 \\
\hline 15 & 65.5 & 5 & 2 & 107.16 & 45 & 10.46 & 0.68 & 197 & 2.82 & 57.93 \\
\hline 16 & 48.8 & 5 & 2 & 33.33 & 28.33 & 7.28 & 0.63 & 81 & 1.25 & 53.5 \\
\hline 17 & 45.8 & 5 & 2 & 33.33 & 28.33 & 7.28 & 0.63 & 81 & 1.25 & 53.5 \\
\hline 18 & 56 & 5 & 2 & 33.33 & 28.33 & 7.28 & 0.63 & 81 & 1.25 & 53.5 \\
\hline 19 & 113.7 & 5 & 2.5 & 129.46 & 54.67 & 13.69 & 0.8 & 366 & 3.25 & 64.73 \\
\hline 20 & 100.5 & 5 & 2.5 & 129.46 & 54.67 & 13.69 & 0.8 & 366 & 3.25 & 64.73 \\
\hline 21 & 116.6 & 5 & 2.5 & 129.46 & 54.67 & 13.69 & 0.8 & 366 & 3.25 & 64.73 \\
\hline 22 & 91.3 & 5 & 2.5 & 107.16 & 45 & 10.46 & 0.68 & 197 & 2.82 & 57.93 \\
\hline 23 & 91.1 & 5 & 2.5 & 107.16 & 45 & 10.46 & 0.68 & 197 & 2.82 & 57.93 \\
\hline 24 & 90.5 & 5 & 2.5 & 107.16 & 45 & 10.46 & 0.68 & 197 & 2.82 & 57.93 \\
\hline 25 & 72.8 & 5 & 2.5 & 33.33 & 28.33 & 7.28 & 0.63 & 81 & 1.25 & 53.5 \\
\hline 26 & 70.1 & 5 & 2.5 & 33.33 & 28.33 & 7.28 & 0.63 & 81 & 1.25 & 53.5 \\
\hline 27 & 71.6 & 5 & 2.5 & 33.33 & 28.33 & 7.28 & 0.63 & 81 & 1.25 & 53.5 \\
\hline
\end{tabular}

To be continued 


\begin{tabular}{|c|c|c|c|c|c|c|c|c|c|c|}
\hline & snapback & $\begin{array}{l}\text { rest } \\
\text { time }\end{array}$ & $\begin{array}{l}\text { reduction } \\
\text { ratio }\end{array}$ & $\begin{array}{l}\text { Mixo } \\
\text { Work }\end{array}$ & $\begin{array}{l}\text { Mixo peak } \\
\text { height }\end{array}$ & $\begin{array}{l}\text { protein } \\
\text { content }\end{array}$ & $\begin{array}{l}\text { Alveo } \\
\text { P/L }\end{array}$ & $\begin{array}{l}\text { Alveo } \\
\text { work }\end{array}$ & $\begin{array}{c}\text { Mixo } \\
\text { mixing time }\end{array}$ & $\begin{array}{c}\text { Farino water } \\
\text { absorption }\end{array}$ \\
\hline 28 & 151.2 & 5 & 3 & 129.46 & 54.67 & 13.69 & 0.8 & 366 & 3.25 & 64.73 \\
\hline 29 & 141.4 & 5 & 3 & 129.46 & 54.67 & 13.69 & 0.8 & 366 & 3.25 & 64.73 \\
\hline 30 & 149.1 & 5 & 3 & 129.46 & 54.67 & 13.69 & 0.8 & 366 & 3.25 & 64.73 \\
\hline 31 & 115.3 & 5 & 3 & 107.16 & 45 & 10.46 & 0.68 & 197 & 2.82 & 57.93 \\
\hline 32 & 121.7 & 5 & 3 & 107.16 & 45 & 10.46 & 0.68 & 197 & 2.82 & 57.93 \\
\hline 33 & 109 & 5 & 3 & 107.16 & 45 & 10.46 & 0.68 & 197 & 2.82 & 57.93 \\
\hline 34 & 77.3 & 5 & 3 & 33.33 & 28.33 & 7.28 & 0.63 & 81 & 1.25 & 53.5 \\
\hline 35 & 83 & 5 & 3 & 33.33 & 28.33 & 7.28 & 0.63 & 81 & 1.25 & 53.5 \\
\hline 36 & 88.1 & 5 & 3 & 33.33 & 28.33 & 7.28 & 0.63 & 81 & 1.25 & 53.5 \\
\hline 37 & 48.5 & 15 & 1.5 & 129.46 & 54.67 & 13.69 & 0.8 & 366 & 3.25 & 64.73 \\
\hline 38 & 48.5 & 15 & 1.5 & 129.46 & 54.67 & 13.69 & 0.8 & 366 & 3.25 & 64.73 \\
\hline 39 & 45.3 & 15 & 1.5 & 129.46 & 54.67 & 13.69 & 0.8 & 366 & 3.25 & 64.73 \\
\hline 40 & 42.3 & 15 & 1.5 & 107.16 & 45 & 10.46 & 0.68 & 197 & 2.82 & 57.93 \\
\hline 41 & 39.1 & 15 & 1.5 & 107.16 & 45 & 10.46 & 0.68 & 197 & 2.82 & 57.93 \\
\hline 42 & 38.9 & 15 & 1.5 & 107.16 & 45 & 10.46 & 0.68 & 197 & 2.82 & 57.93 \\
\hline 43 & 27.2 & 15 & 1.5 & 33.33 & 28.33 & 7.28 & 0.63 & 81 & 1.25 & 53.5 \\
\hline 44 & 28.9 & 15 & 1.5 & 33.33 & 28.33 & 7.28 & 0.63 & 81 & 1.25 & 53.5 \\
\hline 45 & 30 & 15 & 1.5 & 33.33 & 28.33 & 7.28 & 0.63 & 81 & 1.25 & 53.5 \\
\hline 46 & 70.7 & 15 & 2 & 129.46 & 54.67 & 13.69 & 0.8 & 366 & 3.25 & 64.73 \\
\hline 47 & 74.1 & 15 & 2 & 129.46 & 54.67 & 13.69 & 0.8 & 366 & 3.25 & 64.73 \\
\hline 48 & 75.2 & 15 & 2 & 129.46 & 54.67 & 13.69 & 0.8 & 366 & 3.25 & 64.73 \\
\hline 49 & 57.9 & 15 & 2 & 107.16 & 45 & 10.46 & 0.68 & 197 & 2.82 & 57.93 \\
\hline 50 & 62 & 15 & 2 & 107.16 & 45 & 10.46 & 0.68 & 197 & 2.82 & 57.93 \\
\hline 51 & 63.6 & 15 & 2 & 107.16 & 45 & 10.46 & 0.68 & 197 & 2.82 & 57.93 \\
\hline 52 & 38.3 & 15 & 2 & 33.33 & 28.33 & 7.28 & 0.63 & 81 & 1.25 & 53.5 \\
\hline 53 & 33.2 & 15 & 2 & 33.33 & 28.33 & 7.28 & 0.63 & 81 & 1.25 & 53.5 \\
\hline 54 & 32.7 & 15 & 2 & 33.33 & 28.33 & 7.28 & 0.63 & 81 & 1.25 & 53.5 \\
\hline
\end{tabular}

To be continued 


\begin{tabular}{|c|c|c|c|c|c|c|c|c|c|c|}
\hline & snapback & $\begin{array}{l}\text { rest } \\
\text { time }\end{array}$ & $\begin{array}{l}\text { reduction } \\
\text { ratio }\end{array}$ & $\begin{array}{l}\text { Mixo } \\
\text { Work }\end{array}$ & $\begin{array}{c}\text { Mixo peak } \\
\text { height }\end{array}$ & $\begin{array}{l}\text { protein } \\
\text { content }\end{array}$ & $\begin{array}{l}\text { Alveo } \\
\mathrm{P} / \mathrm{L}\end{array}$ & $\begin{array}{l}\text { Alveo } \\
\text { work }\end{array}$ & $\begin{array}{c}\text { Mixo } \\
\text { mixing time }\end{array}$ & $\begin{array}{c}\text { Farino water } \\
\text { absorption }\end{array}$ \\
\hline 55 & 99.9 & 15 & 2.5 & 129.46 & 54.67 & 13.69 & 0.8 & 366 & 3.25 & 64.73 \\
\hline 56 & 95.6 & 15 & 2.5 & 129.46 & 54.67 & 13.69 & 0.8 & 366 & 3.25 & 64.73 \\
\hline 57 & 96.5 & 15 & 2.5 & 129.46 & 54.67 & 13.69 & 0.8 & 366 & 3.25 & 64.73 \\
\hline 58 & 75.6 & 15 & 2.5 & 107.16 & 45 & 10.46 & 0.68 & 197 & 2.82 & 57.93 \\
\hline 59 & 80.9 & 15 & 2.5 & 107.16 & 45 & 10.46 & 0.68 & 197 & 2.82 & 57.93 \\
\hline 60 & 76.3 & 15 & 2.5 & 107.16 & 45 & 10.46 & 0.68 & 197 & 2.82 & 57.93 \\
\hline 61 & 56.4 & 15 & 2.5 & 33.33 & 28.33 & 7.28 & 0.63 & 81 & 1.25 & 53.5 \\
\hline 62 & 47.4 & 15 & 2.5 & 33.33 & 28.33 & 7.28 & 0.63 & 81 & 1.25 & 53.5 \\
\hline 63 & 54.9 & 15 & 2.5 & 33.33 & 28.33 & 7.28 & 0.63 & 81 & 1.25 & 53.5 \\
\hline 64 & 118.5 & 15 & 3 & 129.46 & 54.67 & 13.69 & 0.8 & 366 & 3.25 & 64.73 \\
\hline 65 & 109.3 & 15 & 3 & 129.46 & 54.67 & 13.69 & 0.8 & 366 & 3.25 & 64.73 \\
\hline 66 & 117.5 & 15 & 3 & 129.46 & 54.67 & 13.69 & 0.8 & 366 & 3.25 & 64.73 \\
\hline 67 & 95.5 & 15 & 3 & 107.16 & 45 & 10.46 & 0.68 & 197 & 2.82 & 57.93 \\
\hline 68 & 94.8 & 15 & 3 & 107.16 & 45 & 10.46 & 0.68 & 197 & 2.82 & 57.93 \\
\hline 69 & 99.5 & 15 & 3 & 107.16 & 45 & 10.46 & 0.68 & 197 & 2.82 & 57.93 \\
\hline 70 & 60 & 15 & 3 & 33.33 & 28.33 & 7.28 & 0.63 & 81 & 1.25 & 53.5 \\
\hline 71 & 51 & 15 & 3 & 33.33 & 28.33 & 7.28 & 0.63 & 81 & 1.25 & 53.5 \\
\hline 72 & 67.2 & 15 & 3 & 33.33 & 28.33 & 7.28 & 0.63 & 81 & 1.25 & 53.5 \\
\hline 73 & 41.2 & 25 & 1.5 & 129.46 & 54.67 & 13.69 & 0.8 & 366 & 3.25 & 64.73 \\
\hline 74 & 47.5 & 25 & 1.5 & 129.46 & 54.67 & 13.69 & 0.8 & 366 & 3.25 & 64.73 \\
\hline 75 & 48.1 & 25 & 1.5 & 129.46 & 54.67 & 13.69 & 0.8 & 366 & 3.25 & 64.73 \\
\hline 76 & 35.8 & 25 & 1.5 & 107.16 & 45 & 10.46 & 0.68 & 197 & 2.82 & 57.93 \\
\hline 77 & 32.8 & 25 & 1.5 & 107.16 & 45 & 10.46 & 0.68 & 197 & 2.82 & 57.93 \\
\hline 78 & 34.6 & 25 & 1.5 & 107.16 & 45 & 10.46 & 0.68 & 197 & 2.82 & 57.93 \\
\hline 79 & 27.2 & 25 & 1.5 & 33.33 & 28.33 & 7.28 & 0.63 & 81 & 1.25 & 53.5 \\
\hline 80 & 28.9 & 25 & 1.5 & 33.33 & 28.33 & 7.28 & 0.63 & 81 & 1.25 & 53.5 \\
\hline 81 & 30 & 25 & 1.5 & 33.33 & 28.33 & 7.28 & 0.63 & 81 & 1.25 & 53.5 \\
\hline
\end{tabular}

To be continued 


\begin{tabular}{|c|c|c|c|c|c|c|c|c|c|c|}
\hline & snapback & $\begin{array}{l}\text { rest } \\
\text { time }\end{array}$ & $\begin{array}{l}\text { reduction } \\
\text { ratio }\end{array}$ & $\begin{array}{l}\text { Mixo } \\
\text { Work }\end{array}$ & $\begin{array}{l}\text { Mixo peak } \\
\text { height }\end{array}$ & $\begin{array}{l}\text { protein } \\
\text { content }\end{array}$ & $\begin{array}{l}\text { Alveo } \\
\mathrm{P} / \mathrm{L}\end{array}$ & $\begin{array}{l}\text { Alveo } \\
\text { work }\end{array}$ & $\begin{array}{c}\text { Mixo } \\
\text { mixing time }\end{array}$ & $\begin{array}{c}\text { Farino water } \\
\text { absorption }\end{array}$ \\
\hline 82 & 67.1 & 25 & 2 & 129.46 & 54.67 & 13.69 & 0.8 & 366 & 3.25 & 64.73 \\
\hline 83 & 67.3 & 25 & 2 & 129.46 & 54.67 & 13.69 & 0.8 & 366 & 3.25 & 64.73 \\
\hline 84 & 64.2 & 25 & 2 & 129.46 & 54.67 & 13.69 & 0.8 & 366 & 3.25 & 64.73 \\
\hline 85 & 53.8 & 25 & 2 & 107.16 & 45 & 10.46 & 0.68 & 197 & 2.82 & 57.93 \\
\hline 86 & 47.2 & 25 & 2 & 107.16 & 45 & 10.46 & 0.68 & 197 & 2.82 & 57.93 \\
\hline 87 & 49.5 & 25 & 2 & 107.16 & 45 & 10.46 & 0.68 & 197 & 2.82 & 57.93 \\
\hline 88 & 38.3 & 25 & 2 & 33.33 & 28.33 & 7.28 & 0.63 & 81 & 1.25 & 53.5 \\
\hline 89 & 33.2 & 25 & 2 & 33.33 & 28.33 & 7.28 & 0.63 & 81 & 1.25 & 53.5 \\
\hline 90 & 32.7 & 25 & 2 & 33.33 & 28.33 & 7.28 & 0.63 & 81 & 1.25 & 53.5 \\
\hline 91 & 80.9 & 25 & 2.5 & 129.46 & 54.67 & 13.69 & 0.8 & 366 & 3.25 & 64.73 \\
\hline 92 & 84.4 & 25 & 2.5 & 129.46 & 54.67 & 13.69 & 0.8 & 366 & 3.25 & 64.73 \\
\hline 93 & 87.7 & 25 & 2.5 & 129.46 & 54.67 & 13.69 & 0.8 & 366 & 3.25 & 64.73 \\
\hline 94 & 68 & 25 & 2.5 & 107.16 & 45 & 10.46 & 0.68 & 197 & 2.82 & 57.93 \\
\hline 95 & 66 & 25 & 2.5 & 107.16 & 45 & 10.46 & 0.68 & 197 & 2.82 & 57.93 \\
\hline 96 & 71.8 & 25 & 2.5 & 107.16 & 45 & 10.46 & 0.68 & 197 & 2.82 & 57.93 \\
\hline 97 & 56.4 & 25 & 2.5 & 33.33 & 28.33 & 7.28 & 0.63 & 81 & 1.25 & 53.5 \\
\hline 98 & 47.4 & 25 & 2.5 & 33.33 & 28.33 & 7.28 & 0.63 & 81 & 1.25 & 53.5 \\
\hline 99 & 54.9 & 25 & 2.5 & 33.33 & 28.33 & 7.28 & 0.63 & 81 & 1.25 & 53.5 \\
\hline 100 & 108.3 & 25 & 3 & 129.46 & 54.67 & 13.69 & 0.8 & 366 & 3.25 & 64.73 \\
\hline 101 & 104.8 & 25 & 3 & 129.46 & 54.67 & 13.69 & 0.8 & 366 & 3.25 & 64.73 \\
\hline 102 & 100 & 25 & 3 & 129.46 & 54.67 & 13.69 & 0.8 & 366 & 3.25 & 64.73 \\
\hline 103 & 83 & 25 & 3 & 107.16 & 45 & 10.46 & 0.68 & 197 & 2.82 & 57.93 \\
\hline 104 & 78.1 & 25 & 3 & 107.16 & 45 & 10.46 & 0.68 & 197 & 2.82 & 57.93 \\
\hline 105 & 85.6 & 25 & 3 & 107.16 & 45 & 10.46 & 0.68 & 197 & 2.82 & 57.93 \\
\hline 106 & 60 & 25 & 3 & 33.33 & 28.33 & 7.28 & 0.63 & 81 & 1.25 & 53.5 \\
\hline 107 & 51 & 25 & 3 & 33.33 & 28.33 & 7.28 & 0.63 & 81 & 1.25 & 53.5 \\
\hline 108 & 67.2 & 25 & 3 & 33.33 & 28.33 & 7.28 & 0.63 & 81 & 1.25 & 53.5 \\
\hline
\end{tabular}


Table B. 2 The snapback relative to flour properties and process conditions for the second flour set

\begin{tabular}{|c|c|c|c|c|c|c|c|c|c|c|}
\hline & snapback & $\begin{array}{l}\text { rest } \\
\text { time }\end{array}$ & $\begin{array}{l}\text { reduction } \\
\text { ratio }\end{array}$ & $\begin{array}{l}\text { Mixo } \\
\text { Work }\end{array}$ & $\begin{array}{l}\text { Mixo peak } \\
\text { height }\end{array}$ & $\begin{array}{l}\text { protein } \\
\text { content }\end{array}$ & $\begin{array}{l}\text { Alveo } \\
\mathrm{P} / \mathrm{L}\end{array}$ & $\begin{array}{l}\text { Alveo } \\
\text { work }\end{array}$ & $\begin{array}{c}\text { Mixo } \\
\text { mixing time }\end{array}$ & $\begin{array}{c}\text { Farino water } \\
\text { absorption }\end{array}$ \\
\hline 109 & 112.6 & 5 & 1.5 & 180.23 & 55 & 13.63 & 0.72 & 398 & 4.45 & 60.3 \\
\hline 110 & 113.2 & 5 & 1.5 & 180.23 & 55 & 13.63 & 0.72 & 398 & 4.45 & 60.3 \\
\hline 111 & 103.7 & 5 & 1.5 & 180.23 & 55 & 13.63 & 0.72 & 398 & 4.45 & 60.3 \\
\hline 112 & 112.6 & 5 & 1.5 & 111.15 & 48 & 11.29 & 0.58 & 219 & 2.85 & 55.2 \\
\hline 113 & 113.2 & 5 & 1.5 & 111.15 & 48 & 11.29 & 0.58 & 219 & 2.85 & 55.2 \\
\hline 114 & 103.7 & 5 & 1.5 & 111.15 & 48 & 11.29 & 0.58 & 219 & 2.85 & 55.2 \\
\hline 115 & 25.5 & 5 & 1.5 & 58.28 & 40 & 9 & 0.43 & 84 & 1.88 & 51.77 \\
\hline 116 & 26.7 & 5 & 1.5 & 58.28 & 40 & 9 & 0.43 & 84 & 1.88 & 51.77 \\
\hline 117 & 29.2 & 5 & 1.5 & 58.28 & 40 & 9 & 0.43 & 84 & 1.88 & 51.77 \\
\hline 118 & 132.7 & 5 & 2 & 180.23 & 55 & 13.63 & 0.72 & 398 & 4.45 & 60.3 \\
\hline 119 & 167.3 & 5 & 2 & 180.23 & 55 & 13.63 & 0.72 & 398 & 4.45 & 60.3 \\
\hline 120 & 143.7 & 5 & 2 & 180.23 & 55 & 13.63 & 0.72 & 398 & 4.45 & 60.3 \\
\hline 121 & 100.5 & 5 & 2 & 111.15 & 48 & 11.29 & 0.58 & 219 & 2.85 & 55.2 \\
\hline 122 & 98.8 & 5 & 2 & 111.15 & 48 & 11.29 & 0.58 & 219 & 2.85 & 55.2 \\
\hline 123 & 109 & 5 & 2 & 111.15 & 48 & 11.29 & 0.58 & 219 & 2.85 & 55.2 \\
\hline 124 & 43.1 & 5 & 2 & 58.28 & 40 & 9 & 0.43 & 84 & 1.88 & 51.77 \\
\hline 125 & 40.4 & 5 & 2 & 58.28 & 40 & 9 & 0.43 & 84 & 1.88 & 51.77 \\
\hline 126 & 42.3 & 5 & 2 & 58.28 & 40 & 9 & 0.43 & 84 & 1.88 & 51.77 \\
\hline 127 & 192.4 & 5 & 2.5 & 180.23 & 55 & 13.63 & 0.72 & 398 & 4.45 & 60.3 \\
\hline 128 & 216.8 & 5 & 2.5 & 180.23 & 55 & 13.63 & 0.72 & 398 & 4.45 & 60.3 \\
\hline 129 & 212.8 & 5 & 2.5 & 180.23 & 55 & 13.63 & 0.72 & 398 & 4.45 & 60.3 \\
\hline 130 & 123.5 & 5 & 2.5 & 111.15 & 48 & 11.29 & 0.58 & 219 & 2.85 & 55.2 \\
\hline 131 & 126.5 & 5 & 2.5 & 111.15 & 48 & 11.29 & 0.58 & 219 & 2.85 & 55.2 \\
\hline 132 & 125.9 & 5 & 2.5 & 111.15 & 48 & 11.29 & 0.58 & 219 & 2.85 & 55.2 \\
\hline 133 & 51.3 & 5 & 2.5 & 58.28 & 40 & 9 & 0.43 & 84 & 1.88 & 51.77 \\
\hline 134 & 52.7 & 5 & 2.5 & 58.28 & 40 & 9 & 0.43 & 84 & 1.88 & 51.77 \\
\hline 135 & 52.7 & 5 & 2.5 & 58.28 & 40 & 9 & 0.43 & 84 & 1.88 & 51.77 \\
\hline
\end{tabular}

To be continued 


\begin{tabular}{|c|c|c|c|c|c|c|c|c|c|c|}
\hline & snapback & $\begin{array}{l}\text { rest } \\
\text { time }\end{array}$ & $\begin{array}{l}\text { reduction } \\
\text { ratio }\end{array}$ & $\begin{array}{l}\text { Mixo } \\
\text { Work }\end{array}$ & $\begin{array}{l}\text { Mixo peak } \\
\text { height }\end{array}$ & $\begin{array}{l}\text { protein } \\
\text { content }\end{array}$ & $\begin{array}{l}\text { Alveo } \\
\mathrm{P} / \mathrm{L}\end{array}$ & $\begin{array}{l}\text { Alveo } \\
\text { work }\end{array}$ & $\begin{array}{c}\text { Mixo } \\
\text { mixing time }\end{array}$ & $\begin{array}{c}\text { Farino water } \\
\text { absorption }\end{array}$ \\
\hline 136 & 232 & 5 & 3 & 180.23 & 55 & 13.63 & 0.72 & 398 & 4.45 & 60.3 \\
\hline 137 & 232.5 & 5 & 3 & 180.23 & 55 & 13.63 & 0.72 & 398 & 4.45 & 60.3 \\
\hline 138 & 260.9 & 5 & 3 & 180.23 & 55 & 13.63 & 0.72 & 398 & 4.45 & 60.3 \\
\hline 139 & 165.5 & 5 & 3 & 111.15 & 48 & 11.29 & 0.58 & 219 & 2.85 & 55.2 \\
\hline 140 & 155.7 & 5 & 3 & 111.15 & 48 & 11.29 & 0.58 & 219 & 2.85 & 55.2 \\
\hline 141 & 162.1 & 5 & 3 & 111.15 & 48 & 11.29 & 0.58 & 219 & 2.85 & 55.2 \\
\hline 142 & 64.3 & 5 & 3 & 58.28 & 40 & 9 & 0.43 & 84 & 1.88 & 51.77 \\
\hline 143 & 61.2 & 5 & 3 & 58.28 & 40 & 9 & 0.43 & 84 & 1.88 & 51.77 \\
\hline 144 & 65.7 & 5 & 3 & 58.28 & 40 & 9 & 0.43 & 84 & 1.88 & 51.77 \\
\hline 145 & 89.9 & 15 & 1.5 & 180.23 & 55 & 13.63 & 0.72 & 398 & 4.45 & 60.3 \\
\hline 146 & 100 & 15 & 1.5 & 180.23 & 55 & 13.63 & 0.72 & 398 & 4.45 & 60.3 \\
\hline 147 & 91 & 15 & 1.5 & 180.23 & 55 & 13.63 & 0.72 & 398 & 4.45 & 60.3 \\
\hline 148 & 55.9 & 15 & 1.5 & 111.15 & 48 & 11.29 & 0.58 & 219 & 2.85 & 55.2 \\
\hline 149 & 51.6 & 15 & 1.5 & 111.15 & 48 & 11.29 & 0.58 & 219 & 2.85 & 55.2 \\
\hline 150 & 70.6 & 15 & 1.5 & 111.15 & 48 & 11.29 & 0.58 & 219 & 2.85 & 55.2 \\
\hline 151 & 23.3 & 15 & 1.5 & 58.28 & 40 & 9 & 0.43 & 84 & 1.88 & 51.77 \\
\hline 152 & 26.2 & 15 & 1.5 & 58.28 & 40 & 9 & 0.43 & 84 & 1.88 & 51.77 \\
\hline 153 & 21 & 15 & 1.5 & 58.28 & 40 & 9 & 0.43 & 84 & 1.88 & 51.77 \\
\hline 154 & 126.7 & 15 & 2 & 180.23 & 55 & 13.63 & 0.72 & 398 & 4.45 & 60.3 \\
\hline 155 & 136.7 & 15 & 2 & 180.23 & 55 & 13.63 & 0.72 & 398 & 4.45 & 60.3 \\
\hline 156 & 140.4 & 15 & 2 & 180.23 & 55 & 13.63 & 0.72 & 398 & 4.45 & 60.3 \\
\hline 157 & 84.9 & 15 & 2 & 111.15 & 48 & 11.29 & 0.58 & 219 & 2.85 & 55.2 \\
\hline 158 & 85 & 15 & 2 & 111.15 & 48 & 11.29 & 0.58 & 219 & 2.85 & 55.2 \\
\hline 159 & 92.3 & 15 & 2 & 111.15 & 48 & 11.29 & 0.58 & 219 & 2.85 & 55.2 \\
\hline 160 & 30.7 & 15 & 2 & 58.28 & 40 & 9 & 0.43 & 84 & 1.88 & 51.77 \\
\hline 161 & 36.2 & 15 & 2 & 58.28 & 40 & 9 & 0.43 & 84 & 1.88 & 51.77 \\
\hline 162 & 34.6 & 15 & 2 & 58.28 & 40 & 9 & 0.43 & 84 & 1.88 & 51.77 \\
\hline
\end{tabular}

To be continued 


\begin{tabular}{|c|c|c|c|c|c|c|c|c|c|c|}
\hline & snapback & $\begin{array}{l}\text { rest } \\
\text { time }\end{array}$ & $\begin{array}{l}\text { reduction } \\
\text { ratio }\end{array}$ & $\begin{array}{l}\text { Mixo } \\
\text { Work }\end{array}$ & $\begin{array}{l}\text { Mixo peak } \\
\text { height }\end{array}$ & $\begin{array}{l}\text { protein } \\
\text { content }\end{array}$ & $\begin{array}{l}\text { Alveo } \\
\mathrm{P} / \mathrm{L}\end{array}$ & $\begin{array}{l}\text { Alveo } \\
\text { work }\end{array}$ & $\begin{array}{c}\text { Mixo } \\
\text { mixing time }\end{array}$ & $\begin{array}{c}\text { Farino water } \\
\text { absorption }\end{array}$ \\
\hline 163 & 157 & 15 & 2.5 & 180.23 & 55 & 13.63 & 0.72 & 398 & 4.45 & 60.3 \\
\hline 164 & 168.5 & 15 & 2.5 & 180.23 & 55 & 13.63 & 0.72 & 398 & 4.45 & 60.3 \\
\hline 165 & 171.1 & 15 & 2.5 & 180.23 & 55 & 13.63 & 0.72 & 398 & 4.45 & 60.3 \\
\hline 166 & 104.5 & 15 & 2.5 & 111.15 & 48 & 11.29 & 0.58 & 219 & 2.85 & 55.2 \\
\hline 167 & 120.6 & 15 & 2.5 & 111.15 & 48 & 11.29 & 0.58 & 219 & 2.85 & 55.2 \\
\hline 168 & 124.8 & 15 & 2.5 & 111.15 & 48 & 11.29 & 0.58 & 219 & 2.85 & 55.2 \\
\hline 169 & 45.7 & 15 & 2.5 & 58.28 & 40 & 9 & 0.43 & 84 & 1.88 & 51.77 \\
\hline 170 & 44.3 & 15 & 2.5 & 58.28 & 40 & 9 & 0.43 & 84 & 1.88 & 51.77 \\
\hline 171 & 45 & 15 & 2.5 & 58.28 & 40 & 9 & 0.43 & 84 & 1.88 & 51.77 \\
\hline 172 & 188.2 & 15 & 3 & 180.23 & 55 & 13.63 & 0.72 & 398 & 4.45 & 60.3 \\
\hline 173 & 197.5 & 15 & 3 & 180.23 & 55 & 13.63 & 0.72 & 398 & 4.45 & 60.3 \\
\hline 174 & 199 & 15 & 3 & 180.23 & 55 & 13.63 & 0.72 & 398 & 4.45 & 60.3 \\
\hline 175 & 125 & 15 & 3 & 111.15 & 48 & 11.29 & 0.58 & 219 & 2.85 & 55.2 \\
\hline 176 & 140.8 & 15 & 3 & 111.15 & 48 & 11.29 & 0.58 & 219 & 2.85 & 55.2 \\
\hline 177 & 148.1 & 15 & 3 & 111.15 & 48 & 11.29 & 0.58 & 219 & 2.85 & 55.2 \\
\hline 178 & 54.2 & 15 & 3 & 58.28 & 40 & 9 & 0.43 & 84 & 1.88 & 51.77 \\
\hline 179 & 58.1 & 15 & 3 & 58.28 & 40 & 9 & 0.43 & 84 & 1.88 & 51.77 \\
\hline 180 & 56.4 & 15 & 3 & 58.28 & 40 & 9 & 0.43 & 84 & 1.88 & 51.77 \\
\hline 181 & 76.7 & 25 & 1.5 & 180.23 & 55 & 13.63 & 0.72 & 398 & 4.45 & 60.3 \\
\hline 182 & 89.2 & 25 & 1.5 & 180.23 & 55 & 13.63 & 0.72 & 398 & 4.45 & 60.3 \\
\hline 183 & 82.3 & 25 & 1.5 & 180.23 & 55 & 13.63 & 0.72 & 398 & 4.45 & 60.3 \\
\hline 184 & 47 & 25 & 1.5 & 111.15 & 48 & 11.29 & 0.58 & 219 & 2.85 & 55.2 \\
\hline 185 & 56 & 25 & 1.5 & 111.15 & 48 & 11.29 & 0.58 & 219 & 2.85 & 55.2 \\
\hline 186 & 61.2 & 25 & 1.5 & 111.15 & 48 & 11.29 & 0.58 & 219 & 2.85 & 55.2 \\
\hline 187 & 19.3 & 25 & 1.5 & 58.28 & 40 & 9 & 0.43 & 84 & 1.88 & 51.77 \\
\hline 188 & 16.3 & 25 & 1.5 & 58.28 & 40 & 9 & 0.43 & 84 & 1.88 & 51.77 \\
\hline 189 & 19 & 25 & 1.5 & 58.28 & 40 & 9 & 0.43 & 84 & 1.88 & 51.77 \\
\hline
\end{tabular}

To be continued 


\begin{tabular}{|c|c|c|c|c|c|c|c|c|c|c|}
\hline & snapback & $\begin{array}{l}\text { rest } \\
\text { time }\end{array}$ & $\begin{array}{l}\text { reduction } \\
\text { ratio }\end{array}$ & $\begin{array}{l}\text { Mixo } \\
\text { Work }\end{array}$ & $\begin{array}{l}\text { Mixo peak } \\
\text { height }\end{array}$ & $\begin{array}{l}\text { protein } \\
\text { content }\end{array}$ & $\begin{array}{l}\text { Alveo } \\
\mathrm{P} / \mathrm{L}\end{array}$ & $\begin{array}{l}\text { Alveo } \\
\text { work }\end{array}$ & $\begin{array}{c}\text { Mixo } \\
\text { mixing time }\end{array}$ & $\begin{array}{c}\text { Farino water } \\
\text { absorption }\end{array}$ \\
\hline 190 & 100.5 & 25 & 2 & 180.23 & 55 & 13.63 & 0.72 & 398 & 4.45 & 60.3 \\
\hline 191 & 115.6 & 25 & 2 & 180.23 & 55 & 13.63 & 0.72 & 398 & 4.45 & 60.3 \\
\hline 192 & 110.5 & 25 & 2 & 180.23 & 55 & 13.63 & 0.72 & 398 & 4.45 & 60.3 \\
\hline 193 & 72.6 & 25 & 2 & 111.15 & 48 & 11.29 & 0.58 & 219 & 2.85 & 55.2 \\
\hline 194 & 74.2 & 25 & 2 & 111.15 & 48 & 11.29 & 0.58 & 219 & 2.85 & 55.2 \\
\hline 195 & 64.5 & 25 & 2 & 111.15 & 48 & 11.29 & 0.58 & 219 & 2.85 & 55.2 \\
\hline 196 & 28.2 & 25 & 2 & 58.28 & 40 & 9 & 0.43 & 84 & 1.88 & 51.77 \\
\hline 197 & 30.8 & 25 & 2 & 58.28 & 40 & 9 & 0.43 & 84 & 1.88 & 51.77 \\
\hline 198 & 33.1 & 25 & 2 & 58.28 & 40 & 9 & 0.43 & 84 & 1.88 & 51.77 \\
\hline 199 & 147.3 & 25 & 2.5 & 180.23 & 55 & 13.63 & 0.72 & 398 & 4.45 & 60.3 \\
\hline 200 & 146.5 & 25 & 2.5 & 180.23 & 55 & 13.63 & 0.72 & 398 & 4.45 & 60.3 \\
\hline 201 & 144.1 & 25 & 2.5 & 180.23 & 55 & 13.63 & 0.72 & 398 & 4.45 & 60.3 \\
\hline 202 & 85.7 & 25 & 2.5 & 111.15 & 48 & 11.29 & 0.58 & 219 & 2.85 & 55.2 \\
\hline 203 & 87.9 & 25 & 2.5 & 111.15 & 48 & 11.29 & 0.58 & 219 & 2.85 & 55.2 \\
\hline 204 & 86.3 & 25 & 2.5 & 111.15 & 48 & 11.29 & 0.58 & 219 & 2.85 & 55.2 \\
\hline 205 & 39.2 & 25 & 2.5 & 58.28 & 40 & 9 & 0.43 & 84 & 1.88 & 51.77 \\
\hline 206 & 41 & 25 & 2.5 & 58.28 & 40 & 9 & 0.43 & 84 & 1.88 & 51.77 \\
\hline 207 & 41.5 & 25 & 2.5 & 58.28 & 40 & 9 & 0.43 & 84 & 1.88 & 51.77 \\
\hline 208 & 175.8 & 25 & 3 & 180.23 & 55 & 13.63 & 0.72 & 398 & 4.45 & 60.3 \\
\hline 209 & 173.2 & 25 & 3 & 180.23 & 55 & 13.63 & 0.72 & 398 & 4.45 & 60.3 \\
\hline 210 & 169.9 & 25 & 3 & 180.23 & 55 & 13.63 & 0.72 & 398 & 4.45 & 60.3 \\
\hline 211 & 115.6 & 25 & 3 & 111.15 & 48 & 11.29 & 0.58 & 219 & 2.85 & 55.2 \\
\hline 212 & 117.8 & 25 & 3 & 111.15 & 48 & 11.29 & 0.58 & 219 & 2.85 & 55.2 \\
\hline 213 & 116.9 & 25 & 3 & 111.15 & 48 & 11.29 & 0.58 & 219 & 2.85 & 55.2 \\
\hline 214 & 49.4 & 25 & 3 & 58.28 & 40 & 9 & 0.43 & 84 & 1.88 & 51.77 \\
\hline 215 & 50.5 & 25 & 3 & 58.28 & 40 & 9 & 0.43 & 84 & 1.88 & 51.77 \\
\hline 216 & 52.6 & 25 & 3 & 58.28 & 40 & 9 & 0.43 & 84 & 1.88 & 51.77 \\
\hline
\end{tabular}


Table B. 3 The snapback relative to flour properties and process conditions for the third first flour set

\begin{tabular}{|c|c|c|c|c|c|c|c|c|c|c|}
\hline & snapback & $\begin{array}{l}\text { rest } \\
\text { time }\end{array}$ & $\begin{array}{l}\text { reduction } \\
\text { ratio }\end{array}$ & $\begin{array}{l}\text { Mixo } \\
\text { Work }\end{array}$ & $\begin{array}{l}\text { Mixo peak } \\
\text { height }\end{array}$ & $\begin{array}{l}\text { protein } \\
\text { content }\end{array}$ & $\begin{array}{l}\text { Alveo } \\
\mathrm{P} / \mathrm{L}\end{array}$ & $\begin{array}{l}\text { Alveo } \\
\text { work }\end{array}$ & $\begin{array}{c}\text { Mixo } \\
\text { mixing time }\end{array}$ & $\begin{array}{c}\text { Farino water } \\
\text { absorption }\end{array}$ \\
\hline 217 & 71.2 & 5 & 1.5 & 135 & 55 & 12.86 & 0.85 & 398 & 3 & 61.6 \\
\hline 218 & 83.6 & 5 & 1.5 & 135 & 55 & 12.86 & 0.85 & 398 & 3 & 61.6 \\
\hline 219 & 89.9 & 5 & 1.5 & 135 & 55 & 12.86 & 0.85 & 398 & 3 & 61.6 \\
\hline 220 & 109.3 & 5 & 2 & 135 & 55 & 12.86 & 0.85 & 398 & 3 & 61.6 \\
\hline 221 & 126.5 & 5 & 2 & 135 & 55 & 12.86 & 0.85 & 398 & 3 & 61.6 \\
\hline 222 & 114.1 & 5 & 2 & 135 & 55 & 12.86 & 0.85 & 398 & 3 & 61.6 \\
\hline 223 & 155 & 5 & 2.5 & 135 & 55 & 12.86 & 0.85 & 398 & 3 & 61.6 \\
\hline 224 & 151.2 & 5 & 2.5 & 135 & 55 & 12.86 & 0.85 & 398 & 3 & 61.6 \\
\hline 225 & 166.6 & 5 & 2.5 & 135 & 55 & 12.86 & 0.85 & 398 & 3 & 61.6 \\
\hline 226 & 180.8 & 5 & 3 & 135 & 55 & 12.86 & 0.85 & 398 & 3 & 61.6 \\
\hline 227 & 190.9 & 5 & 3 & 135 & 55 & 12.86 & 0.85 & 398 & 3 & 61.6 \\
\hline 228 & 173 & 5 & 3 & 135 & 55 & 12.86 & 0.85 & 398 & 3 & 61.6 \\
\hline 229 & 67.8 & 15 & 1.5 & 135 & 55 & 12.86 & 0.85 & 398 & 3 & 61.6 \\
\hline 230 & 69.4 & 15 & 1.5 & 135 & 55 & 12.86 & 0.85 & 398 & 3 & 61.6 \\
\hline 231 & 73.4 & 15 & 1.5 & 135 & 55 & 12.86 & 0.85 & 398 & 3 & 61.6 \\
\hline 232 & 96.3 & 15 & 2 & 135 & 55 & 12.86 & 0.85 & 398 & 3 & 61.6 \\
\hline 233 & 92 & 15 & 2 & 135 & 55 & 12.86 & 0.85 & 398 & 3 & 61.6 \\
\hline 234 & 118 & 15 & 2 & 135 & 55 & 12.86 & 0.85 & 398 & 3 & 61.6 \\
\hline 235 & 131.1 & 15 & 2.5 & 135 & 55 & 12.86 & 0.85 & 398 & 3 & 61.6 \\
\hline 236 & 138.4 & 15 & 2.5 & 135 & 55 & 12.86 & 0.85 & 398 & 3 & 61.6 \\
\hline 237 & 139 & 15 & 2.5 & 135 & 55 & 12.86 & 0.85 & 398 & 3 & 61.6 \\
\hline 238 & 151.2 & 15 & 3 & 135 & 55 & 12.86 & 0.85 & 398 & 3 & 61.6 \\
\hline 239 & 168.5 & 15 & 3 & 135 & 55 & 12.86 & 0.85 & 398 & 3 & 61.6 \\
\hline 240 & 170.4 & 15 & 3 & 135 & 55 & 12.86 & 0.85 & 398 & 3 & 61.6 \\
\hline 241 & 65.8 & 25 & 1.5 & 135 & 55 & 12.86 & 0.85 & 398 & 3 & 61.6 \\
\hline 242 & 63.9 & 25 & 1.5 & 135 & 55 & 12.86 & 0.85 & 398 & 3 & 61.6 \\
\hline 243 & 68.8 & 25 & 1.5 & 135 & 55 & 12.86 & 0.85 & 398 & 3 & 61.6 \\
\hline
\end{tabular}

To be continued 


\begin{tabular}{|l|c|c|c|c|c|c|c|c|c|c|}
\hline & snapback & $\begin{array}{c}\text { rest } \\
\text { time }\end{array}$ & $\begin{array}{c}\text { reduction } \\
\text { ratio }\end{array}$ & $\begin{array}{c}\text { Mixo } \\
\text { Work }\end{array}$ & $\begin{array}{c}\text { Mixo peak } \\
\text { height }\end{array}$ & $\begin{array}{c}\text { protein } \\
\text { content }\end{array}$ & $\begin{array}{c}\text { Alveo } \\
\text { P/L }\end{array}$ & $\begin{array}{c}\text { Alveo } \\
\text { work }\end{array}$ & $\begin{array}{c}\text { Mixo } \\
\text { mixing time }\end{array}$ & $\begin{array}{c}\text { Farino water } \\
\text { absorption }\end{array}$ \\
\hline 244 & 90.1 & 25 & 2 & 135 & 55 & 12.86 & 0.85 & 398 & 3 & 61.6 \\
\hline 245 & 88.9 & 25 & 2 & 135 & 55 & 12.86 & 0.85 & 398 & 3 & 61.6 \\
\hline 246 & 101.2 & 25 & 2 & 135 & 55 & 12.86 & 0.85 & 398 & 3 & 61.6 \\
\hline 247 & 116.7 & 25 & 2.5 & 135 & 55 & 12.86 & 0.85 & 398 & 3 & 61.6 \\
\hline 248 & 122.4 & 25 & 2.5 & 135 & 55 & 12.86 & 0.85 & 398 & 3 & 61.6 \\
\hline 249 & 134.9 & 25 & 2.5 & 135 & 55 & 12.86 & 0.85 & 398 & 3 & 61.6 \\
\hline 250 & 138.5 & 25 & 3 & 135 & 55 & 12.86 & 0.85 & 398 & 3 & 61.6 \\
\hline 251 & 148.4 & 25 & 3 & 135 & 55 & 12.86 & 0.85 & 398 & 3 & 61.6 \\
\hline 252 & 165.4 & 25 & 3 & 135 & 55 & 12.86 & 0.85 & 398 & 3 & 61.6 \\
\hline
\end{tabular}

Concluded 


\section{Appendix C - RSM}

Using Model: STD 3_VAR | C 123122313112233

Coefficient of Determination $\left(\mathrm{R}^{\wedge} 2\right)=0.90012$

Coefficient of Multiple Correlation $=0.94874$

Standard Error of Estimate 15.26598

The $2^{\text {nd }}$ order regression equation for 3 factors is

SNAPBACK $=+22.8437474$

$-0.6005180 *$ MIX-WORK

$+8.2650851 *$ RED-RATIO

$-0.2326954 *$ REST-TIME

$+0.3654636 *$ MIX-WORK * RED-RATIO

$-0.5406127 *$ RED-RATIO * REST-TIME

$-0.0102471 *$ MIX-WORK * REST-TIME

$+0.0032125 *$ MIX-WORK * MIX-WORK

$+1.0712917 *$ RED-RATIO * RED-RATIO

$+0.0396248 *$ REST-TIME * REST-TIME 
Response in SNAPBACK

(Stepping Variable: REST-TIME $=5$ )

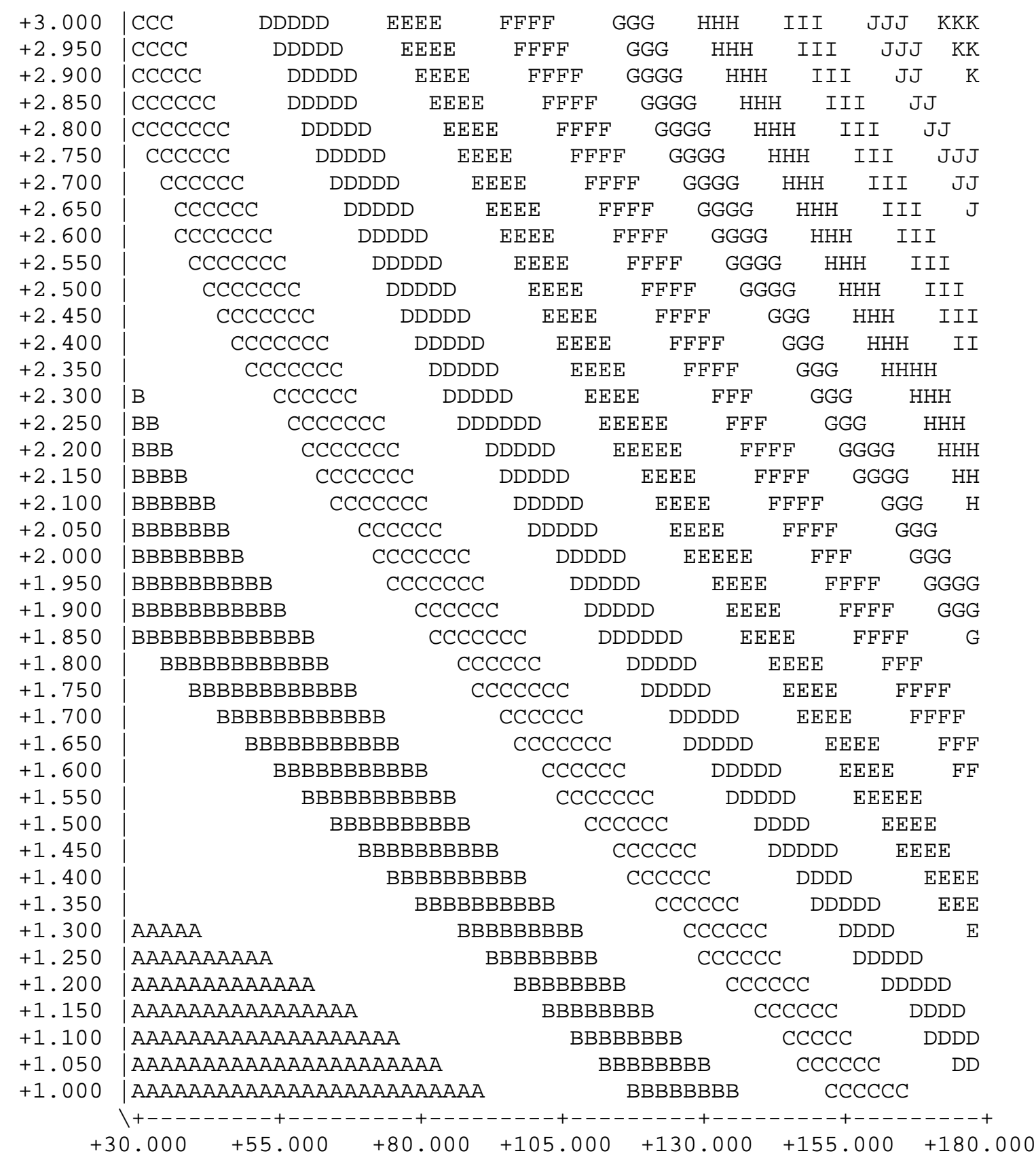

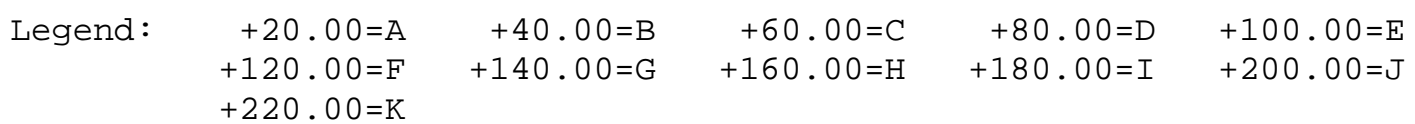


Response in SNAPBACK

(Stepping Variable: REST-TIME = 15)

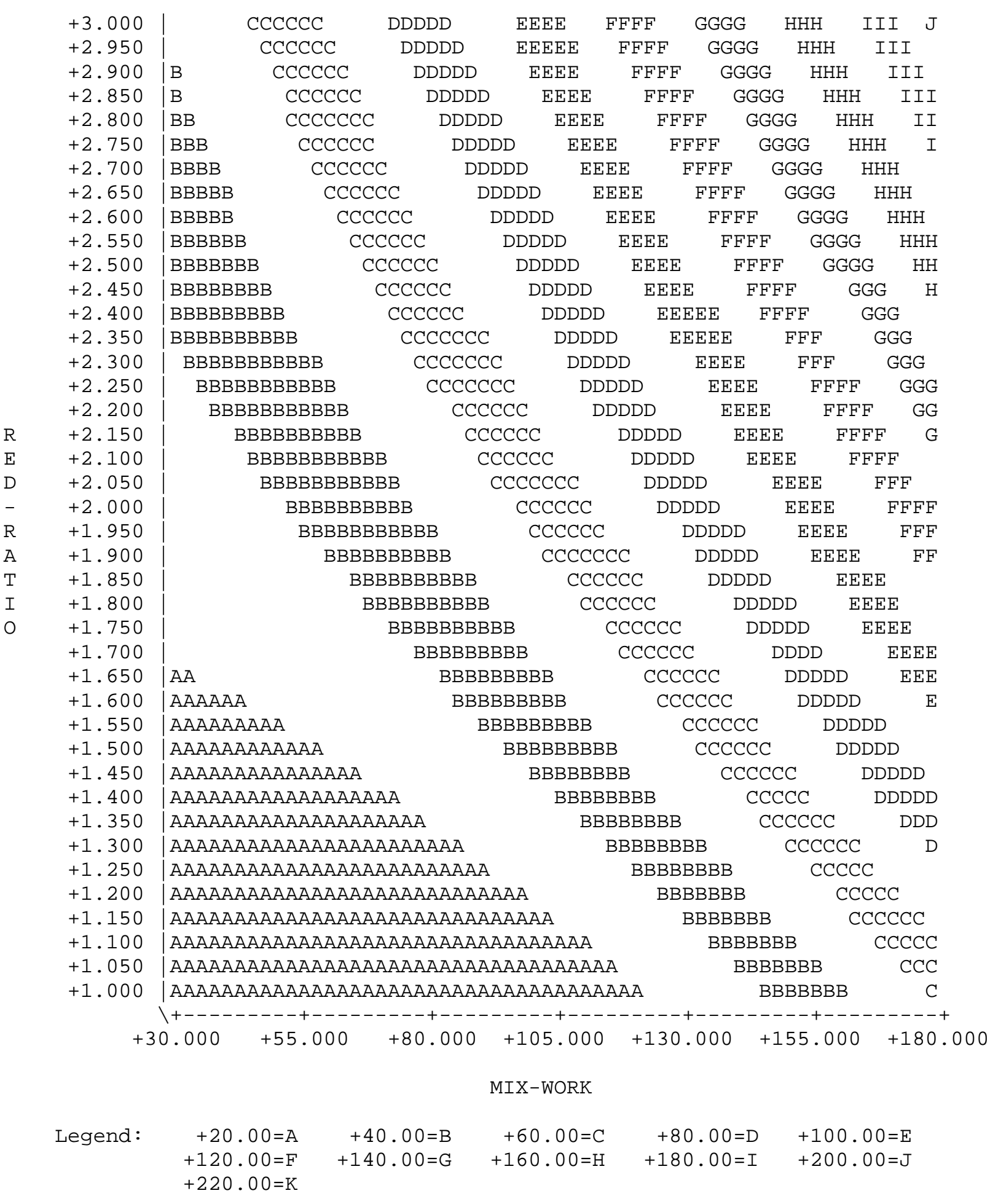


Response in SNAPBACK

(Stepping Variable: REST-TIME = 25)

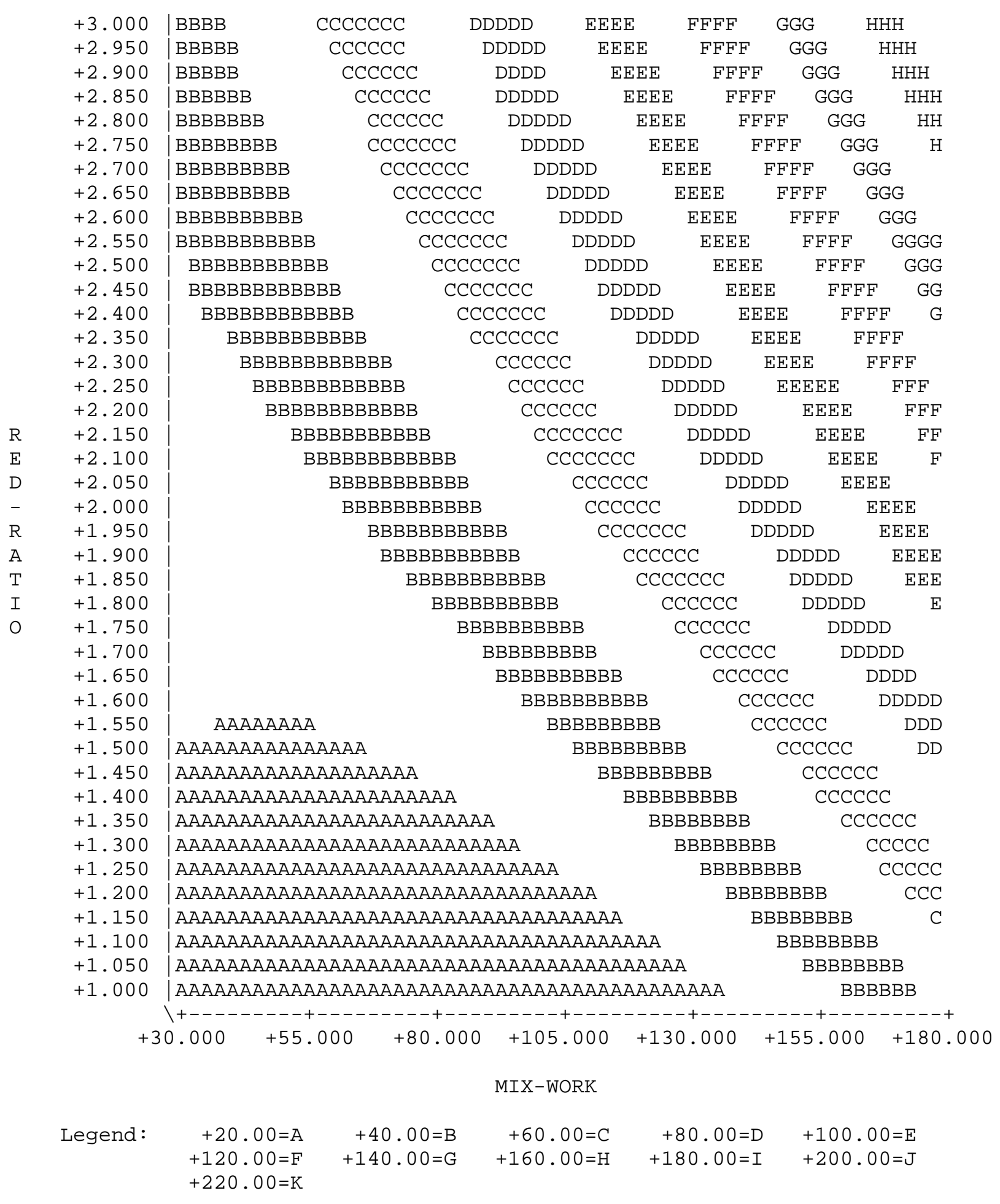

